NIST Technical Note 1446

\title{
Estimating Reduced Fire Risk Resulting From An Improved Mattress Flammability Standard
}

Thomas J. Ohlemiller

Richard G. Gann

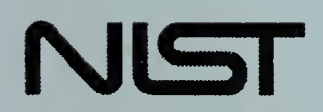

National Institute of Standards and Technology

$Q C$

Jlogy Administration, U.S. Department of Commerce

100

.45753

$\$ 1446$

2002

c. 2 



\section{Estimating Reduced Fire Risk Resulting From An Improved Mattress Flammability Standard}

Thomas J. Ohlemiller

Richard G. Gann

Building and Fire Research Laboratory

National Institute of Standards and Technology

Gaithersburg, MD 20899-8664

August 2002

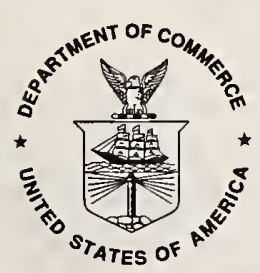

U.S. Department of Commerce

Donald L. Evans, Secretary

Technology Administration

Phillip J. Bond, Under Secretary for Technology

National Institute of Standards and Technology

Dr. Arden L. Bement, Jr., Director 
National Institute of Standards and Technology

Technical Note 1446

Natl. Inst. Stand. Technol.

Tech. Note 1446

79 pages (August 2002)

CODEN: NTNOEF
U.S. Government Printing Office Washington: 2002

For sale by the Superintendent of Documents Government Printing Office Washington, DC 20402-9325 


\section{Table of Contents}

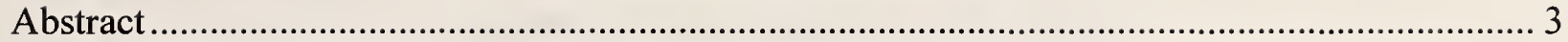

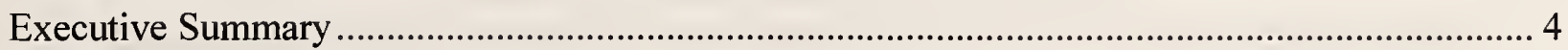

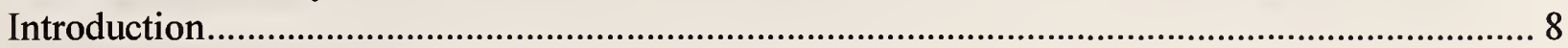

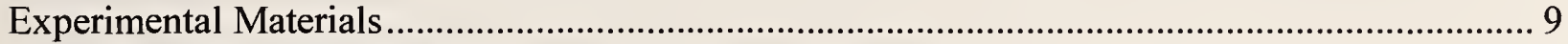

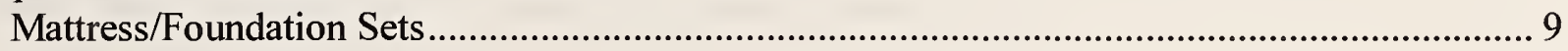

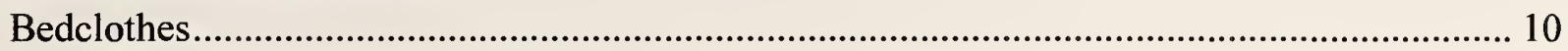

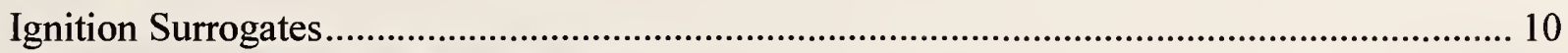

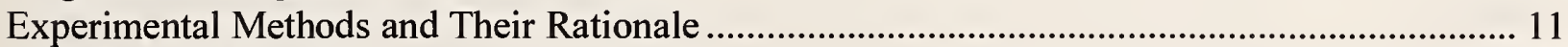

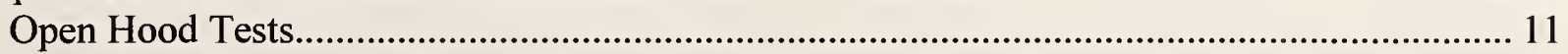

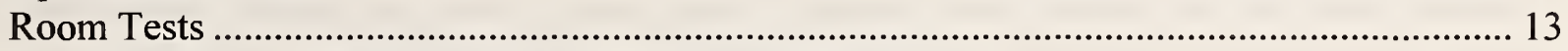

Cone Calorimeter Characterization of Surrogate Materials............................................. 16

Results and Discussion .......................................................................................... 16

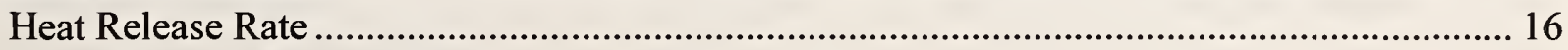

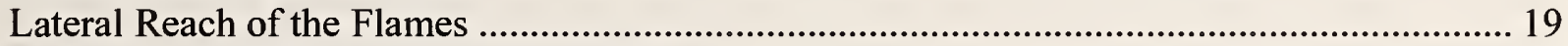

Radiant Heat Fluxes to the Surroundings ................................................................. 20

Ignitability of the Surrogate Materials ............................................................... 22

Predicted Reach for Piloted Radiative Ignition .......................................................... 23

Fraction of Room at Risk for Piloted Ignition ............................................................ 26

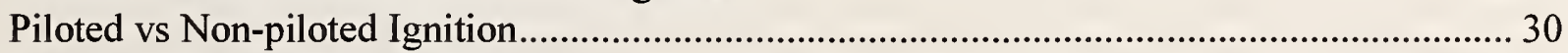

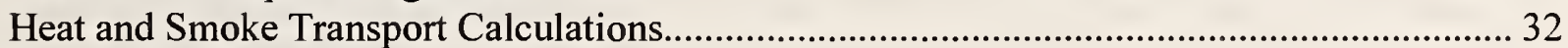

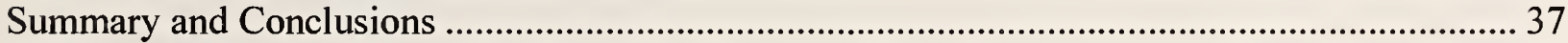

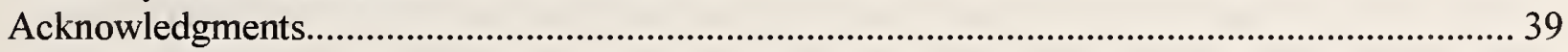

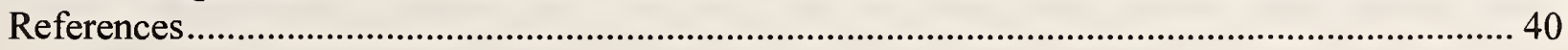

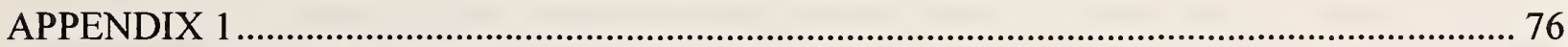

Thermal Ignition Models for Surrogate Materials .......................................................... 76

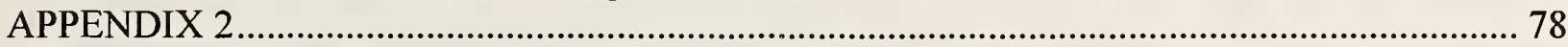

Estimates of Fuel Package Contributions in M3 and M5 Bed Fires........................78 


\title{
Estimating Reduced Fire Risk \\ Resulting From An Improved Mattress Flammability Standard
}

\author{
T. J. Ohlemiller and R. G. Gann
}

\begin{abstract}
$\underline{\text { Abstract }}$
This study addresses the hazards posed by bed fires of varied sizes in an effort to relate potential fire size reduction to decreased risk of bed fire fatalities. For this purpose, a "bed" refers to a mattress, a foundation and bedclothes. There are three hazards: (1) the potential for a bed fire, by itself, to cause flashover in a bedroom; (2) the probability that a bed fire will ignite additional objects in the same room as a result of the fire's radiated heat; possibly leading to flashover and (3) the heat and toxic gas threat, in the room of fire origin and beyond, due to the bed fire alone. To address the first two issues, twin and king-size beds of three designs (always using the same bedclothes) were burned in duplicate both under an open hood and in a room. The three designs (termed M1, M3 and M5, consistent with previous usage) produced widely different peak heat release rates; open hood peaks ranged from $160 \mathrm{~kW}$ (M3 twin fire) to $3850 \mathrm{~kW}$ (M1 king fire). The radiant heat flux distribution around the fires was measured using up to two arrays of five flux gages each. These radiant flux reach data were translated into piloted ignition reach outward from the edge of the burning bed by means of ignitability results for seven materials. These materials are viewed as surrogates for the surfaces of other potentially significant combustible objects such as chairs or drapes which, if ignited by the bed fire, could push the room to a flashover condition. The results were then cast into a form that should be related to the probability of ignition in the overall population of bedrooms, i.e., the fraction of the room area (beyond the bed) that is at risk of piloted ignition of a second object by a bed fire. This fraction is strongly influenced by the size of the bed fire and of the size of the room. Both M1 and M5 fires are inferred to present substantial threats of second object ignition. The threat for an M3 fire is localized to the bed periphery but could be problematical in small bedrooms. To address the third hazard, heat and toxic gases, CFAST was run using the measured heat release rate curves from the room tests as input. This program predicts the spread of hot, toxic smoke in the room of fire origin and beyond. Here the context was a single story house consisting of four monitored spaces. The M1 and M5 fires presented a substantial lethal threat due to heat exposure in the room of fire origin and some spaces beyond. The M3 fire (consisting mainly of the bedclothes with little contribution from the mattress/foundation) was substantially less threatening but not innocuous, especially with a king size bed. Minimizing the occurrence of flashover and its attendant fatalities would require limiting the heat release rate peak from a mattress/foundation to less than that of an M5 fire. Localizing the fire to the bed would save significantly more lives but would require limiting the mattress/foundation heat release rate to near zero as with the M3 design. Even this case presents some threat of heat lethality away from the bed (in addition to the localized threat) since the bedclothes set used here yielded a $400 \mathrm{~kW}$ fire atop a king-size M3 mattress. Overall the study suggests that beds with fire performance similar to the M3 design would achieve very significant reduction in fire risk. Since the bedclothes contributed the bulk of the heat release seen with the M3 beds, further reduction in fire fatalities would probably have to address the bedclothes flammability as well.
\end{abstract}




\section{Executive Summary}

Fire risk is the melding of the probability that a type of fire will occur and the magnitude of the losses (hazard) from those fires. The risk of a harmful bed (i.e., a mattress, a foundation and bedclothes) fire is a function of the probabilities that:

- the bed will be ignited,

- the bed burning alone will lead to harm to people and/or property, and

- the fire will spread from the bed to other combustibles, with the combined fire leading to significant further harm to people and/or property.

The estimates developed here are couched in terms of the reduction in risk attendant on ignition of mattresses having lesser flammability than those currently in residential use.

The estimation model is based on the following concepts:

- Assuming the frequency of ignition and the flammability properties of bedclothes are unchanged, future mattresses will continue to be ignited with the same frequency as current mattresses. This is a conservative statement, since some measures to reduce mattress fire growth rates could also reduce susceptibility to a given ignition source.

- The severity of the consequences of bed fires is related to the ultimate extent of the fires. About two-thirds of bed fire fatalities occur in the room of origin, with the victims split evenly between being "intimate with ignition" and "not intimate but in room of fire origin." Bed fires that lead to flashover account for about two-thirds of the total bed fire fatalities, which represent nearly all the deaths that occur outside the room of fire origin and about half those that occur within.

- Thus, elimination of flashover as a result of reduced bed fire size could save about one third of the $\approx 500$ annual bed fire victims in the United States.

- Flashover elimination may also save a comparable number of victims within the room of origin, but this is less clear.

- An additional substantial fraction of deaths might be eliminated if the fire were confined to the bed itself.

- There is a critical heat release rate that determines whether a room fire will proceed to flashover. Staying below this value can be accomplished by reducing the heat release rate of the bed and/or by reducing the capability of the burning bed to ignite other combustibles.

- Ignition of additional items by a burning bed will either be by direct flame impingement (contiguous items) or by fire-generated thermal radiation (separated items). This remote, radiative ignition is characterized by a maximum piloted ignition reach from the burning bed; this reach depends on the nature of the remote item being ignited and the radiant energy generated by the burning bed.

- There is in real life a distribution of locations (distances from the bed) of these additional items in bedrooms. Generally, a smaller maximum piloted ignition reach will encompass 
a smaller fraction of these potential combustibles. Since the distribution of locations is unknown, a more quantitative statement regarding risk reduction is not possible.

Data from the burning of three mattress designs (M1, M3, M5) in both twin and king size were used to develop the risk reduction estimates. M1 is the design most like current residential mattresses and produces a relatively high heat release rate. M3 is an experimental design that normally yields very little heat release rate when exposed to burning bedding. M5 is an experimental design that yields an intermediate level of heat release rate.

\section{The study leads to the following inferences regarding the potential for a bed fire to lead to flashover:}

- For ordinary-size bedrooms, a peak heat release rate larger than about $1000 \mathrm{~kW}$ will lead to flashover.

- A mattress/foundation set that generates over $500 \mathrm{~kW}$ could lead to flashover, since the bedclothes used with that set could contribute up to $400 \mathrm{~kW}$ (king size bedclothes assembly in a room environment). Combined, such a bed fire could generate upwards of $900 \mathrm{~kW}$. Secondary ignition of contiguous items, normally present, could readily push the fire over the flashover limit.

- The potential for flashover from a burning king bed in the size of room typical for that bed size may be higher than for a twin bed in its smaller size room. Thus, for a given mattress design, the fire behavior of larger size units needs to be considered in estimating risk reduction.

\section{With regard to the potential for a bed fire to ignite remote object(s) in the same room:}

- Twin and king-size beds of the three designs (always using the same bedclothes) were burned under an open hood and in a room. The three designs produced widely different peak heat release rates. Open hood peaks ranged from $160 \mathrm{~kW}$ (M3 twin fire) to 3850 $\mathrm{kW}$ (M1 king fire). Inside a room the values generally tended to be higher; even the M3 king showed a heat release rate boost from the room environment.

- From each test, the measured radiant heat flux distribution around the fire was translated into a piloted ignition reach outward from the edge of the burning bed by means of ignitability results for seven materials. (Piloted ignition implies the presence of a "hot spot" to ignite flammable gases evolving from an object.) The ignitability behavior measured in the Cone Calorimeter was translated into ignition reach by means of an ignition model calibrated with the Cone data.

- The piloted ignition reach for a typical fabric (representing the surface of a second, remote object in the room) was then converted into the fraction of the room area (beyond the bed) that is at risk of piloted ignition of such a second object. This fraction is significantly influenced by the size of the bed fire and the size of the room; the dimensions of the second object also matter for smaller rooms. Both M1 and M5 fires 
present substantial threats of second object ignition. The threat for an M3 fire is localized to the bed periphery but could be problematical in small bedrooms.

- The risk of second item ignition is higher for more susceptible "targets" and/or those nearer the burning bed. Fabric-like objects (upholstered chairs, a second bed, draperies) are at risk of ignition down to incident heat fluxes of about $10 \mathrm{~kW} / \mathrm{m}^{2}$; such flux levels can be experienced far from the burning bed. Wooden objects require higher heat fluxes for ignition and are therefore at lesser risk at the same distance from a burning bed. As the radiant ignition reach from the burning bed decreases, the risk of a larger fire decreases substantially.

- M3 fires have an at-risk area for piloted ignition that largely overlaps the actual flame reach of the bed fire so ignition is highly likely only very near the bed. This is mainly a problem in a small room where any second object is very near the bed.

\section{In addition to second item ignition threat, the heat and toxic gas threats were assessed, in the room of fire origin and beyond, due to the bed fire alone.}

- Using the measured heat release rate curves from the room tests as input, CFAST was used to predict the spread of hot, toxic $(\mathrm{CO})$ smoke in the room of fire origin and throughout a single story house consisting of four spaces.

- The largest size bed is the best choice for modeling the effect of mattress design on life safety threat. Increasing the size of the bed leads to a significant increase in the heat and smoke generated. Even though larger beds are generally in larger rooms, the effect of room floor area has a much smaller effect on the time to hazardous conditions.

- The M1 and M5 fires were shown to present substantial life safety threats due to heat exposure in the room of fire origin and in some spaces beyond. The M3 fire (consisting mainly of the bedclothes with little contribution from the mattress/foundation) was substantially less threatening but not innocuous, especially with a king size bed that yielded a $400 \mathrm{~kW}$ fire.

\section{This study leads to the following overall conclusions as regards reduction in bed fire fatalities:}

- Elimination of flashover calls for keeping the peak heat release rate from a bed fire in a typical room (with other contents present) below $1000 \mathrm{~kW}$. Doing so could reduce by one-third, and probably more, the annual number of victims of bed fires. For bedclothes such as those used in this study, assuring this calls for lowering the heat release rate behavior of a mattress/foundation substantially below that given by an M5 design because of the combined threats of remote object ignition and heat lethality implicit in an M5 size fire.

- A further decrease in peak heat release rate from the mattress/foundation could be expected to reduce the radius for remote object ignition and mitigate the generation of lethal conditions, thereby lowering further the number of fire fatalities. There is a limit to 
this benefit, since the ignition reach becomes dominated by the burning of bedclothes on the side of the bed. In addition, the still-large total heat release rate from the bed fire continues to produce untenable temperatures in the fire room and possibly beyond.

- Confining a bed fire to the immediate periphery of the bed could reduce the number of victims by perhaps two-thirds and possibly more. For bedclothes such as those used in this study, achieving this requires limiting the mattress/foundation heat release rate to near zero, as in the M3 case. The full benefit of this improvement may require some limitation on the bedclothes, since a king size bedclothes set of the type used here alone yielded $400 \mathrm{~kW}$ (atop an M3 bed) in a room environment. The threats that remain for such a case are those of burns to occupants of the bed and heat in the upper layer gases that reach down to a height that agile adults could probably avoid but others may not.

Overall the study suggests that beds with fire performance similar to the M3 design would achieve very significant reduction in fire risk. Since the bedclothes contributed the bulk of the heat release seen with the $\mathrm{M} 3$ beds, further reduction in fire fatalities would probably have to address the bedclothes flammability as well. 


\section{$\underline{\text { Introduction }}$}

The present report is part of a project entitled "Assessing Potential Hazard Reduction for Bed Fires," sponsored by the Sleep Products Safety Council. Earlier work [1] on bed fires looked at the interaction between burning bedclothes (usually ignited first in real fires incidents) and the mattress/foundation beneath them. That work assessed the heat flux patterns imposed on a mattress by burning bedclothes and developed a gas-fired burner set that mimicked this exposure. The burner is a reproducible tool for assessing more fire resistant mattress/foundation designs.

The goal of the present effort is to quantify, to the extent possible, the change in fire risk that results from changes in the fire intensity of a bed, i.e., a mattress, a foundation and a set of bedclothes (e.g., mattress pad, sheets, pillow and pillowcase, blanket and comforter). The bedclothes combination used here was fixed; the mattress/foundation design was varied so that fires of varying size resulted. One design is representative of currently marketed residential beds; the other two designs are experimental. The hazard from the fires is assessed here, first, in terms of their direct and indirect threat of producing flashover in the room of fire origin and second, in terms of the heat and carbon monoxide hazard in the fire room and beyond.

Flashover is the point in a room fire at which radiant heat from the hot smoke accumulating in the upper portions of the room ignites all flammable materials within the room. The resultant generalized burning condition results in an abrupt transition to oxygen supply-limited combustion of the various fuel gases and a large increase in the fraction of gases turned into carbon monoxide. These hot, toxic gases leave the room and pose a very serious threat to occupants elsewhere in the building. Overall, nearly $60 \%$ of the fire deaths in the United States occur in rooms other than the ones in which the fires started [2].

Of particular interest here, however, are statistics for fires in which a bed is the first item ignited, as shown in Table 1 [3]. There is a significantly different distribution of fire death localities than that noted above. About two thirds of the fatalities result from fires that proceed beyond the room of fire origin (flashover). Their locations are roughly evenly divided between inside that room and outside it. About two thirds of the fatalities occur within the room of fire origin, half intimate with the bed and half elsewhere in the room [4].

The figures suggest that elimination of flashover as a result of reduced bed fire size could potentially save about one third of the approximately 500 annual bed fire victims in the United States. Flashover elimination may also save up to a roughly comparable number of victims within the room of fire origin (though this cannot be stated with as much certainty). The results suggest that an additional substantial fraction could be eliminated if the bed fire were confined to the bed itself. ${ }^{1}$

\footnotetext{
${ }^{1}$ The available fire statistics do not directly reveal the cause of death and how, within the room of origin, it relates to proximity to the fire. In particular, the reach of toxic gases is greater than that of an ignition threat. This makes it difficult to state with any certainty that, for example, confining the fire to the bed would also confine the victims to
} 
There is another, related incentive to limiting the fire size on the bed: this is the only way to greatly lessen the chances that it will spread to other items in the room of fire origin. Such spread is a potential pathway to room flashover even if the bed fire alone is incapable of causing this. In addition, for sub-flashover fires, one can expect that the threat to room occupants (and those beyond) is reduced if the fire size is reduced. The results reported below demonstrate this for a limited set of scenarios.

Given the above considerations, we infer that, in assessing the hazards presented by bed fires, it is important to focus on both the size of fire (i.e., heat release rate) that results from the flaming ignition of a bed assembly (bedclothes, mattress, foundation) and the ignition threat that such a fire poses to its immediate surroundings. Since one cannot control the nature of adjacent objects in a bedroom, and some of these objects (e.g., upholstered chairs) can create a fire large enough for the combined fires to yield flashover, the ultimate goal may be to confine any bed fire to the bed itself. This implies minimizing the "ignition reach" of the bed fire. Ignition reach is the farthest distance from the edge of the bed at which a fire on the bed could ignite other objects.

The present study addresses the two related issues of bed fire size and the ignition reach of that fire. Beds based on three mattress/foundation designs and two sizes (twin and king size) were burned in two separate conditions, under an open hood and in a room. The three designs allowed a wide variation in peak heat release rate. In all cases the beds were covered with the same bedclothes (Combination \#4 from Ref. 1: a mattress pad, two sheets, a blanket, comforter and pillow(s)). The ignition mode was the same in all cases: a match-size flame applied to the bottom of the hanging bedclothes. The heat release rate of the bed fire was measured by oxygen consumption calorimetry. Arrays of heat flux gages were used to characterize the reach of radiant heat away from the burning bed. To put these flux data into a quantitative reference frame, the ignitability behavior of a set of seven surrogate ignition materials was characterized using the NIST Cone Calorimeter. These seven materials were surrogates for the types of objects that might be found in a bedroom. Simple ignition models were fit to these ignition delay time data (as a function of incident radiant flux) and the models were then used to predict the maximum distance from the bed fire for which piloted ignition of the surrogate ignition materials could occur. This allows calculation of the relation between fire size, room size and the fraction of room area where other object ignition might occur. The measured heat release rate results are projected into other room conditions using the heat and smoke transport model CFAST to assess the reach of heat and toxic gas threats to occupants in the room of fire origin and beyond. The results, viewed in light of the fire statistics quoted above, have implications for the potential savings in life attendant on reduction in peak bed fire size.

\section{Experimental Materials}

\section{Mattress/Foundation Sets}

The three bed designs were nominally the same as three used in Ref. 1; Table 2, derived from Ref. 1, gives their construction details. Design M1 is representative of the products currently on 
the market for residential use. Designs M3 and M5 are experimental designs incorporating certain technologies that decrease the heat release rate in a fire; their marketability is not established.

Figure 1, also from Ref. 1, shows the locations of the various materials and components in the mattress and foundation. Note that the present test series also included king size mattress/foundation sets. These sets had the same nominal construction as the twins except that the foundation of a king set consisted of side-by-side twin size foundations. This compartmentalized the space beneath the king size mattress, interposing two contiguous foundation side wall structures beneath the longitudinal centerline of the bed. This appeared to slow fire spread in the foundation for some designs.

Note that while the materials used in the construction of these beds were nominally the same as was used in Ref. 1, there have been some indications, in related work, of batch-to-batch variability and thus one should not assume that the behavior here will be identical to that reported in Ref. 1 for the same mattress/foundation design.

\section{Bedclothes}

The bedclothes set was similar to set \#4 used in Ref. 1. The mattress pad was of a distinctly different design here, however, consisting of a one-piece polyester/cotton pad (with no enclosing shell) which wrapped fully around the top and sides of the mattress (and a small, peripheral portion of the mattress bottom). Atop this was a fitted sheet and then a flat sheet, both 50/50 polyester/cotton. An acrylic blanket was placed on top of the sheets and a comforter formed the topmost layer. The comforter was filled with polyester fiberfill that was encased within a polyester/cotton shell. The pillow (two, in the case of the king size beds) was filled with polyester fiberfill and had a polyester/cotton shell as well as a polyester/cotton pillowcase. All of these materials were from different batches than those used in Ref. 1 but no striking differences in fire behavior were evident.

The bedclothes were placed on the mattress with attention paid to removal of wrinkles and to reproducible positioning. The covers, up to and including the blanket (not the comforter), were folded under the foot end of the mattress using "hospital corners." The head end covers were folded back $0.42 \mathrm{~m}$ (16.5 in) evenly over the width of the bed leaving space for the pillow(s) and yielding a doubled section of covers approximately this width adjacent to the pillow. The two pillows used on a king-size mattress were each centered on their respective sides of the bed and, as a consequence, did not touch in the middle of the bed.

\section{Ignition Surrogates}

The seven materials used as surrogates for other objects are listed in Table 3, along with the type of object for which they substitute. Note that the list is plausibly representative but not even remotely exhaustive, especially in the area of fabrics, which can vary widely in fiber composition and weight. The approach implicit in some choices is that an object such as a chair could be ignited by an item of clothing or a newspaper laying on it, possibly more easily than it might be 
ignited directly. It is, of course, the larger objects, having a large heat release rate potential, which pose a real threat of supplementing the bed fire to a point at or beyond room flashover.

\section{Experimental Methods and Their Rationale}

\section{Open Hood Tests}

The fire tests were all conducted in NIST's newly operational 6 meter heat release rate calorimeter. This facility is intended to measure the heat release rate of fires up to about $4 \mathrm{MW}$.

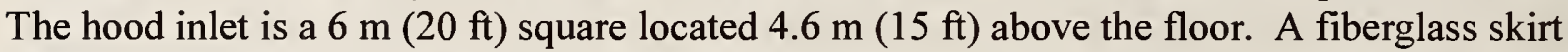
draped downward from the hood lip effectively lowers its inlet to $3.05 \mathrm{~m}(10 \mathrm{ft})$ above the floor, assuring that the plume from relatively small fires is captured fully and properly measured. The skirt also provides extra volume to assure plume capture if a fire should temporarily exceed the nominal $4 \mathrm{MW}$ rating of the hood ${ }^{2}$. In the present tests, which ranged in peak heat release rate from under $200 \mathrm{~kW}$ to about $4 \frac{1}{2} \mathrm{MW}$, there was no loss of the smoke plume at any time, nor any appreciable build-up of smoke in the hood volume.

Heat release rate is measured by oxygen consumption calorimetry (which requires full capture of the fire plume). This type of calorimetry has an inherent uncertainty of $\pm 5 \%$, when applied to mixed organic materials like those here, due to this amount of variability in the heat evolved per unit mass of oxygen consumed. This system was repeatedly calibrated before and during the tests series, using carefully measured flows of natural gas, with fires as large as $2 \mathrm{MW}$. The 95 $\%$ confidence limits on the calibration data add only about $\pm 0.5 \%$ to the $\pm 5 \%$ inherent uncertainty. Zero drift correction uncertainties are typically less than $\pm 1 \%$ for fires of a few hundred $\mathrm{kW}$ or greater. System noise, coupled with inherent fire variability, limits the accuracy of reading sharp heat release rate peaks (as it does in any heat release rate system). Accuracy of reading a brief heat release rate peak is comparable to the level of system noise in the peak but a complete analysis of this is not yet available.

The beds were placed on top of a scale to obtain a record of sample weight as a function of time during the fire. Skirts were placed around the scale periphery to minimize any aerodynamic lifting effects by the incoming air. A point of interest is the correlation between the maximum rate of weight loss and the peak heat release rate. In Ref. 1, these two were shown to correlate reasonably well.

In addition to heat release rate, the tests were intended to develop information on the distances from a bed fire at which various objects might be ignited by that fire. The ignition threat is twofold. Very close objects will be contacted by flames from the bed and will likely be ignited rather quickly since flame contact fluxes are of the order of $30 \mathrm{~kW} / \mathrm{m}^{2}$ or more. More distant objects see a radiant heat flux that decreases with distance from the fire. Radiant heat is capable of causing ignition directly but this requires relatively high

\footnotetext{
${ }^{2}$ Such smoke build-up in the hood volume implies some time-smearing of the heat release peak which causes it. Thus the peak is somewhat flattened during this build-up. This is preferable to smoke spillover from the hood since such spillage causes an indeterminate error in the heat release peak. Note that tests run in a room have a similar peak smoothing effect due to the re-circulation which occurs in the smoke layer beneath the ceiling.
} 
fluxes (discussed below). Lesser fluxes can still yield ignition if the hot gases evolving from the surface of an object are subjected to a "pilot heat source." In a room fire, there is an unknown probability of the presence of a pilot source (discussed further below).

The radiant flux seen at any distance from a fire is a function of the size of that fire, which is changing with time. In the case of the smallest fires addressed here, which involved little more than the bedclothes, the fire was also moving over the bed surface. Thus it is necessary to have some means of radiant flux measurement that can be moved during a test if desired. Figure $2 b$ shows one of two heat flux gage arrays assembled for this purpose. The array is based on a framework that rides on a set of four wheels. Medtherm ${ }^{3} 6 \mathrm{~mm}$ dia, Schmidt-Boelter, watercooled heat flux gages were held at the top end of telescoping tubes to allow variable height placement above the floor. These gages have a nearly $180^{\circ}$ field of view and a maximum flux rating of $100 \mathrm{~kW} / \mathrm{m}^{2}$. According to the manufacturer, these gages have a response time of less than $0.2 \mathrm{~s}$. The gage support tubes were in turn attached to holders that could be moved along an axis perpendicular to the bed edge. Water inlet tubes and drains were run up to the gages directly behind the supporting telescoping tubes. The dimensions of all of these parts were minimized so as to reduce the shadowing inherent in placing flux gages, more or less in line, at varying distances from a radiant source. Corrections were made to all of the heat flux data for these shadowing effects. The corrections, which depended on gage spacing and on fire size, amounted to as much as $20 \%$ for the rearmost gage in an array.

For the bed fire tests directly under the open hood, two flux gage arrays were used. Both used the same arrangement of five gages each, all oriented horizontally, facing toward the bed. Three of these gages were set at the same height (typically, but not always, at the top height of the mattress), more or less in a straight line perpendicular to the edge of the bed. At the middistance location, two additional gages were placed, typically (but not always) at $\pm 15 \mathrm{~cm}$ above and below the main line gage. These allowed some estimate of the effect of not having the main line gages at the height where the radiant flux was a maximum. This implied correction for the effect of height was typically $10 \%$ or less but note that this correction can still yield a flux value which is less than the true maximum since there is not enough information to fix that maximum. A typical initial placement of the arrays was to have one facing the folded-back covers on the side of the bed being ignited. The other array faced the pillow on the head end of the bed. After the pillow burning had passed its peak, that array was moved to a position opposite the foldedback covers on the side of the bed opposite the ignited side. This placement tended to catch what appeared to be the most intensely radiating areas on the $\mathrm{M} 3$ beds, for which the bulk of the material burning was the bedclothes. For the other two mattress/foundation designs, the preferred placement for catching what appeared to be the most intense radiation was to place one array at mid-length along the ignited side of the bed and the other array mid-way along the opposite side. The array placements out from the edge of the bed and the spacings of the gages were initially estimated using the heat flux estimate procedures in NFPA 555 [5]. They were then adjusted in accord with the results seen experimentally. The goal was to bracket heat fluxes as low as $10 \mathrm{~kW} / \mathrm{m}^{2}$ or less since this is in the range of the minimum flux for ignition of many of

\footnotetext{
${ }^{3}$ Certain trade names and commercial products are mentioned in the text or identified in an illustration in order to specify adequately the experimental procedure and equipment used. In no case does this imply recommendation or endorsement by the National Institute of Standards and Technology, nor does it imply that the products are necessarily the best available for the purpose.
} 
the surrogate ignition materials. This is roughly where the maximum reach of the fire exists for piloted ignition of a given material.

As an additional check on the "radiative ignition reach" to be inferred from the heat flux results measured here, one or two holders containing two horizontally-oriented samples of selected surrogate ignition materials was placed near the burning bed. Each holder incorporated a single, horizontally-oriented heat flux gage of the same type as was used in the arrays (see Figure 2a). It also included, over each sample, a thermocouple (chromel/alumel, $0.5 \mathrm{~mm}$ dia. sheath enclosing the junction) as an indicator of possible ignition. There was no pilot source to assure ignition of gasifying samples. Note that the intent in placing these samples (typically at the foot end or along one side) was not necessarily to confirm that it could ignite (though many did) but rather to confirm the model predictions below that piloted ignition was plausible. The small size of the samples (ca. $7 \mathrm{~cm} \times 1.9 \mathrm{~cm} ; 2.75$ in $\times 0.75 \mathrm{in}$ ) made non-piloted ignition, especially at lower incident heat fluxes, improbable.

The open hood tests also included a simple system to measure flame reach out from the ignited side of the bed (i.e., perpendicular to that side). A camcorder was placed well off the foot end of the bed (more than $3 \mathrm{~m}$ ) so that its line of sight was along the ignited side of the bed, about 60 $\mathrm{cm}$ above the floor. Off the head end, on the same side of the bed, a "stripe board" was placed. The board had black, vertical stripes every $7.6 \mathrm{~cm}$ ( 3 in). The camcorder saw the burning process along the side of the bed silhouetted against the stripes on the board allowing a measure of the apparent outward reach of the flames on the side of the bed. These apparent numbers were corrected for the position of the flames along the line of sight using another camera view of the fire. The camcorder data were reduced to give both the farthest flame reach lasting at least one second and the farthest reach lasting one video frame $(0.03 \mathrm{~s})$.

\section{Room Tests}

Half of the tests were done with the burning bed in a room environment and the single room door was placed under the edge of the plume collection hood. The room was nominally $4.27 \mathrm{~m} \mathrm{x} 4.27$ $\mathrm{m} \times 2.44 \mathrm{~m}$ high ( $14 \mathrm{ft} \times 14 \mathrm{ft} \times 8 \mathrm{ft}$ high). It was constructed using ordinary steel wall studs and was lined (all internal surfaces) with two layers of $1.27 \mathrm{~cm}$ (0.5 in) gypsum board. The lining was not changed throughout the test series; this lead to some variation in room lining contribution, as discussed below. The bed was placed, on top of a scale, at an angle with respect to the room walls so as to keep it away from the walls and minimize their effect. See Fig. 3.

The room tests were intended to capture some of the effects that a fire enclosure brings. In particular, such an enclosure captures the smoke plume from the fire leading to the build-up of a hot gas layer under the ceiling whose depth depends on both the heat release rate, the smoke plume entrainment rate and the room door opening dimensions. The hot gases radiate downward toward the bed fire. This radiation, even when it is insufficient to ignite anything directly (as it does at the point of flashover) does preheat the upward facing portions of the bed and this can accelerate fire spread on these surfaces. Note that a bed has more upward facing surface area per 
unit of mass than does an item of furniture such as a chair or sofa and so is more susceptible to this but the actual effect depends on the burning mechanism of a particular bed design ${ }^{4}$.

Flashover, in effect, extends the radiative reach of the fire to the room walls since radiation from the hot smoke layer dominates the other object ignition process. This precludes a measure of the increased reach the room causes in sub-flashover conditions. This is the reason the tests were intended to remain in a sub-flashover condition. It should be noted that there is a continuum of room interaction with a bed fire (or any type of fire). A very small fire in a very large room yields only a minimally heated upper layer. This low temperature layer cannot emit enough radiation to significantly affect the bed fire. As the bed fire becomes larger and the room smaller, the smoke layer becomes hotter and thus a stronger radiator, accelerating the bed fire more strongly. The particular result for any given size depends both on the bed design and on the room ventilation. Here we have obtained only a very limited measure of the room interaction effects.

Another possible effect of a room enclosure is that the hot smoke layer will descend all the way down to the point where part of the bed is immersed in it. The impact of this will depend on the extent of immersion and the oxygen content of this smoke layer, which tends to decay as the fire grows. Decreased oxygen content will have little effect on the fire initially but as it drops, it can have a strong inhibiting effect. In the extreme, if the room door is nearly or fully closed, it can put the fire out while leaving a very toxic atmosphere [6]. ${ }^{5}$ The present work focuses on fires that do not become starved for oxygen except by a transition to flashover. Thus the principle room effect is a possible radiative enhancement of the burning rate and heat release rate. Since the goal was to get a measure of this enhancement (and its effect on the radiative ignition reach of the fire short of flashover), an increase of the room door width was used to inhibit flashover for the larger fires. This was successful except for the very largest fires.

The room door opening was defined by a fixed soffit height $(2 \mathrm{~m} ; 80 \mathrm{in})$ above the floor and a pair of $1.27 \mathrm{~cm}(0.5 \mathrm{in})$ thick slabs of gypsum board that gave a varied-width opening in the center of one side of the room. As noted above, the goal was to have the room impose a limited amount of radiative enhancement of the bed fires, short of flashover. Room flashover has been studied by a number of investigators who have offered correlations of the results in terms of heat release rate and room ventilation (size of door opening). Ref. 7 includes a recent summary of these correlations. It was used to construct Fig. 4 which shows an estimate of the heat release rate required to cause flashover in a room as a function of the width of the door opening. The figure indicates two difficulties here. First, one must know the heat release rate to pick a door width. While the open hood results were available as a guide, there was no measure of how much enhancement to expect from the room. Second, the available correlations have a large amount of uncertainty in their predictive capability, as indicated by the range between the lower limit and upper limit estimates. To avoid flashover as much as possible while still getting some

\footnotetext{
${ }^{4}$ For some bed designs, the fire in the foundation is a critical forcing mechanism for greater mattress burning. The foundation fire is shielded from any significant effect of radiation from a hot gas layer below the ceiling.

${ }^{5}$ It is shown in Ref. 6 that the burning of less than $0.4 \mathrm{~kg}$ of material in a small, closed room $\left(9 \mathrm{~m}^{2}\right.$ of floor area) can lead to an incapacitating atmosphere in the room. This case could impose a severe limitation on allowable fire size in the event of a closed door. The frequency of occurrence of such fires in the real world is unknown but this case must be kept in mind.
} 
room effect on the fire, an attempt was made to stay close to the lower limit curve in estimating required door width. Note that this led to some very wide door openings with the largest fires. Specifically, the door widths used were as follows:

\begin{tabular}{cc}
$\begin{array}{c}\text { Mattress } \\
\text { Design \& Size }\end{array}$ & Door Width (m) \\
\cline { 1 - 2 } M3 Twin & 0.5 \\
M3 King & 1.0 \\
M5 Twin & 1.5 \\
M5 King & 1.5 \\
M1 Twin & \\
M1 King & 2.7 \\
& 2.7
\end{tabular}

For the tests done in the room, there was not sufficient space for two heat flux arrays. One array was set up with 8 heat flux gages. In addition to the 5 gages arranged as above, each main line gage holder also held a gage pointed directly upward to measure the heat flux coming down from the combination of hot gases below the ceiling and the fire plume on the bed. During a room fire test, the environment changes more than during a hood test since the hot gas layer could possibly descend down to the level of one or more of the flux gages. At that point, the gage receives input from both radiation and convection. This type of gage measures a "cold-wall" convective heat flux that is only fully valid as a measure of what a heated item sees initially; it exaggerates the convective flux thereafter. To check for this kind of effect, a separate vertically pointing flux gage was placed in the room, near the portable array. This separate gage stand incorporated two thermocouples (chromel/alumel, 36 gage wire, bare junction), one on each side protected from direct fire radiation by a clean piece of aluminum foil. These were intended to give a reasonably accurate estimate of the gas temperature at the height of the several flux gages. The results from these thermocouples were used to estimate the convective inputs the gages were seeing in the various room tests. Generally the convective flux was less than $1 \mathrm{~kW} / \mathrm{m}^{2}$, often a fraction of this, so no corrections of this type were made to the raw flux results reported here.

In the room tests, the flux array was placed on the ignited side of the bed, either near the foldedover covers (M3 beds) or midway along the side of the bed (other designs). It was not possible to move it during a test since personnel could not remain in the room. In retrospect, this placement on the ignited side may have missed some of the radiative reach enhancement for the beds giving larger fires. This enhancement tended to manifest itself in an acceleration of the fire spread on the covers on top of the bed and resulted in a larger fire on the side opposite the ignited side. Thus it is likely that the radiative ignition reach on the unmeasured side was greater than that recorded here (for the cases where there was an appreciable room enhancement of the burning). Since we ultimately declare cases with such substantial room enhancement to be unacceptable, even without this effect, it does not affect the overall conclusions of the study. 
One surrogate sample holder was used in the room tests. It was placed near the head end of the bed, on the bed centerline. Lateral flame reach data could not be taken in the room but they would not be expected to differ, on the ignited side, from the data measured under the open hood since the flame behavior is dominated by localized phenomena.

The room tests also included two small thermocouple trees having three thermocouples each (30 gage chromel/alumel wire; bare junctions) to get a measure of the temperature of the hot smoke layer. One tree was placed near $(60 \mathrm{~cm}$ from) a rear corner of the room (away from the door) and the other was placed near a front corner of the room (toward the door). Each array placed the thermocouple junctions $15 \mathrm{~cm}(6 \mathrm{in}), 38 \mathrm{~cm}$ (15 in) and $61 \mathrm{~cm}(24 \mathrm{in})$ down from the ceiling.

All of the tests were recorded from two angles using a pair of camcorders. The tests under the hood were taped from the ignited side and from the foot end. The room tests required camera placement outside the room. For the smallest fires, having the smallest door opening, the cameras' views of the fires were severely truncated.

\section{Cone Calorimeter Characterization of Surrogate Materials}

Samples $10 \mathrm{~cm}$ (4 in) square were tested in air in a vertical orientation (with the rear surface insulated by ceramic wool) from an incident radiant flux level of $65 \mathrm{~kW} / \mathrm{m}^{2}$ down to fluxes in the range of $10 \mathrm{~kW} / \mathrm{m}^{2}$ to $15 \mathrm{~kW} / \mathrm{m}^{2}$ to get an estimate of the minimum flux required for ignition. For this characterization of ignitability, the normal spark igniter was placed above the sample to act as a pilot. Thus as soon as an ignitable mixture was evolving from the sample surface, it was caused to flame by the spark igniter. This is termed piloted ignition and it yields flaming ignition all the way down to heat fluxes just sufficient to heat the sample surface to a point of rapid degradation/gasification (required to get an ignitable gas phase air/fuel vapor mixture). Typically this was in the $10 \mathrm{~kW} / \mathrm{m}^{2}$ to $15 \mathrm{~kW} / \mathrm{m}^{2}$ range, as indicated above.

Radiative ignition is somewhat unique in that the sample surface is (in the absence of a pilot heat source) the hottest point in the near-surface region. This makes it difficult for the gases evolved from the surface into a much cooler buoyant convection boundary layer to ignite spontaneously (which is termed non-piloted ignition). The present samples require much higher radiant heat fluxes to yield non-piloted ignition (in the absence of any, even very brief external spark). While precise values were not measured, only the newsprint yielded non-piloted ignition at $35 \mathrm{~kW} / \mathrm{m}^{2}$; all other materials had piloted ignition temperatures above this and the two wood samples ${ }^{6}$ required more than $50 \mathrm{~kW} / \mathrm{m}^{2}$. This issue of which minimum ignition flux, piloted or nonpiloted, is most pertinent to a room fire will be discussed further below.

\section{$\underline{\text { Results and Discussion }}$}

\section{Heat Release Rate}

\footnotetext{
${ }^{6}$ Non-piloted ignition of wood can occur at fluxes as low as $20 \mathrm{~kW} / \mathrm{m}^{2}$ but this occurs via a glowing mechanism which requires a longer time than is relevant to the present experiments [8].
} 
Table 4 is a compilation of the peak heat release rate values obtained in duplicate tests of the two sizes of bed for the three mattress/foundation designs, tested both under an open hood and in a room. If there were two distinct peaks in the heat release rate curve, the secondary peak is included in parentheses. Note that the largest of the two peaks sometimes is the earlier and sometimes the later one. The higher peak data (only) are plotted in Figure 4. The footnotes to Table 4 indicate which of the room fire peaks had contributions from the burning of the paper on various room surfaces. (Since the room was not re-lined during the test series, a given area made a contribution only in one test.) Most of the cases of room surface involvement involved the largest fires, as they neared or passed the point of flashover. The only unexpected case of a large contribution is that of the first of the twin-size M5 beds. The fire was roughly at the $600 \mathrm{~kW}$ level when the gypsum board paper on the ceiling (and an upper section of one wall) ignited (the first test in which this happened) and yielded a brief (ca. $50 \mathrm{~s}$ at its half-height) but intense leap to the nearly $1.7 \mathrm{MW}$ level reported in Table 4 . This points out the need to consider wall linings (painted gypsum board and/or wallpapered gypsum board, not just wood paneling) as possible second objects igniting in response to a bed fire.

These same mattress designs, in twin-size with nominally the same bedclothes, had been measured previously under an open hood, using the facilities at an outside laboratory before the NIST facility was on-line [1]. The heat release rate peaks reported here for the largest fires (M1 twin) are about double those reported previously. As noted above, the NIST facility was carefully and repeatedly calibrated during this test series so confidence in these numbers is high; there were no problems with smoke plume capture. At our request, the outside lab facility was also calibrated daily during the NIST work there but their calibration was necessarily limited to small test fires $(150 \mathrm{~kW})$. As was noted in Ref. 1, their hood tended not to capture all of the smoke from a large fire such as that produced by an M1 mattress. It is impossible to quantify the error that occurs when the entire plume is not captured but this is undoubtedly part of the source of the difference. We do have one additional piece of evidence, and that is the peak rate of mass loss for the M1 twins, as measured in the two laboratories. It was shown in Ref. 1 that this aspect of the sample mass behavior correlates rather well with the peak rate of heat release. Examination of the peak mass loss rates from the two labs gives an average value of $0.11 \mathrm{~kg} / \mathrm{s}$ in the NIST M1 twin tests and an average value of $0.075 \mathrm{~kg} / \mathrm{s}$ in the outside lab tests. The peak heat release rate ratio was thus 2.2 while the peak mass loss ratio was about 1.5 . This suggests that there were possibly two contributors to the observed difference in peak heat release rate: (1) smoke spillover at the outside lab leading to about half of the observed difference and (2) materials variability leading to the other half. Materials variability is not a concern in the present study since it focuses on only the present set of data; this issue is discussed in a separate report [9].

Inspection of Table 4 and Figure 5 indicates a general tendency for the room environment to enhance the heat release rate peak, even in the absence of any contribution from the wall linings. This is expected, of course, for the largest fires. It is worth noting, however, that there appears to be a significant room effect ${ }^{7}$ even for the M3 king-size beds. Under the open hood these gave peaks below $300 \mathrm{~kW}$; in the room these gave peaks of about $400 \mathrm{~kW}$. The peak upper layer temperature readings for these $\mathrm{M} 3$ tests were in the $200^{\circ} \mathrm{C}$ to $250{ }^{\circ} \mathrm{C}$ range yielding recorded

\footnotetext{
${ }^{7}$ The limited number of replicates here makes it difficult to assert that there is a statistically significant effect but the effect does appear to be real.
} 
peak $^{8}$ downward heat fluxes of $3 \mathrm{~kW} / \mathrm{m}^{2}$ to $4 \mathrm{~kW} / \mathrm{m}^{2}$. This is a fairly low number (compared to the minimum flux for ignition) but, given enough time, it can raise the top surface temperature of the comforter to somewhere in the range of $180^{\circ} \mathrm{C}$ to $220^{\circ} \mathrm{C}$, accelerating flame spread over it by roughly a factor of two. This in turn leads to a larger area burning at any given time and a higher heat release rate. Evidently, this self-accelerating effect needs the larger dimensions (and longer burning time) of the king size bed to be manifested here. A similar effect is seen with the M5 beds. Note that it is the bedclothes (specifically the comforter) that are inferred to be at the core of this behavior here, since they are facing the upper layer radiation.

There is no fixed relationship between the peak heat release rate of a fire that a king size bed of a given design yields relative to the fire size from the twin bed". Under an open hood, the differences are clearly design-dependent. For M5 it is not clear (in Fig. 5) that there is a size effect; for Ml the effect is strong (but less than the factor of two difference in bed top area). In the room, the bed size differences for M3 and M5 designs are more accentuated, presumably for the reasons indicated above regarding radiative pre-heating of the top of the bed. For M1 the size effect seems to be decreased but the room values are influenced in varying degrees by the proximity to flashover (and its attendant oxygen supply limitations) plus wall/floor surface contributions so that it is difficult to say anything definitive.

The nature of the bed fires tends to change as one móves from the largest to the smallest.

- The M1 fires developed quickly and, at their peak, involved the whole bed, not greatly unlike a pool fire, i.e., a (generally liquid fuel) fire on a horizontal surface where the entire surface is flaming. A pool fire is the physical picture assumed in NFPA 555 in its rules for estimating the radiation versus distance from a burning object [5]. As the bed fires get smaller, they tend to get more complex.

- The M5 beds actually tended to give two heat release peaks. The first occurred during a fire spread stage and involved materials on a portion of the sides of the bed along with most of the material on the top. After a lull in which the foundation got fully involved, a second, typically larger peak ensued in which the intense foundation burning forced more complete burning of the mattress residue from the first peak. The physical picture is somewhat closer to a burning wood crib than a pool fire.

- The M3 burns essentially involved a localized fire propagating over the bedclothes, arrayed on the mattress top and sides. This last case is particularly disjointed in its connection between overall heat release rate and radiant heat flux to the surroundings. Only that portion of the propagating fire near the edge of the bed contributed significantly to the net radiant flux sent to nearby objects. Portions of the fire near the top center of the bed, for example, were too far away to contribute much radiation (especially for the

\footnotetext{
${ }^{8}$ There is radiative view factor from the hot smoke to the flux gage that plays a role here but it is difficult to estimate since the radiation comes from within the depth of the smoke layer. The gage was about $1 \mathrm{~m}$ from the edge of the room. More central locations in the room (where the bed was) would have a higher radiative view factor and therefore a somewhat higher radiant flux than that reported here.

${ }^{9}$ If a bed fire were a simple spread process over a flammable material which burned for a time that is long compared to the spread time, then the heat release rate peak would tend to double with the doubled bed top area in going from twin to king size. Bed fires are not this simple, however. Material burn-out during spread occurs with some designs and others exhibit much more complex spread in and among the various bed elements.
} 
king size case). This should be borne in mind when considering the relation between radiant flux reach and peak heat release rate.

The times to the heat release rate peaks are summarized in Table 5. Again, if there were two reasonably distinct peaks, the time to the lesser of the two is in parentheses. The largest fires (M1 designs) also yielded the earliest peaks. With the M5 king-size beds in the room, the earlier peaks were nearly as severe as the later peaks which were plotted in Figure 5. The cause of the separate peaks for the M5 design was noted above. The same observation regarding the relative sizes of the two peaks holds also for the M3 twins. In this case the peaks were due to a combination of the pillow burning, along with the bed covers on top of the bed (earlier peak) or to the flame fronts on the bedclothes converging on the bedclothes hanging from the side of the bed opposite that ignited (later peak).

\section{Lateral Reach of the Flames}

This is of interest because the flames can heat adjacent items by direct contact or, if they flicker even very briefly through ignitable vapors from another object, can act as a pilot to ignite that object. Recall that this was measured on the ignited side of the bed only and only under the open hood. Table 6 summarizes the results in terms of two measures: maximum instantaneous reach of the flames (1 video frame $=1 / 30 \mathrm{~s})$ and maximum reach persisting for at least one second. In both cases the reach is measured perpendicular to the side of the bed. The height above the floor at which these maximum flame extents occurred was typically at mid-mattress level or above. The data from Table 6 are plotted in Figure 6. Note that the flame reach values for the M1 and M5 beds are substantially the same even though they burned quite differently. Also note that, for any given design, the twin and king size beds gave very similar numbers (the twin values are the first two columns in each group of columns in Fig. 6).

Since the M3 data are from the ignited side of the beds, there is no reason to expect a bed size effect; this is too early in this particular type of fire for there to be any interaction between the fire, spreading on the bedclothes, and the more remote portions of the bed. The four M3 data points can thus be regarded as four samples of the maximum reach in four successive tests and, for this design, they pertain essentially to the burning bedclothes (and, of course, might well be different for other bedclothes combinations). The average of the four instantaneous reach values was $20.4 \mathrm{~cm}$ with a standard deviation of $2.0 \mathrm{~cm}$. The average one second reach was $15.8 \mathrm{~cm}$ with a standard deviation of $1.6 \mathrm{~cm}$. On the assumption that these values would, in a large number of tests, follow a normal distribution with this standard deviation, then reach values can be expected to be as large as $26.4 \mathrm{~cm}$ (instantaneous reach) or $20.6 \mathrm{~cm}$ (one second reach) in less than $1 \%$ of such $\mathrm{M} 3$ bed fires [10].

For the M5 twin beds, there are three independent values for flame reach ${ }^{10}$. The average instantaneous flame reach for this case was $39.1 \mathrm{~cm}(\mathrm{~s} . \mathrm{d} .=5.2 \mathrm{~cm})$; the average one second reach was $31.4 \mathrm{~cm}(\mathrm{~s} . \mathrm{d} .=1.9 \mathrm{~cm})$. These values imply a less than $1 \%$ probability of an instantaneous reach beyond $54 \mathrm{~cm}$ and of a one second reach beyond $37 \mathrm{~cm}$.

\footnotetext{
${ }^{10}$ The heat release rate data from the extra test here were lost due to a data system failure.
} 
For the other bed fires there are only two replicates since it cannot be assumed that twin and king data can be lumped together for these designs; the maxima may be occurring at differing stages of the fire, depending on bed size. Since the main area of application of these data is with the smaller fires, this is not a problem. Below, the flame reach data will be compared to the radiative ignition reach.

\section{Radiant Heat Fluxes to the Surroundings}

Figure 7 shows an example of the type of results obtained from one of the flux arrays (five gages); this is from the ignited side of an M3 king-size bed under the open hood. Note the distances of the gages from the edge of the bed. The longitudinal placement of the array along this side of the bed was several centimeters toward the foot end from the center of the folded back portion of the bed covers. This distance along the side is roughly where the fluxes are expected to be a maximum for this mattress design since the longer burning of the doubled layers of covers leads to an enlarged radiating area. (This consideration pertains mainly to the localized flaming for M3 beds.)

Figure 7 shows the flux received by the five gages at three distances out from the edge of the bed. The middle three gages were at the same distance from the bed but at three heights $( \pm 15$ $\mathrm{cm}$ above and below the gage on the main line). At the time of ignition of the bottom, head end corner of the bedclothes, the fire was too small to give a measurable flux to even the closest gage. The flames spread up the covers on the side of the bed and then began to spread laterally on the doubled hanging covers (combination of flat sheet, blanket and comforter). This increasing flame area backed by hot, degrading and charring materials, gave an increasing heat flux seen by all of the gages; the flux, of course, decreased with the distance away from the fire. By about $100 \mathrm{~s}$ after ignition, the radiating area in front of the gage array reached a maximum (for M3 fires at this location, about $0.4 \mathrm{~m}^{2}$ including the visible plume above the side of the bed). The noise in the heat flux signals was due to the rapidly changing flame configuration, which was not uniform over the side of the bed. The gage array remains stationary throughout this entire duration to record the flux history seen by a given set of locations in a plane normal to the edge of the bed ${ }^{11}$. The flames, on the other hand, were propagating toward the foot end of the bed on the hanging covers, toward the head end of the bed on the fitted sheet and across the top of the bed. Because the M3 design incorporates an effective barrier material around the bulk of the mattress and foundation, the initially burning material opposite the flux array (essentially only the bedclothes layers) eventually burned out and the fluxes seen by the gages decayed as the various radiating areas got further away from them. Note that for an M5 or M1 design, the mattress gets involved and local burn-out is delayed. For those designs, the radiating area simply kept growing larger and the heat fluxes to the surroundings increased accordingly until burn-out of the whole bed intervened ${ }^{12}$.

\footnotetext{
${ }^{11}$ In general, a flux array could not be moved to another location until the flames in front of it had died down so that a reasonably complete local history was obtained. Because of the relative timing of fire growth and fire spread for the materials studied here, along with other physical restrictions, this meant that the only practical movement was for the other flux array, from the pillow area to the non-ignited side, folded-back cover region (and then only for M3 tests under the open hood).

${ }^{12}$ The details are substantially more involved than this, especially with M5 designs that go through two peak burning periods. More description of the burning processes can be found in Ref. 1 .
} 
Figure 7 shows that the three gages at the middle distance from the bed did not record the same peak flux values. This is a result of the gages having had differing view factors relative to the radiating area on the bed. For a uniformly radiating area, the maximum view factor and maximum flux would occur on a line perpendicular to the center of that radiating area. The gages could not, of course, be placed on that centerline beforehand since there was no way to know where it would be. Thus the three gages were used to give an indication of the extent to which the mid-height gage underestimated the peak flux at its distance from the bed (along a line perpendicular to the floor). For all of the test data, the mid-height, middle gage reading and the other two gage readings (closer to and further from the bed) were corrected by the ratio of the peak middle gage reading to the reading of the mid-height, middle gage (usually only on the order of a $5 \%$ correction). Note, as pointed out previously, this is a non-conservative correction, i.e., it may be insufficient to capture the true maximum fluxes. However, the fact that the correction was typically small ${ }^{13}$ implies that its use in the manner applied here should not greatly underestimate the true maximum flux.

As noted above, Fig. 7 shows that the data fluctuate due to specific, random variations during a given fire test. For use in the ignition model below, it is much easier to use a smooth curve that approximates the experimental curve. Thus Gaussian curves were fitted to the data using a leastsquares routine. Figure 8 shows an example of such a fit. Since the ignition model shows that the results of interest (discussed below) occur at or just after the peak flux, this region of the curve was given more attention in the fitting process. When data at longer times (well past the peak) were such that inclusion of them would have altered the fit in the peak region unfavorably, they were omitted in the fit process. Not all of the fits could be done as well as that shown in Fig. 8; in such cases the best fit was taken as that which would give conservative (i.e., greater) results in the ignition reach calculations discussed below. Generally, goodness of fit was not a major factor in determining ignition reach.

As noted previously, the flux gage data also needed correction for the fact that the gages that were not closest to the bed fire had some shadowing by the gage(s) in front of them. The corrections took into account the lateral dimensions of the gage holders and their support tubes, as projected onto the plane on the near side of the bed. The projected gage shadow area(s) were assessed as a fraction of the fire area in that plane. One of the video cameras, placed behind the gage array, was used to estimate the fire area at the time of the flux gage peak readings.

Corrections to the mid-height, middle gage were generally quite small ( $\leq 3 \%$ even for the worst cases which corresponded to the smallest area fires) since only the front gage created any shadowing. Corrections to the rear gage reading for shadowing could (slightly) exceed $20 \%$ for the smallest area fires since there were four gages in front of it. In general, all such corrections decreased as the fire size at the flux peak increased. Since the correction process was quite time consuming, the corrections were made only to the "worst case" radiant heat flux distributions, i.e., those for which the radiant heat flux reach was greatest. This is in keeping with the use for these data below to calculate the farthest distances at which piloted ignition of the surrogate materials is possible.

\footnotetext{
${ }^{13}$ Also relevant to this statement is the fact that the flames did not much exceed a factor of two above the gage height, except in the M1 fires.
} 
The information for making such corrections was available only for the ignited side of the bed and only from tests outside of the room. In one or two cases of fires under the open hood where the measured flux reach was greater on the side of the bed opposite that ignited, the corrections applied were derived from the view on the ignited side of the bed. For tests in the room, an appropriate video view of the fire size seen by the flux gage array was not available and so the shadowing corrections used were derived from the fire size as seen under the open hood. All of the room fire flux data there were from the ignited side of the bed only. Recall that in the room, there was some indication that even for the M3 king-size beds, the fire was getting larger as it spread to the side away from the ignited side. The bigger fire implies a need for a smaller shadowing correction but it also implies that the radiant flux reach was greater than that measured on the ignited side. There is a tendency for these two sources of error to counter each other but, it seems likely that the fire size effect, being more direct, is larger and that the radiant flux reach values in the room are greater than those inferred from the available data. In this sense, the data should be utilized conservatively in assessing second item ignition. As will be seen below, there are other issues that imply the piloted ignition data are, on balance, conservative as a basis for assessing the threat these data imply.

The corrected peak flux versus distance will be used below to infer how far out from the bed the most ignitable surrogate materials could be subject to piloted ignition. Figure 9 is an example of the raw data for peak heat fluxes as read by the flux gage array and the data as corrected for the effects of both shadowing and for height above the floor. The effect of the corrections and their uncertainties, as described above, is put into perspective by a plot such as this.

The effect of these corrections on the maximum piloted ignition reach is modest, about a $5 \mathrm{~cm}$ effect for the M3 case and about a $10 \mathrm{~cm}$ effect for the next bigger fires (M5). The most ignitable material requires at least a heat flux in the neighborhood of $8 \mathrm{~kW} / \mathrm{m}^{2}$. At this flux level, the corrections move the location of the reach of such a flux level outward only about 5 $\mathrm{cm}$. If the minimum flux for ignition were as low as $6 \mathrm{~kW} / \mathrm{m}^{2}$, or if the curve near $8 \mathrm{~kW} / \mathrm{m}^{2}$ had the lower slope seen near $6 \mathrm{~kW} / \mathrm{m}^{2}$, then the effect of the corrections would be about a $10 \mathrm{~cm}$ shift outward in the maximum piloted ignition reach for the material. Errors in the shadowing and height corrections are expected to have a lesser effect. The underestimation of the radiant flux reach in the room due to the fire getting bigger as it accelerated toward the other side of the bed (pertinent mainly to the M3 king-size bed) could not be estimated, however.

\section{Ignitability of the Surrogate Materials}

The Cone Calorimeter data on piloted radiative ignition time versus incident heat flux for the seven surrogate materials are presented in Figures $10 \mathrm{a}$ to $10 \mathrm{~g}$. Note that the data are all for a constant level of heat flux, i.e., the exposure was initiated by the removal of a cover on front of the sample face and that face saw a constant incident heat flux until it ignited. The flux seen by a second object in a real fire is time-dependent, as discussed above. For this reason, the Cone data cannot be used directly here to estimate the reach of piloted ignition.

As expected, all of the ignitability curves are shaped similarly, in a qualitative sense. At high incident heat fluxes ignition occurred rapidly. As the flux was reduced to lower levels, a longer time was needed for the sample surface to reach a temperature required for it to generate an ignitable gas mixture in the space adjacent to the surface. Finally, as the flux was lowered, in 
successive experiments, each with a new sample, to still lower levels, it was no longer possible for that flux to raise the sample surface temperature to the level required to generate the ignitable mixture of degradation gases and no ignition occurred. This temperature level depends on the chemical composition of the sample (and, secondarily, on the rate of heat loss from the front surface of the sample). For most of the fabric samples, the other parameter that determines the ignition delay time is the amount of heat required to raise that specific material at its given thickness per degree of temperature rise. This is termed its thermal inertia. ${ }^{14}$ For the thicker materials (terry cloth and the two wood samples), it is thermal conductivity rather than thickness which sets the value of thermal inertia. The terry cloth, with its open physical structure, also needs to have its radiation penetrability described.

The quantitative values for the effective ignition temperature and thermal inertia (shown on the plots) vary significantly but not dramatically among the various materials. The only surprise in Fig. 10 is the high effective ignition temperature for newsprint, considering that its chemistry is similar to the cotton cloth ${ }^{15}$. Evidently, the paper is so thin that at low heat fluxes it loses so much reactable material during heat up that it has not got enough remaining to yield an ignitable gas mixture. If so, this material departs appreciably from the implicit assumptions in the ignition model. Nevertheless, the model appears to be able to describe the ignition behavior quite adequately for the present purpose.

\section{Predicted Reach for Piloted Radiative Ignition}

The ignition behavior of these materials can be described quantitatively by a simple thermal model of piloted ignition that includes those parameters just mentioned. The model accounts for the incoming radiation, the thermal inertia of the material and heat losses from the front by radiation and buoyant convection (the same losses from the back can also be included if desired). The model, which differs in details for thin and thick materials, is summarized in Appendix 1; it is essentially similar to thermal ignition models that have been used in the fire literature for decades. As piloted ignition models, these assume that ignition follows instantly when the sample surface reaches its ignition temperature. In the Cone Calorimeter, a spark source is present in the evolved gas plume to assure that this is the case. Since the model is non-linear via the surface radiation losses, it requires computer solution, as described in Appendix 1.

The first application of the thermal ignition model was made to deduce the parameter values needed to get a good quantitative fit of the model to the Cone ignition data. This was done essentially by trial and error but with some literature procedures (and experimental convective heat loss coefficient measurements) as guidelines, especially for a first estimate of the ignition temperature. The final fitting was guided by the observation that the thermal inertia most influences the high flux ignition data and the ignition temperature most influences the low flux data. The fitted curves are included in Fig. 10 and the inferred model parameter values are listed

\footnotetext{
${ }^{14}$ In Fig. 10, the inferred ignition temperature is denoted as $\mathrm{T}_{\text {ign. }}$ and is reported in ${ }^{\circ} \mathrm{C}$; thermal inertia is denoted as "Thermin" and is reported in m-k-s units; in-depth absorption coefficient (Fig. 10e) is denoted as "Alpha" and is reported in $\mathrm{cm}^{-1}$.

${ }^{15}$ In contrast to the behavior noted here for a single flat sheet of newsprint, crumpled newsprint behaves differently. It is often used as a flashover indicator in room fires where the crumpled mass ignites spontaneously (no pilot needed) at a flux of about $20 \mathrm{~kW} / \mathrm{m}^{2}$. Its behavior in that situation suggests that it would undergo piloted ignition at a lower incident flux.
} 
on the graph for each material. It is evident that the thermal model can give quite a reasonable description of the observed Cone ignition behavior.

The second application of the model was to calculate the farthest distance from a given bed fire at which piloted ignition of a given surrogate material can possibly occur (via any pilot source available in the fire room, not necessarily the flames on the bed itself ${ }^{16}$ ). This defines the threat radius of a fire for second item ignition of specific materials. Since a major goal of this study is to define the fire conditions that make second item ignition improbable, this is a key outcome. It will provide a measure of the area fraction of any given room that is at risk of piloted ignition of a second object for the three bed designs studied here.

This second application used the inferred parameters for each material and the Gaussian fits to the measured radiant flux vs time from the bed fires. It is again trial and error in nature but now one is iterating to find the farthest distance from the edge of the bed at which the model predicts the ignition temperature of a particular surrogate can just be reached. This is referred to here as the "piloted ignition reach" of the bed fire. Actually, the model only predicts the lowest heat flux at which piloted ignition can occur, given the Gaussian-approximation to the measured dependence on time for a chosen bed fire. The assessment of that minimum flux is narrowed to within $0.2 \mathrm{~kW} / \mathrm{m}^{2}$ by iterating the model. The corrected curve of flux vs. distance from the bed (e.g., Fig. 9) is then used to obtain the maximum distance from the edge of the bed to which this minimum radiant flux for piloted ignition corresponds.

When applying the model in this second stage, the application is intended to mimic the conditions seen in a growing room fire scenario. Thus it is necessary to be explicit about the heat loss conditions assumed since they affect the results. All of the surrogate materials represent objects that could have a substantial vertical dimension on the side facing the bed fire. The cooling of a vertical surface by upward, buoyant air flow, goes through a minimum at about $60 \mathrm{~cm}(2 \mathrm{ft})$ up from the bottom edge of the surface as the boundary layer goes from laminar to turbulent [11]. Since ignition is a localized phenomenon, there will be a tendency for ignition to occur first at this height since the heat losses there are less (given equal incident radiant flux intensity vs height). This minimum is not a very large effect (30\%) but in the general spirit here of being conservative (i.e., plausibly worst case) as to the ignition threat, this minimum convective loss coefficient has been assumed to apply in all cases.

The issue of whether there will be any significant heat losses from the backside of the surrogate material is explicitly dependent on the assumed scenario. Rear losses slow the heating of a material. (Like front surface losses, they dump some of the incoming radiant heat to the air.) Thus, rear losses can shorten the maximum piloted ignition reach of the material. Here the wood materials are assumed to be vertical parts of furniture or wall paneling. One expects that some convective and radiative loss would normally be present on the rear surface of these components. Here it has been assumed that the front and rear surfaces are subject to the same convective and radiative loss conditions for the two wood materials. The various fabrics might be exposed in differing sets of circumstances. Upholstery fabric normally covers polyurethane foam or polyester fiber, two low density, insulating materials. Thus, for this application, the two materials in Table 3 that are upholstery surrogates are modeled as having no rear heat losses.

${ }^{16}$ The use of this conservative definition for the potential ignition reach of a bed fire is considered further below. 
One of the materials is also listed as a drapery surrogate; in this application there may be equal losses from front and back surfaces (though a lining could decrease the rear losses). The terry cloth, newsprint and clothing weight materials were included as materials that could be draped over a chair or other larger object, providing a large ignition source to it. Such draped materials would tend to have minimal rear surface heat losses. For most of the fabrics, then, the no rear loss condition is assumed. The $100 \%$ cotton fabric has been run through the maximum piloted ignition reach prediction process both with and without rear heat losses (of the same magnitude as the front surface losses) to illustrate the impact of this scenario factor.

Table 7 summarizes the predicted results for the maximum reach, from the edge of the bed, of piloted ignition for the seven surrogate materials and different experimental bed fires. Several points should be noted first.

- The M3 mattress/foundation design was run with radiant flux distribution results from three different tests and the predictions of maximum reach were all about the same

- $(50 \mathrm{~cm})$.

- In general, the flux array results to be used here have been taken as those with the maximum reach as seen in the original peak flux versus distance plots (analogous to Fig. 9).

- Potentially, a broader peak with a somewhat lower maximum flux value at a given distance from the bed could have yielded a larger reach for ignition. These M3 results indicate that peak width and peak height trade-offs yielded little change in maximum piloted ignition reach.

- All of the results used are from the ignited side of the bed (the only side from which results were obtained inside the room). Most of the measured flux distribution results from the opposite side of the bed were similar (and more difficult to correct for gage shadowing).

- None of the results are for the gage array placed at the head end, opposite the pillow. The reach of the fires was less in this direction and, since the head end of a bed is usually against a wall, less relevant to calculating maximum ignition reach.

Where the numbers are stated to be $\geq$ the indicated value (i.e., for the M1 king-size bed test used here), the results are from an essentially linear extrapolation of the measured peak flux versus distance. For these tests the flux array was too close to record flux peaks lower than about 20 $\mathrm{kW} / \mathrm{m}^{2}$; a linear extrapolation underestimates the actual reach somewhat. ${ }^{17}$ Where the numbers are stated to be $<$ the given value (for the two woods and the M3 king-size bed), an extrapolation of the measured flux array results toward the bed was called for but was not done since the closer distances were into the flame contact zone where convective ignition, not piloted radiative ignition, is probably the controlling process.

The presence of rear surface heat losses does make a substantial difference in the maximum ignition reach for the two fabrics examined with and without those losses. Thus, if either of these fabrics were used as a drape material instead of an upholstery material, it would have to be closer to the bed fire in order to be ignited by radiation.

\footnotetext{
${ }^{17}$ This underestimate on this high end of the heat release rate behavior has no influence on deliberations regarding acceptable heat release rate behavior near the low end.
} 
The $100 \%$ cotton fabric, treated as an upholstery fabric (i.e., with no rear surface heat losses) gave the greatest ignition reach values for all three mattress/foundation designs. The maximum piloted ignition reach for some of the other fabrics is really not much less, especially for the M3 bed cases. In contrast, the reach for the two wood materials is substantially less, as one might expect, given the large differences in the energy required to get these denser, thicker materials heated to the point of ignition.

As a reality check on the above predictions, the same computer program was also run using as input the measured flux-time results from the surrogate sample array holders in a few tests. Thus, for the newsprint and for the terry cloth fabric, the model predicted near ignition conditions should have been achieved given the measured flux vs time seen at the location of these sample holders during the bed fire. The samples did not actually ignite in any of these comparisons but, in all cases, they were turned a medium to dark brown indicating that they were in fact degrading and gasifying substantially. This is a semi-quantitative confirmation of the model predictions of expected sample behavior. As was noted earlier, in the absence of a pilot heat source, actual ignition was not to be expected in the present tests. Early room fire growth experiments by Fang [12] demonstrated similar behavior.

\section{Fraction of Room at Risk for Piloted Ignition}

Real rooms may contain an indefinitely large variety of other objects arranged in an indeterminate number of ways. While one could, in principle, calculate the fire growth behavior among some set of chosen objects in a series of specific arrangements, there is no way to infer from this what the average hazard in the nationwide population of bedrooms might be. In particular, one would be very hard pressed to make credible quantitative predictions about how much a given change in bed fire heat release rate peak would decrease the overall mortality of bed fires when using a series of essentially arbitrary scenarios to make this inference (unless that scenario list was very large). Here, a more modest but plausible approach is taken. The threat of other object ignition (and, therefore, the threat of fire spread to significant other objects beyond the bed) is assumed to be proportional to the fraction of the floor area of the room that is at risk of piloted ignition. This implicitly assumes that all portions of the floor area present an equal threat, which is a simplification - people tend to place more objects around the edges of rooms. Nevertheless, it is plausible that minimizing this at-risk area fraction will reduce the threat of fire growth to other objects. ${ }^{18}$ There will always be fire scenarios that defeat this fire-spread limitation. As was pointed out earlier, even a very small fire in a closed room could create incapacitating toxicity conditions there [6].

The use of the maximum piloted ignition reach of a bed fire as a measure of threat will be reconsidered below. Also below, the calculated room-wide threats due to heat and toxic gases will also be introduced as an aid in assessing the threat of fires of varying intensity (heat release rate).

\footnotetext{
${ }^{18} \mathrm{~A}$ corollary of this is that larger rooms are at a lesser risk of piloted ignition as a result of a bed fire. On average, this also seems plausible since it allows a greater average spacing between objects. Of course, one could put more objects in the room but one would have to maintain the same number of objects per unit floor area to fully defeat this benefit.
} 
In keeping with the trend of being conservative here, the $100 \%$ cotton fabric (used as an upholstery fabric, i.e., with no rear heat losses) is chosen as the material with which to calculate the fraction of room floor area at risk of piloted ignition from an M3, M5 or M1 fire (see Table 7). Figure 11a shows an example of this concept. The chosen illustration is for a twin bed in a 3 $\mathrm{m} \times 3 \mathrm{~m}(10 \mathrm{ft} \times 10 \mathrm{ft})$ bedroom. The bed is placed with its head end against one wall and both sides well-removed from the other walls. This is a plausible worst case placement. If the bed were close to the wall on one long side, as well, it would eliminate some of the threatened area of the room ${ }^{19}$. The dashed periphery around the bed in this particular illustration is the radius at risk of piloted ignition as a result of an M3 fire on the bed using the value shown in Table 7 (50 cm; ca 20 in).

The use of a constant value for risk radius around a bed (as in Fig. 11a) is appropriate for M5 and M1 mattresses (see below) but it is overly conservative for the M3 case. Fig. $11 \mathrm{~b}$ is a more realistic representation of the more complex situation presented by the $\mathrm{M} 3$ bed behavior. It also introduces another complication pertinent to all bed designs, discussed below. The complex shape of the dashed line around the area at-risk for piloted ignition by an M3 fire is a consequence of the fact that the fire essentially propagates on the bedclothes. The two large radius areas are associated with the folded-back bed covers and both correspond to worst-case measured reach values for the ignited side and opposite side of the bed. The lesser reach values on the remainder of the two sides and even smaller value on the foot end are inferred (not measured) from the smaller burning areas, recorded on the videotapes, in these regions where the bedclothes were single-layer (and where, at the foot end, everything but the comforter was tucked in). One can show that the outward reach of any given radiant flux level is proportional to the radiating (burning) area. The net result here is a decreased area of the room that is at-risk of piloted ignition (as compared to Fig. 11a). Note that the folded bedclothes could, in principle, occur anywhere (or nowhere) on the bed periphery. ${ }^{20}$

The other complication in Fig. $11 \mathrm{~b}$, common to all of the mattress fires, is suggested by the position of the chair. The chair assumed here is $0.6 \mathrm{~m} \times 0.6 \mathrm{~m}(2 \mathrm{ft} \times 2 \mathrm{ft})$. It is taken as an example of a real second item of potential significance in a bedroom fire. Other upholstered items such as this present one of the largest potential heat release rate contributors to a bed fire and thus one of the biggest threats of pushing the room to flashover. In other words, ignition of such items is especially to be avoided. The essential feature of significance in Fig. $11 \mathrm{~b}$ is simply the finite size of the chair. There is no room for the chair to be placed any further toward either upper corner of the room (as viewed in Fig. 11b) without having the chair overlap the at-risk radius from the bed fire. This means that, for a second item this size, the at-risk area fraction of the room is effectively enlarged. Note that the effect is worse in Fig. 11a where a chair this size could only fit in the two lower corners of the room. In other words, the effect is worse for the M5 and M1 fires since they have a constant at-risk radius (which is also larger). The effect

\footnotetext{
${ }^{19}$ Placement of a bed near or against a wall will have other effects of unknown net impact. In particular, the air supply to the burning bed will be one-sided and this could slow the burning process. On the other hand, the fire plume will entrain less air, leading to a hotter upper layer and more radiative feedback from this layer, tending to accelerate the burning. A gypsum board wall surface also can be expected to ignite, creating an additional, brief but intense heat release rate and more feedback of heat to the top of the bed.

${ }^{20}$ The argument here also implies that the threat radius is dependent on the width of the folded-back covers and on the specific set of bed clothes.
} 
abruptly disappears as soon as the room is enlarged and the space between the at-risk radius and the room wall exceeds the chair depth.

A non-conservative element not included in Figure $11 \mathrm{~b}$ is the room effect on fire size alluded to previously. For M3 designs, only the king-size bed seemed to exhibit an accelerated fire growth in the room environment (Fig. 5). As mentioned previously, this could have resulted in a greater radiative ignition reach on the side opposite the ignited side of the bed. The same heat release rate enhancement effect is present for M5 king-size beds, but is, again, not accounted for here since we have no quantitative estimate of it. The situation for M5 twin beds is ambiguous since one case ignited the ceiling gypsum board (suggesting considerable room enhancement) but its replicate gave no enhancement of heat release relative to the tests in the open hood.

There is another non-conservative element in Fig. 11b, the lack of accounting for other flammable objects immediately adjacent to the bed as normally used in a bedroom. If there were a bed stand on one side of the bed (at the head end), this would qualify, under the rules of NFPA 555 , as part of the "fuel package" forming the primary fire. ${ }^{21}$ That is, it would be assumed that everything in the primary fuel package burns as a direct result of the initiation of the bed fire since such adjacent objects are within the flame reach of the bed fire. A bed stand, being most likely made of wood, would tend to burn more slowly than the bedding but its mode of behavior would be highly dependent on the nature of its materials ${ }^{22}$ and any items on top of it. When it did burn, it would create its own radius of piloted ignition risk extending out from its borders; thus near it, the piloted ignition radius is larger than in Fig.1 lb. For the specific case of that Figure, this would overlap the at-risk area posed by the chair, but this overlap does not hold in general. Fuel package issues are discussed further in Appendix 2.

With the preceding caveats and assumptions in mind, it is of interest to see how the size of the room is estimated to affect the floor area fraction at risk of piloted ignition from a given fire. The picture in Fig. $11 \mathrm{~b}$ is used in this estimate, i.e., a chair of the size shown there is the assumed second item. Calculations are also made for a second object that is vanishingly thin to eliminate this second object size effect (drapery or wall paneling approach this limiting behavior). In doing this calculation, we make no distinction in the maximum reach results between twin and king-size beds since the available data do not suggest such a distinction can be made. The calculation of room size effect on at-risk fraction is simple. For a given bed fire and thin second object, the at-risk area remains constant (area within the maximum reach border for the $100 \%$ cotton cloth, bed area excluded) and the room area (minus bed area) is varied.

Area Fraction At Risk $=\frac{(\text { Area Inside Piloted Ign. Boundary }- \text { Bed Area })}{(\text { Room Area }- \text { Bed Area })}$

\footnotetext{
${ }^{21}$ Also to be included in the "fuel package" is anything under the bed, especially carpeting, any head board on the bed and anything, including contiguous drapes or the paper on the gypsum board, at the head end of the bed. These can extend the flaming ignition threat radius and, to the extent that they boost the peak overall heat release rate, they tend to push the maximum piloted ignition threat radius outward also.

${ }^{22}$ Heavy wood construction would likely lead to slower involvement and a lack of synchronization between the bed fire and the bed stand fire. In such cases the two items do not become an additive threat.
} 
Basically this looks at the area in the room that is available for the placement of second items and finds the fraction of that area which is at risk for piloted ignition by the bed fire. When the bed fire's at-risk border will not permit a chair to be inserted in an area, that area is added to the total at-risk area to illustrate this effect.

The absolute area at-risk is also pertinent to the overall threat of a bed fire. Thus, while an M3 and an M5 fire could each be reduced to the same small at-risk area fraction by suitable choices of room sizes, the M5 fire would still pose the greater absolute risk.

Calculated at-risk area fractions for M3 and M5 bed fires are shown in Fig.12. Since the bed size affects the result, there are two separate graphs for twin and king-size beds (though, again, the same maximum ignition reach value is used here for both bed sizes). For each size of mattress design there are two branches to each curve, one for the vanishingly thin second object and another for the chair, sized as above, being the second object. The Figure indicates that an M5 fire threatens piloted ignition in all or nearly all rooms. even those that are on the large end of the spectrum shown. The chair as a second object is probably especially relevant near the large end of the room spectrum. For an M5 fire, a second object this size keeps the at-risk floor area fraction high up to the largest rooms for which the calculations were done.

The M3 story in Fig. 12 is more complex. For large rooms the at-risk floor area fraction is small. As Fig. 11b shows, it is also (in all cases) localized around the bed periphery making it a threat mainly to objects placed near the bed. However, as the room size decreases, the walls move nearer the bed forcing any second objects to be more and more likely to be within this localized threat radius. Ultimately, in the smallest rooms, an object the size of a chair has a high probability of being close enough to the bed fire to be threatened by it. In the smallest rooms, it is likely that an upholstered chair would not be the second object; some other item of bedroom furniture such as a chest of drawers is more probable. If the second object is wood, the bed fire threat radius shrinks and Fig. 12 exaggerates the risk. If the second object is a potentially high heat release rate item (e.g., a thermoplastic object of a few kilograms mass) its relatively high ignition resistance could be compromised by the presence of exposed clothing on or near it so that the higher risk in Fig. 12 could still pertain. The highest at-risk values for king-size M3 beds in the smallest rooms are unrealistic since such a bed barely fits into such rooms. Both the twin and king M3 beds could still pose appreciable at-risk area fractions (30\%-40\%) for situations that do appear to be plausible (though how common, we cannot assess). Note that this is for a bed fire that consists of little more than burning bedclothes. Bear in mind, however, this result is inferred from the maximum reach of the bed fire for piloted ignition. This assumption is addressed further below.

Note that the real risk in the limit of large rooms would be greater if more objects are present, increasing the chances that one or more is within the at-risk radius. It would be less than indicated if the number of objects tended to stay constant and they were kept near the room periphery, further from the bed.

It is pertinent, at this point to inquire as to whether there is anything exceptional about the ignitability of the $100 \%$ cotton fabric used here to define the area fractions in Fig. 12. Reference to various literature sources [Refs. $6,13,14]$ on upholstery fabric ignition behavior indicates that 
it is unexceptional. If one were to use the ignition reach results in Table 7 for the $38 \% \mathrm{PE} / 62 \%$ cotton fabric instead of the $100 \%$ cotton result, all of the area fractions in Fig. 12 for the twin bed would decrease only about $20 \%$ from the indicated values; the percentage decrease is the same for the king-size beds. Again, the real world contains a large spectrum of materials of varied composition and weight that might be found in bedrooms. Some will be more ignitable than our examples here, some less. The best that can be hoped for here is reasonably representative materials and a realization that, because of the inherent unknowns, the results are best applied conservatively.

\section{Piloted vs Non-piloted Ignition}

Recall that this distinction depends on whether there is an energy source (a pilot) present in the plume of polymer degradation gases emitted by the heated second object that can ignite those gases $^{23}$. Note that piloted ignition values for radiant ignition reach from the edge of the bed have been emphasized throughout this report. These were derived from the Cone Calorimeter ignition tests and correspond approximately to the distance at which the minimum flux for piloted ignition is reached. This is also one of the conservative assumptions that went into Figure 12.

As indicated above in the discussion of the Cone Calorimeter results, non-piloted radiative ignition requires a substantially greater incident heat flux than does piloted ignition. The difference is so great that the M3 and M5 non-piloted ignition reach values tend to pull back inside the flame reach peripheries reported in Table 6 for these beds. Thus, if one chose nonpiloted ignition as the determinant of risk radius around a bed, the values in Table 6 , or their estimated outer limits in the text above would take over to determine the area fraction at risk. The process would then be one of radiative heating (plus some flame heating) from the bed fire followed by ignition of the gases from the second object by momentary flames licking out from the bed fire. Figure 13 shows the calculated at-risk area fractions for M3 and M5 twin beds based on outward reach of the bed fire flames alone; the curves are for the case of a vanishingly thin second object; a finite-sized second object will boost the at-risk area fraction for both mattress designs in small rooms (more so for M5 than for M3). Figure 14 combines and re-plots the M3 twin and M5 twin results to more clearly show the effects of the two different estimates of ignition reach on the at-risk area fraction of a room. Again, the two reach estimates are based on (1) piloted ignition of second object gases by flickering flames from the bed fire or (2) piloted ignition by any heat source that can reach out to the maximum distance at which flammable gases are being generated as a result of radiation from the bed fire.

The difference in the two estimates for M5 bed fires is considerable: the at-risk area fraction increases by a factor of four in the large room limit if one goes from bed flame piloting to piloting by any source that may (or may not) happen to be present out to the approximate location of the minimum flux for ignition. The effect for M3 twin beds is minimal; the boundary

\footnotetext{
${ }^{23}$ The pilot needs to be present where the concentration of gases is within the flammable limits. This implies a probable heated object size dependence for the requisite proximity between the pilot and the heated surface but there is no experimental information on this dependence available.
} 
in Fig. $11 \mathrm{~b}$ is already near the flame reach limit over much of the bed periphery ${ }^{24}$. Note that there will still be a sharply increased at-risk area fraction on the small room end of the M3 and M5 flame reach curves in Fig. 13 and 14 for a chair-sized second object. The shape will differ from that in Fig. 12 for M3, for example, since the M3 flame reach does not exhibit the outward "humps" shown in Fig. 11b.

Figure 14 implies there is no ambiguity in the at-risk area fraction for M3 beds. Thus the discussion above about the potentially significant threat of M3 bed fires in small rooms still pertains. Further perspective on the hazards of such fires is provided below from the CFAST calculations of heat and toxic gas threats.

Figure 14 implies that there is a considerable ambiguity about at-risk area fraction for the M5 beds, however, and choosing between the two M5 curves in that Figure requires information that is lacking. The issue is whether real bedroom fires tend to provide the requisite heat source (pilot) to the plumes of flammable gases emitted from objects all the way out to the distances at which ignition is, in principle, possible. The flammable gases are there out to these distances. Thus the situation is poised for ignition but it may not occur if a flammable part of the gas plume does not meet an energy source.

There are factors at work in a real fire that make the M5 picture presented by Fig. 13 too optimistic in as much as piloted ignition could occur further out than the indicated bed fire flame reach. Thus the bed fire plume itself tends to induce a flow in the room that pulls the second object gas plume toward the bed fire. Furthermore, "fuel package" items, as discussed above, tend to take the flames outward from the bed fire toward the second object. These could include, in addition to the bed stand discussed above, fire spread on the wall surface at the head of the bed and fire spread on carpeting below the bed. Both flame spread processes are under the influence of the radiation field from the bed fire and so go further, faster as the bed fire becomes larger. Radiation from these items adds to that from the bed fire to enhance the gasification rate from the second object, increasing its ignitable plume volume and, therefore, the probability of its ignition. Another possible effect comes from any minor objects between the bed fire and a potentially major heat release rate producer such as a chair. Ignition of the minor object is insignificant in itself but provides a potential pilot source closer to the major second object, increasing the chances of ignition of its gas plume. Also, some materials (especially cellulosics) shed glowing char fragments into a fire plume. These can recirculate into the flammable gas plume from the second object and serve as the requisite pilot for ignition. ${ }^{25}$ Finally, since the flux onto the second object falls off with its distance from the bed fire, the rate of gasification from its surface will fall off with distance. This implies any turbulent plume of ignitable gases will remain within the flammable limit for a longer distance if it originates closer to the fire; thus closer gas plumes tend to provide larger targets for glowing char fragments or any other hot spot $^{26}$. The general trend then is for ignition to be less probable as one moves, in Fig. 14, from

\footnotetext{
${ }^{24}$ The area fractions are very similar but the actual areas threatened differ significantly. The bed fire flame reach is estimated to be constant around the bed periphery. For piloted ignition from any source, Fig. 11b shows the boundary of the at-risk area is irregular.

${ }^{25}$ Some mattress designs based on the use of barriers undergo abrupt internal deflagrations within the mattress volume [1]. This could cause a substantial, though very brief, increase in flame reach and other disruptions.

${ }^{26}$ Large area targets at any distance provide larger flammable gas plumes off of surfaces generally parallel to an edge of the bed.
} 
the M5 line defined by bed fire flame piloting toward the line defined by "piloted ignition from any source". The probability is essentially one just inside the lower line and it goes to zero just above the upper line. The shape of the probability variation in-between cannot be determined with the available information.

All that can be established with reasonable certainty is that an M5 fire has the potential to ignite second objects throughout much of the volume of even fairly large rooms. For an M3 fire, the at-risk area for second item ignition is mainly confined to the immediate area around the bed and this poses a substantial fire spread threat only in a room so small as to force other objects into this relatively narrow threatened zone.

There appears to be no readily accessible information on the actual mechanisms of flame initiation on second items within furnished rooms. Even the most extensively instrumented bedroom fire tests on record $[15,16]$ provided no direct information on how a second item actually gets ignited though they revealed the controlling roles of direct plume radiation and hot smoke layer radiation. (Smoke obscuration can make the identification of actual flame initiation sources a real challenge.) It should be apparent from the preceding paragraphs that there are a large number of chance elements to the second item ignition process. Pinning down the probabilities in a definitive manner would require a very extensive experimental study. The nature of the M3 fires was such as to only weakly couple overall heat release rate to the second item ignition threat. This was a result of the bulk of the heat release being on top of the bed while the portion of the fire most likely to ignite other objects was that on the bedclothes hanging over the side of the bed. The procedures in NFPA 555 miss this sort of complexity. Heat release rate is, however, a good measure of heat and toxic gas threat generated by any size of fire. Even an M3 fire can produce non-local hazards through the movement of its smoke. This issue has been investigated, as described below.

\section{Heat and Smoke Transport Calculations}

CFAST (Consolidated Fire and Smoke Transport model) is a NIST-developed program for assessing the transport of heat and smoke from specified fires in multi-room buildings [17]. It takes advantage of the fact that hot smoke from a fire rises to form a fairly distinct and wellmixed layer that tends to flow throughout a multi-room building like a lighter-than-air fluid. The bulk of the toxic gas threat is contained in this hot smoke layer ${ }^{27}$. Direct exposure to the hot smoke layer also poses a burn injury threat but that can extend below the layer as well by radiation. Here CFAST is a tool for supplementing the information developed above on the threat of second item ignition by a bed fire. It also provides an approximate way in which to assess how different room conditions (sizes, door opening) would affect the implications of the results.

The toxicity and burn injury threats are not localized around the bed fire in the same way as is the ignition threat. The hot smoke first fills the space below the bedroom ceiling down to the soffit of the doorway. It then begins to spill out into the hallway outside. The smoke volume

\footnotetext{
${ }^{27}$ The only toxicant included here was $\mathrm{CO}$. $\mathrm{HCN}$ was included in one calculation since it is produced by the burning of polyurethane but, in this case, it shortened the times to incapacitation due to gas inhalation by only a few percent.
} 
generated by a fire depends on its heat release rate and air entrainment rate; thus the smoke layer usually fills the room of fire origin to well below the doorway soffit level and has plenty of driving force to move down a hallway and spill upward into upper portions of any other rooms open to the hallway. There is some mixing with cool air as the smoke moves in this manner, plus the movement requires time. Thus the threat posed by the smoke tends to arrive in other rooms later and is generally less severe than in the bedroom of origin. Nevertheless, a fire can be fatal in remote rooms, especially if the original room goes to flashover, strongly boosting the carbon monoxide production there.

In the present calculations, a simple but plausible room layout is assumed for illustrative purposes. A single floor of a house is considered. It is divided into four spaces: (1) the bedroom where the experimentally-measured fires are to be placed, (2) a hallway immediately outside the bedroom doorway, (3) a second, passive bedroom across the hallway and (4) a large space off the end of the hallway representing the rest of the house. The total floor area of the house is $109 \mathrm{~m}^{2}$ $\left(\mathrm{ca} .1200 \mathrm{ft}^{2}\right.$ ) and this is kept constant when the bedroom sizes are changed below. There are no window openings to the outside of the building ${ }^{28}$ and there is no ventilation system circulating air among the rooms.

Note that CFAST does not contain a fire growth model for beds. It uses as input the experimentally-measured heat release rates (and carbon monoxide generation rates) as a function of time for the various bed fires. Since a room can influence (via radiation feedback from the hot smoke layer) the fire growth process, the input curves used here are those from the measured room fires. However, recall that the doorway to the experimental room was deliberately varied in width in order to avoid flashover, if possible. Thus the experimental room fire data do not necessarily contain the full heat release rate enhancing effects that the rooms assumed here might produce and the input data do not change in response to differing room conditions for a fixed mattress design. Thus while room size and doorway opening effects can be explored here, the model is not fully accounting for the altered fire growth behavior that might accompany these variations. This is not expected to substantially influence any qualitative conclusions inferred from the modeling.

Another model limitation occurs when the air flow into the bedroom is insufficient to sustain the fire as specified (e.g., the room has flashed over or the door is nearly closed). The fire continues at the specified rate but some of the fuel gases generated burn outside the bedroom where they encounter more air (a realistic phenomenon). In reality the rate of burning of the bed would be altered in such circumstances (differently with a flashed over room versus a nearly closed door). This limitation to the modeling does not come into play for most cases of interest here, except for the first case discussed, which is at the extreme high end of fire intensity.

As an example of a CFAST prediction, the first case examined is that due to an M1 twin bed fire

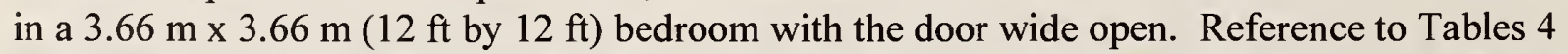
and 5 shows that this design gave fast, very intense fires; the case used here gave a heat release rate peak of just under $3 \mathrm{MW}$ in less than six minutes. In the experimental room ( $4.27 \mathrm{~m} \mathrm{x} 4.27$

\footnotetext{
${ }^{28}$ There is a weak generalized venting from the upper and lower layers in all of the spaces representing the leakiness of walls. It prevents a pressure build-up as the average gas temperature increases. This leakiness has minimal effect on the results.
} 
$\mathrm{m} ; 2.7 \mathrm{~m}$ wide doorway) this fire reached very near flashover, in spite of the very large doorway. Here it flashed over the room of fire origin at $320 \mathrm{~s}$ after ignition.

Figure 15a shows the consequences of such a fire in the room of fire origin; Fig. $15 \mathrm{~b}$ shows the result in the nearby, second bedroom (also having an open door). Note that the temperature (Kelvins) and carbon monoxide volume fraction (ppm) scales differ between Figs. 15a and 15b. The hallway and other space (remainder of house) are not shown. An interesting inference from the hallway upper layer temperature history is that a smoke detector there would have gone off after about $150 \mathrm{~s}$ to $160 \mathrm{~s}$ after the fire was initiated in the bedroom (based on a temperature correlation for smoke detector activation [18]). This is less than $3 \mathrm{~min}$ before the fire reaches flashover.

Fig 15 shows the conditions in the smoke layer and the height above the floor of the bottom of that layer. Note that in the fire room (and, also, in much of the rest of the house) the smoke layer descends close to the floor. It would be difficult to evade this smoke layer by crawling beneath it unless one escapes quickly before it descends. In the bedroom where the fire is, the smoke layer temperature peaks at about $1200 \mathrm{~K}\left(\mathrm{ca} .930^{\circ} \mathrm{C}\right.$ ) and the carbon monoxide level goes over $0.9 \%$ volume fraction $(9000 \mathrm{ppm} \text { by volume })^{29}$. In the bedroom with the fire, incapacitation ${ }^{30}$ of any person present occurs by $200 \mathrm{~s}$ after the fire is initiated as a consequence of the heat exposure; carbon monoxide incapacitation would follow only after another $60 \mathrm{~s}$. Elsewhere in the house, incapacitation occurs over the next $90 \mathrm{~s}$, always due to heat rather than to the accumulated CO dose. Fatal conditions are reached anywhere from $20 \mathrm{~s}$ to $70 \mathrm{~s}$ after incapacitation, depending on the room. This is a reference case away from which the improved mattress designs are expected to move.

The primary cases of interest here are the M5 and M3 fires since we are looking to obtain supplementary information on the hazards of smaller fires, in addition to the second object ignition threat discussed above. Flashover is no longer the hazard as long as nothing else ignites (as assumed here), but heat and/or carbon monoxide may be serious threats.

Appendix 2 contains estimates of the potential contributions to M3 and M5 fires from immediately adjacent items in a bed fire, such as carpeting beneath the bed. For an M3 fire, the contributions tend to be fairly small. For an M5 fire they may be appreciable. These contributions are not added on here for the CFAST calculations but they should be borne in mind.

The calculations require some assumption about the behavior of a person with regard to the smoke layer, since, in general, it does not descend as far as that in the M1 fire ${ }^{31}$. The assumptions here in this regard are the same as in Ref. 21. The principal assumption is that occupants breathe the cleaner, lower air when this is possible without crawling. Thus if the layer

\footnotetext{
${ }^{29}$ For reference, $0.3 \%$ volume fraction ( $3000 \mathrm{ppm}$ by volume) of $\mathrm{CO}$ will cause unconsciousness in $10 \mathrm{~min}$. and 0.9 $\%$ volume fraction ( $9000 \mathrm{ppm}$ by volume) in about $3 \mathrm{~min}$ [19].

${ }^{30}$ By the criterion adopted in the latest draft of ISO Document 13571 on fire hazard analysis [20].

${ }^{31}$ Layer height depends on fire height above the floor, fire plume entrainment rate and door opening. M3 fires are more extended than a typical pool-like fire usually assumed and can be expected to entrain more for this reason, lowering layer height. By putting the model fire at floor level, this is compensated for and the predicted layer height is comparable to that seen experimentally.
} 
height is above $1.5 \mathrm{~m}$, lower layer values for heat and gas exposures are used, since occupants could breathe the lower layer gases while standing. If the layer height is between 1 and $1.5 \mathrm{~m}$, the upper layer values of exposure are used as long as the upper layer temperature is below 50 ${ }^{\circ} \mathrm{C}$, otherwise, the lower layer values are used. This assumes that occupants breathe upper layer gases (which do contain oxygen) when they are not too hot; otherwise they bend down to obtain cooler air. If the layer height drops below $1 \mathrm{~m}$, the upper layer exposures are used since it is difficult to bend this low and move rapidly at the same time. Some occupants might crawl and this would lessen the gas and convective heat exposures but this cannot be assumed to be true in general. Thus the assumption here is conservative.

Table 8a summarizes the base case fire conditions ( $3.66 \mathrm{~m}$ x $3.66 \mathrm{~m}$ room with door wide open) modeled here and their consequences; Table $8 \mathrm{~b}$ summarizes the results of some variations about the base case.

Examination of the M5 results in Table 8a leads to the conclusion that a bed fire this size is very threatening. In the room of fire origin, the M5 twin bed fire by itself can cause incapacitation by heat 9-1/2 min after ignition and death in $10 \mathrm{~min}$. Similar conditions follow in the hallway (not shown), in the second bedroom and then throughout the house (lethal by $1270 \mathrm{~s}$ ). Recall that this size fire puts a large fraction of the room of origin at risk of piloted ignition. This size fire also is likely to be significantly supplemented by burning of immediately adjacent items forming the "fuel package", as discussed in Appendix 2. The fuel package materials, particularly carpeting beneath and near the bed periphery, can boost the peak heat release rate by $25 \%$ or more for this size fire, increasing its chances of igniting still more materials in the room as well as assuring lethality in lesser times than those calculated here. The same mattress design, in king size, in the same room (admittedly somewhat unlikely given the room size but physically quite possible), threatens lethality (due again to heat) throughout the entire house in about half the times that the twin size M5 bed fire causes.

This focuses the discussion on the M3 fires. Table $8 \mathrm{~b}$ shows four variations on the last case in Table 8a, i.e., the M3 king fire. The first two cases in Table 8b show that the effect of the bedroom size (with all other parameters being equal ${ }^{32}$ ) is small in terms of the percentage change it causes in the times to incapacitation and death. The larger bedroom is probably of greater interest. It yields a time to death due to heat about $10 \%$ longer than for the base case bedroom. The second bedroom does not reach lethal conditions but the hallway (not shown) does (in 610 s). Note that any variations in room feedback on the fire (burning rate enhancement due to radiation from the hot smoke layer) are not included here because there is no information on this available. The experimental fire data put into the model are for a $4.27 \mathrm{~m}$ by $4.27 \mathrm{~m}(14 \mathrm{ft} \mathrm{x} 14$ $\mathrm{ft}$ ) room with a $1 \mathrm{~m}(39.4 \mathrm{in})$ doorway opening so they lay between the nominal case and the larger room.

An important implication of the preceding relative insensitivity to room size of the times to toxicity and heat impact end points is that a mattress design is best judged by its worst case size, i.e., king size. The heat hazard of the bigger fire this largest bed size brings is not much alleviated by the fact that the larger bed will typically be found in a larger room. Recall also that

\footnotetext{
${ }^{32}$ A king size bed is unlikely ever to be put in the small bedroom but the point is to illustrate the potential for room size effects on a fixed fire.
} 
there were indications in the room fire tests that the radiant ignition reach of an M3 king size bed fire is likely greater (on the side away from the igniter) than that of an M3 twin but no quantitative measures of this effect were obtained.

Table $8 \mathrm{~b}$ also shows the effect of decreasing the door opening from that in the base case, again with the M3 king fire. This has the effect of slowing air flow into the fire room and also slowing the flow of smoke out. At some point it causes the fire to become air starved, ultimately changing the net formation rate of carbon monoxide drastically but this last effect is chemical kinetic in nature and is not included in CFAST. Since again, the fire is not allowed in the model to change its fuel gasification rate as a result of these room effects, the model result is more suggestive of the trend to be expected, particularly in the case of a $10 \%$ door opening. The trend is what one would expect from the observation that exchange with the other rooms is slowed. That is, the conditions in the fire room become lethal sooner but the conditions elsewhere in the house take longer to reach lethality or do not reach it at all. Incapacitation is reached in some of the spaces beyond the fire room and now it is sometimes due to carbon monoxide rather than heat.

The picture of the M3 fires that emerges from the CFAST cases is that of a marginal situation. The twin bed fires in the base case conditions are incapacitating in some spaces but not lethal anywhere. They could be expected to become more threatening in the room of fire origin if the door were not fully open. The king size bed fires (at approximately twice the peak heat release rate) are lethal in some spaces, particularly the room of fire origin, but are often non-lethal in the bulk of the house assumed here.

Note that this study has not assumed that fire victims will make an effort to escape, but rather has looked at the exposures that ensue from staying in place. The M3 fires tend to yield minimum smoke layer heights of $0.7 \mathrm{~m}$ to $1 \mathrm{~m}$ in most spaces which does permit escape by squatting or crawling. This also tends to be above the height of a person sleeping in the burning bed; an unconscious person thus would tend not to be exposed to the convective heat and toxic gases of the fire (but, of course, he could be burned directly by the fire). Adults with normal agility might well escape but the infirm might not. Children who remain crouched down but in place may also escape. These smaller fires also give a few more minutes (as compared to an M1 fire) to achieve escape before the incapacitation that might ensue from breathing the smoke layer.

Overall the CFAST study indicates that even reducing bed fires to the size of an M3 fire does not guarantee that injuries and fatalities can be limited to only that fraction of bed fire statistics in which victims were "intimate with the fire" (see Table 1 and the discussion of it in the Introduction $)^{33}$. Heat and toxic gases reach out from the bed fire to threaten the entire room of fire origin and sometimes the space beyond. The ignition reach estimates above also indicate some persisting threat that other major objects in a bedroom, if close to the bed, will be ignited by an M3 fire, possibly leading to a much larger fire. However, there is a major decrease in threat level compared to the M1 fire discussed above. The threat of second object ignition is reduced from a certainty (although not even necessary to cause flashover in many M1 fires) to a small (but unquantifiable in the real world) chance with an M3 fire. Thus the threat of flashover

\footnotetext{
${ }^{33}$ The argument here follows a similar line to that in Ref. 22 with regard to potential reductions in the victims of upholstered furniture fires as one makes various possible changes to that product.
} 
from an M3 fire should be very low, ensuing only in cases where a major object like an upholstered chair or a heavy drapery is close enough to the bed fire to be ignited. In most M3 fire cases the bed fire will be supplemented only by the minor enhancements estimated in Appendix 2 and the resulting threats should be comparable to those calculated from CFAST. Table 1 indicates that $2 / 3$ of the victims of these types of fires are associated with the occurrence of flashover. By making flashover a much less likely event, M3 size fires should eliminate a substantial fraction of these fatalities. For the remaining $1 / 3$ of victims associated with fires confined to the room of origin (Table 1), the relatively high smoke layer height accompanying an M3 size fire should permit a good fraction of them to escape. The implication is that M3 fires would make major but uneven reductions in the number of fatalities in all of the categories in Table 1. Presumably the least reduction would be in victims in the room of fire origin and "intimate with the fire," especially if they were unconscious and not rousable by the fire itself.

Since an M3 fire has a minimal (perhaps $10 \%$ to $15 \%$ ) heat release rate contribution from the mattress itself, any further significant improvements would have to come from a decrease in the fire contribution from the bedclothes. Fires with an M3 mattress/foundation and a different bedclothes set could be less or more threatening than those studied here. The radiant ignition reach of what is essentially a bedclothes fire, like that of the M3 fire here, is, for most of the bed periphery, primarily dependent on the burning area, at any given moment, of materials on the side of the bed ${ }^{34}$. This area is decreased by any factor that tends to make the bedclothes burning duration shorter. This could include changes in the composition or in total thickness.

Ultimately, however, the minimum ignition reach on the side of the bed is determined by the reach of flames there. The factors influencing this have not been studied.

Time to peak heat release rate has been reported here (Table 5) but, to this point, there has been no discussion of its relevance. It is apparent that it can be relevant. A very rapid rise (a few minutes) to the peak heat release rate leaves little time for (a) fire discovery, (b) reporting of the fire and (c) fire department reaction. At the opposite extreme, a fire that grows very slowly (20 to $30 \mathrm{~min}$ to go from ignition to peak) so as to allow an extended period for these ameliorative steps clearly has a lesser probability of causing casualties in many, though not all cases. ${ }^{35}$ It is not possible to be more quantitative about the benefits to be gained by slowing the time to the peak to intermediate levels between these extremes. This is because the time between ignition and fire department notification is unknown and may be widely variable [29]. It is not sufficient to gather data on fire department response times as a reference time which time to peak heat release rate must exceed. Thus this issue is not quantified at the present state of knowledge.

\section{Summary and Conclusions}

This study has produced a means for estimating the risk reduction from bed fires that can be achieved by reducing the intensity of the burning bed. This involves reducing the heat release rate of the bed (and thus the associated production of heat and toxic smoke) and/or reducing the

\footnotetext{
${ }^{34}$ The ignition reach from the head end of an M3 bed is mainly a result of the pillow fire.

${ }^{35}$ A fire with an extended smoldering stage could be one exception to this statement. Slowly developing flaming fires involving asleep or unconscious building occupants may not be less lethal, especially if no working smoke detector is present.
} 
fraction of the bedroom in which other combustibles are susceptible to ignition by the burning bed.

The threat posed by a bed fire to its surroundings was assessed by two approaches. The first involved measurement of the heat release rates from and the radiant flux fields around burning beds of three designs of widely differing fire behavior. Measurements done both under an open hood and in a room show that, in general, the room environment enhances the heat release rate; it may also enhance the radiant flux fields. The second approach used the measured heat release curves in the context of CFAST to determine the spread of hot, toxic smoke within the room of fire origin and beyond.

The radiant flux results were put into a useful context by defining their tendency to ignite the types of objects that might be found in a bedroom. Seven surrogate materials were characterized with regard to ignitability using the Cone Calorimeter. These data permitted the estimate, via a calibrated ignition model, of the distance from the edge of a bed fire (of any of the sizes and designs measured) at which radiant heat was just able to ignite the surrogate materials (given the presence of a pilot heat source). This defined a threatened area around each bed fire. These data were then used to calculate the fraction of the room floor area beyond the bed that was at risk of piloted ignition. This at-risk area fraction is the best available measure of the probability, across the spectrum of real-world bedrooms, that another flammable object could be ignited secondarily by the bed fire. The surrogate material of most interest was a $100 \%$ cotton cloth as a representative of such second objects as upholstered chairs and drapery. It is such potentially major secondary fire producers that are of main interest in as much as their ignition is definitely to be avoided.

It was already known that a burning bed assembly of conventional composition (here represented by design M1) puts essentially the whole room, almost regardless of size, at risk, since such fires are large enough to cause flashover in most plausible bedrooms. Thus the real focus was on the smaller fires from designs M5 and M3, which produced progressively lower burning intensities. The M5 fires were found to pose a piloted ignition risk (to the $100 \%$ cotton fabric) over the majority of the floor area of even fairly large bedrooms. Piloted ignition poses a conservative risk criterion since a pilot source may not always be present. For M5 fires, however, this at-risk fraction was so large as to strongly imply that an M5 fire is unacceptable. For M3 fires, essentially only the bedclothes burn and the peripheral region at risk for piloted ignition is reduced to an area quite similar, over most of the bed periphery, to the area at risk of piloting by the bed fire flames themselves. The area fraction at risk of either type of ignition tends to be small unless the proximity of the bedroom walls forces any object of substantial size to be close to the bed. This part of the study raises some cautions about M3 fires primarily in bedrooms that are a rather snug fit for the bed.

The CFAST calculations for the M5-size fires predicted that the build-up of heat and CO (in the upper smoke layer) in various spaces in a model house would be lethal within a few minutes of ignition. This could happen even faster, since the M5-size fire was shown to have the potential to ignite adjacent materials such as carpets and even remote furnishings. The M3 fire, which is due primarily to the bedclothes, was marginal in its threat to house occupants. It could cause 
incapacitating and even lethal conditions but it does this with a smoke layer that tends to stay fairly high off the floor, offering a possible means of escape to many potential victims. This threat is best represented by the performance of the king size version of the bed set.

The worst case M 3 fire seen here ( $400 \mathrm{~kW}$ peak heat release rate in a room environment) should have a minimal chance to cause flashover in the real-world spectrum of bedrooms because both the rate of heat release from the bed and the risk of igniting additional objects are low. This implies the potential for a one-third reduction in fire fatalities, i.e., those outside the room of fire origin. . Furthermore, since an M3 fire should, in most cases, be confined to the bed, there is a possibility of eliminating a substantial fraction of fatalities occurring in the room of origin but away from the bed. More quantitative estimates of the risk reduction due to lowering the rate of heat release and the at-risk fraction of room floor area is hindered by lack of information on such factors as:

- the distributions of types and locations of combustibles in bedrooms,

- the presence of ignition sources other than the flames from the burning bed, and

- the distribution of types of bedclothes sets in use and their conformations at the time of the fire.

Overall the study suggests that beds with fire performance similar to the M3 design would achieve very significant reduction in fire risk. Since the bedclothes contributed the bulk of the heat release seen with the M3 beds, further reduction in fire fatalities would probably have to address the bedclothes flammability as well.

\section{Acknowledgments}

This work was sponsored by the Sleep Products Safety Council. The authors would like to acknowledge valuable discussions with Mr. Richard Peacock. John Demarest ran the CFAST calculations. Gary Roadarmel, Rik Johnson, Roy McLane, Dave Stroup, Lauren DeLauter and Randy Shields were all very helpful in getting the NIST heat release rate facility up and running for these tests. Roy McLane built the flux gage arrays; Randy Shields set them up and calibrated the gages. Randy Shields performed the very tedious measurements of lateral flame reach. 


\section{References}

1) Ohlemiller, T., Shields, J., McLane, R., and Gann, R. "Flammability Assessment Methodology for Mattresses," National Institute of Standards and Technology NISTIR 6497, June, 2000

2) Hall, J., "Patterns of Fire Casualties in Home Fires by Age and Sex," National Fire Protection Association, Quincy, MA, June, 1999

3) Hall, J., personal communication to Patricia Martin, Sleep Products Safety Council, October 15, 2001

4) Hall, J., "Home Fires Starting with Mattresses or Bedding; Patterns, Trends and Their Implications for Strategies," presentation to the Consumer Products Safety Commission, February 4, 1998

5) National Fire Protection Association, "Guide on Methods for Evaluating Flashover Potential," NFPA 555, Quincy MA, 1996

6) Sundstrom, B., CBUF: Fire Safety of Upholstered Furniture - the final report on the CBUF research programme,' Interscience Communications, London (1996) , p. 61

7) Peacock, R., Reneke, P., Bukowski, R. and Babrauskas, V., "Defining Flashover foe Fire Hazard Calculations," Fire Safety Journal 32 (1999), 331-345

8) Quintiere, J., University of Maryland, private communication, 3/2001

9) Ohlemiller, T., "Mini-Matt Flammability and Its Relation to Full-Scale Mattress Behavior," report in preparation

10) Lindgren, B. and McElrath, G, Introduction to Probability and Statistics, MacMillan, New York (1959), p. 103

11) Roshenow, W. and Choi, H., Heat, Mass and Momentum Transfer, Prentice-Hall, Englewood Cliffs, NJ (1961) Chapters 7 and 8

12) Fang, J., "Measurements of the Behavior of Incidental Fires in a Compartment," National Bureau of Standards NBSIR 75-679, March, 1975

13) Babrauskas, V. and Krasny, J., "Fire Behavior of Upholstered Furniture," National Bureau of Standards Monograph 173, Nov., 1985

14) Denize, H., "The Combustion Behavior of Upholstered Furniture Materials in New Zealand," University of Canterbury Report 2000/4, 2000

15) Modak, A. (ed.), "The Third Full-Scale Bedroom Fire Test of the Home Fire Project (July 30, 1975) Vol. II - Analysis of the Results

16) Emmons, H., "Home Fire: Viewed as a Scientific System," Society of Fire Protection Engineers SFPE Annual Seminar, SFPE TR 77-05 (1977)

17) Peacock, R., Forney, G., Reneke, P., and Portier, R. and Jones, W. "CFAST, the Consolidated Model of Fire Growth and Smoke Transport", National Institute of Standards and Technology Technical Note 1299, February 1993

18) Bukowski, R. and Averill, J., "Methods for Predicting Smoke Detector Activation," Proceedings of a symposium entitled Fire Suppression and Detection Research, Research and Practice: Bridging the Gap, Orlando, FL, 1998, National Fire Protection Research Foundation, Quincy, MA

19) Purser, D., "Toxicity Assessment of Combustion Products," Chapter 8, Section 2, SFPE Handbook of Fire Protection Engineering, National Fire Protection Association, Quincy, MA, 1995, p. 2-89 
20) ISO/TS 13571, "Life Threat from Fires - Guidance on the Estimation of Time Available for Escape Using Fire Data, 2002.

21) Gann, R., Averill, J., Butler, K., Jones, W., Mulholland, G., Neviaser, J., Ohlemiller, T., Peacock, R., Reneke, P., and Hall, J., "International Study of the Sublethal Effects of Fire Smoke on Survivability and Health (SEFS): Phase 1 Final Report, National Institute of Standards and Technology NIST Technical Note 1439, August, 2001

22) Hall, J., "Targeting Upholstered Furniture Fires," NFPA Journal, March/April 2001, p. 57

23) Mowrer, F., "The Effect of Blistering on the Ignition and Flammability of Painted Gypsum Wallboard," Proceedings of Fire and Materials 2001, Interscience Communications, London, 2001, p. 197

24) Hoglander, K. and Sundstrom, B., "Design Fires for Preflashover Fires. Characteristic Heat Release Rates of Building Contents," SP Swedish National Testing and Research Institute, SP Report 1997:36 (1998)

25) Kashiwagi, T., "Experimental Observation of Flame Spread Characteristics Over Selected Carpets," JFF/Consumer Product Flammability, Vol.1 (December, 1974), P. 367

26) Hirschler, M., "Smoke and Heat Release and Ignitability as Measures of Fire Hazard from Burning Carpet Tiles," Fire Safety Journal, 18 (1992) p. 305

27) Babrauskas, V., "Burning Rates," Chapter 1, Section 3, SFPE Handbook, op. cit.,

28) Lawson, J., Walton, W. and Twilley, W., "Fire Performance of Furnishings as Measured in the NBS Furniture Calorimeter," National Bureau of Standards NBSIR 83-2787, January, 1984

Hall, J., National Fire Protection Association, private communication, March, 2002 
TABLE 1

Average Statistics (1994-98) for Fatal Home Fires

Beginning with Ignition of Mattress or Bedding

\begin{tabular}{|c|c|}
\hline & Percent of Total \\
\hline Flames Beyond Room of Fire Origin (Flashover) & 37.3 \\
\hline Victim in room of origin & 29.2 \\
\hline Victim outside room of origin & 0.5 \\
\hline Victim location unclassified & $\mathbf{6 7 . 0}$ \\
\hline Total for this fire size & \\
\hline Flames Confined to Room of Fire Origin (Not Flashover) & 27.6 \\
\hline Victim in room of origin & 4.9 \\
\hline Victim outside room of origin & 0.5 \\
\hline Victim location unclassified & $\mathbf{3 3 . 0}$ \\
\hline Total for this fire size & \\
\hline & \\
\hline All Fire Extents Combined & 64.9 \\
\hline Victim in room of origin & 34.1 \\
\hline Victim outside room of origin & 1.0 \\
\hline Victim location unclassified & $\mathbf{1 0 0 . 0}$ \\
\hline Total & \\
\hline
\end{tabular}


TABLE 2

Component Materials in Mattress Designs

(Refer to Figure 1 for Component Locations)

\begin{tabular}{|c|c|c|c|}
\hline & $\begin{array}{c}\text { MATTRESS } \\
1\end{array}$ & MATTRESS 3 & MATTRESS 5 \\
\hline Ticking & Std. Damask & $\begin{array}{l}\text { Combined } \\
\text { fabric/barrier }\end{array}$ & MVSS 302 damask \\
\hline Quilt & $\begin{array}{l}19 \mathrm{~mm}(3 / 4 \mathrm{in}) \\
\text { std. PU foam } \\
\left(19.2 \mathrm{~kg} / \mathrm{m}^{3} \text {, }\right. \\
\left.1.2 \mathrm{lb} / \mathrm{ft}^{3}\right) \text { in } \\
\text { quilt }\end{array}$ & $\begin{array}{l}\text { Same as Mattress } \\
\# 1\end{array}$ & $\begin{array}{l}19 \mathrm{~mm}(3 / 4 \mathrm{in}) \mathrm{TB} \\
117 \mathrm{PU} \text { foam in } \\
\text { quilt }\end{array}$ \\
\hline Topper Pad & $\begin{array}{l}25.4 \mathrm{~mm}(1 \mathrm{in}) \\
\text { std. PU foam } \\
\left(19.2 \mathrm{~kg} / \mathrm{m}^{3}\right. \\
\left.1.2 \mathrm{lb} / \mathrm{ft}^{3}\right)\end{array}$ & $\begin{array}{l}\text { Same as Mattress } \\
\# 1\end{array}$ & $\begin{array}{l}12.7 \mathrm{~mm}(0.5 \mathrm{in}) \\
\text { TB } 117 \mathrm{PU} \text { foam } \\
\left(19.2 \mathrm{~kg} / \mathrm{m}^{3}, 1.2\right. \\
\left.\mathrm{lb} / \mathrm{ft}^{3}\right) \text { over } 1.1 \\
\mathrm{~kg} / \mathrm{m}^{2}\left(3.5 \mathrm{oz} / \mathrm{ft}^{2}\right) \\
\text { boric acid treated } \\
\text { cotton batt }\end{array}$ \\
\hline Insulator & $\begin{array}{l}\text { Thermo-plastic } \\
\text { Mesh Pad }\end{array}$ & $\begin{array}{l}\text { Thermo-plastic } \\
\text { Mesh Pad }\end{array}$ & $\begin{array}{l}\text { Thermo-plastic } \\
\text { Mesh Pad }\end{array}$ \\
\hline Spring Unit & $\begin{array}{l}\text { Twin } \\
\text { Innerspring }\end{array}$ & Twin Innerspring & Twin Innerspring \\
\hline $\begin{array}{l}\text { Mattress } \\
\text { Border }\end{array}$ & $\begin{array}{l}6 \mathrm{~mm}(1 / 4 \mathrm{in}) \\
\text { std. PU foam } \\
\left(19.2 \mathrm{~kg} / \mathrm{m}^{3}\right. \\
\left.1.2 \mathrm{lb} / \mathrm{ft}^{3}\right) \\
\text { under std. } \\
\text { Damask }\end{array}$ & $\begin{array}{l}\text { Same as Mattress } \\
\# 1\end{array}$ & $\begin{array}{l}\text { Boric acid treated } \\
\text { cotton batt under } \\
\text { MVSS } 302 \text { damask }\end{array}$ \\
\hline Thread & Standard & $\begin{array}{l}\text { Combustion } \\
\text { modified }\end{array}$ & Standard \\
\hline $\begin{array}{l}\text { Foundation } \\
\text { Border }\end{array}$ & $\begin{array}{l}\text { Same as } \\
\text { mattress }\end{array}$ & Same as mattress & Same as mattress \\
\hline $\begin{array}{l}\text { Foundation } \\
\text { Top Pad }\end{array}$ & $\begin{array}{l}0.62 \mathrm{~kg} / \mathrm{m}^{2}(2 \\
\left.\mathrm{oz} / \mathrm{ft}^{2}\right) \\
\text { polyester fiber } \\
\text { pad }\end{array}$ & $\begin{array}{l}0.62 \mathrm{~kg} / \mathrm{m}^{2}(2 \\
\left.\text { oz/ } \mathrm{ft}^{2}\right) \text { polyester } \\
\text { fiber pad }\end{array}$ & $\begin{array}{l}0.62 \mathrm{~kg} / \mathrm{m}^{2}(2 \\
\left.\text { oz } / \mathrm{ft}^{2}\right) \text { polyester } \\
\text { fiber pad }\end{array}$ \\
\hline
\end{tabular}


TABLE 3

Materials Used as Surrogates for Other Ignitable Objects in a Room

\begin{tabular}{|c|c|c|}
\hline Material & Weight or Thickness & Surrogate for \\
\hline Sheet of newsprint & $48 \mathrm{~g} / \mathrm{m}^{2}\left(1.4 \mathrm{oz} / \mathrm{yd}^{2}\right)$ & Newspaper or loose papers \\
\hline $\begin{array}{c}65 \% \mathrm{PE}{ }^{36} / 35 \% \text { Cotton } \\
\text { fabric }\end{array}$ & $144 \mathrm{~g} / \mathrm{m}^{2}\left(4.3 \mathrm{oz} / \mathrm{yd}^{2}\right)$ & Shirt, blouse, dress \\
\hline $\begin{array}{c}38 \% \mathrm{PE} / 62 \% \text { Cotton } \\
\text { fabric }\end{array}$ & $275 \mathrm{~g} / \mathrm{m}^{2}\left(8.1 \mathrm{oz} / \mathrm{yd}^{2}\right)$ & Upholstered chair, drapery \\
\hline PE/Cotton terrycloth & $303 \mathrm{~g} / \mathrm{m}^{2}\left(8.9 \mathrm{oz} / \mathrm{yd}^{2}\right)$ & Towel, bathrobe \\
\hline $100 \%$ Cotton fabric & $410 \mathrm{~g} / \mathrm{m}^{2}\left(12.1 \mathrm{oz} / \mathrm{yd}^{2}\right)$ & Upholstered chair, drapery \\
\hline Birch veneer plywood & $3.2 \mathrm{~mm}(1 / 8 \mathrm{in})$ & $\begin{array}{c}\text { Wall paneling, side panel of } \\
\text { bookcase, nightstand, } \\
\text { dresser }\end{array}$ \\
\hline Pine board & $12.7 \mathrm{~mm}(1 / 2 \mathrm{in})$ & $\begin{array}{c}\text { Front panel of wood } \\
\text { furniture items }\end{array}$ \\
\hline
\end{tabular}

${ }^{36} \mathrm{PE}$ is polyester 
TABLE 4

Summary of Peak Heat Release Rate Results

(Parenthetic numbers are secondary peaks)

\begin{tabular}{|c|c|c|c|}
\hline $\begin{array}{c}\text { Mattress/Foundation } \\
\text { Design } \\
\end{array}$ & Bed Size & Test Location & $\begin{array}{c}\text { Peak Heat Release } \\
\text { Rate }\left(\mathrm{kW} / \mathrm{m}^{2}\right)\end{array}$ \\
\hline M3 & Twin & Open Hood & $160,(155)$ \\
\hline " & "6 & "6 & $(165), 187$ \\
\hline M3 & King & "6 & $240^{37}$ \\
\hline “6 & "“ & 6 & 290 \\
\hline M5 & Twin & " & $(230), 655$ \\
\hline$" 6$ & 6 & 6 & $(255), 595$ \\
\hline M5 & King & "6 & $775,(660)$ \\
\hline " & " & "6 & 620 \\
\hline$\overline{\mathrm{M} 1}$ & Twin & 6 & 2275 \\
\hline " & " & " & 2310 \\
\hline M1 & King & "6 & 3370 \\
\hline “" & "6 & “ & 3850 \\
\hline M3 & Twin & Room & $(140), 150$ \\
\hline$"$ & “ & " & $(130), 190$ \\
\hline M3 & King & “ & 390 \\
\hline " & "“ & "“ & $420^{38}$ \\
\hline M5 & Twin & "6 & $(300), 1670^{39}$ \\
\hline " & " & “ & $(225), 540$ \\
\hline M5 & King & " & $(880), 955$ \\
\hline "6 & 6 & "“ & $(700), 815$ \\
\hline$\overline{\mathrm{M} 1}$ & Twin & "6 & $3850^{40}$ \\
\hline$" 6$ & $" 6$ & " & 2995 \\
\hline M1 & King & “" & $3465^{41}$ \\
\hline$"$ & " & 6 & $4620^{42}$ \\
\hline
\end{tabular}

\footnotetext{
${ }^{37}$ The foundation of this test sample ignited on its interior leading, $29 \mathrm{~min}$ after this peak, to a second peak of 750 $\mathrm{kW}$

${ }^{38}$ This test also yielded foundation ignition about $4 \mathrm{~min}$ after the peak reported here. The fire was suppressed with water before it could grow by more than $100 \mathrm{~kW}$.

${ }^{39}$ This test had a strong peak. with a half-height time width about $50 \mathrm{~s}$, due to ignition of the paper on the gypsum board, mainly on the ceiling but also on a portion of one wall. Without this contribution, it appears that the peak from the bed alone would have been approximately $600 \mathrm{~kW}$.

${ }^{40}$ This test also had some contribution from paper on the gypsum board, some on the floor, indicating flashover was occurring. The fire was suppressed with water at or just below its peak.

${ }^{41}$ Suppressed with water, probably below its peak HRR, as flames emerged from the door, indicating flashover was occurring.

${ }^{42}$ This is the peak value as the room began to yield flames out the door but before any other visible surfaces ignited.
} 
TABLE 5

Summary of Time to Peak Heat Release Rate

(Parenthetic numbers are secondary peaks)

\begin{tabular}{|c|c|c|c|}
\hline $\begin{array}{c}\text { Mattress/Foundation } \\
\text { Design }\end{array}$ & Bed Size & Test Location & $\begin{array}{c}\text { Time from } \\
\text { Ignition to Peak } \\
\text { (s) }\end{array}$ \\
\hline $\mathrm{M} 3$ & Twin & Open Hood & ca. $390,($ ca. 710$)$ \\
\hline " & " & " & (са. 360$)$, са. 660 \\
\hline M3 & King & " & 640 \\
\hline 6 & 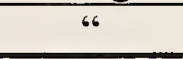 & 6 & 380 \\
\hline M5 & Twin & $"$ & $(405), 715$ \\
\hline “" & 6 & $" “$ & $(420), 880$ \\
\hline M5 & King & “6 & $700,(1240)$ \\
\hline “6 & " & 66 & 1160 \\
\hline M1 & Twin & $"$ & 400 \\
\hline 66 & 6 & "“ & 435 \\
\hline M1 & King & $" “$ & 370 \\
\hline 6 & 16 & " & 305 \\
\hline M3 & Twin & Room & $(490), 680$ \\
\hline$"$ & $" 6$ & $"$ & $(430), 710$ \\
\hline M3 & King & "“ & 550 \\
\hline " & 6 & $" “$ & 525 \\
\hline M5 & Twin & "“ & $(600), 915$ \\
\hline "6 & " & “6 & $(420), 1140$ \\
\hline M5 & King & 6 & $(445), 970$ \\
\hline "6 & " & 6 & $465,(1165)$ \\
\hline M1 & Twin & "“ & 365 \\
\hline "6 & "“ & " & 350 \\
\hline M1 & King & $" \%$ & 305 \\
\hline "“ & "6 & "6 & 335 \\
\hline
\end{tabular}


TABLE 6

Maximum Reach of Flames on Ignited Side of Bed

(For Tests Under Open Hood)

\begin{tabular}{|c|c|c|c|}
\hline $\begin{array}{c}\text { Mattress/Foundation } \\
\text { Design }\end{array}$ & Bed Size & $\begin{array}{l}\text { Maximum } \\
\text { Instantaneous } \\
\text { Reach }(\mathbf{c m})\end{array}$ & $\begin{array}{r}\text { Maximum One } \\
\text { Second Reach } \\
\text { (cm) }\end{array}$ \\
\hline M3 & Twin & 20.8 & 15.7 \\
\hline " & "6 & 23.1 & 18.0 \\
\hline M3 & King & 17.5 & 13.5 \\
\hline$" 6$ & “ & 20.3 & 16.0 \\
\hline M5 & Twin & 32.5 & 30.5 \\
\hline " & $" 6$ & 39.6 & 29.7 \\
\hline 6 & "6 & 45.2 & 34.0 \\
\hline M5 & King & 41.1 & 32.8 \\
\hline "6 & “" & 49.0 & 40.9 \\
\hline M1 & Twin & 40.6 & 31.0 \\
\hline$"$ & "“ & 37.8 & 28.4 \\
\hline M1 & King & 47.0 & 34.0 \\
\hline 6 & 6 & 34.5 & 30.5 \\
\hline
\end{tabular}




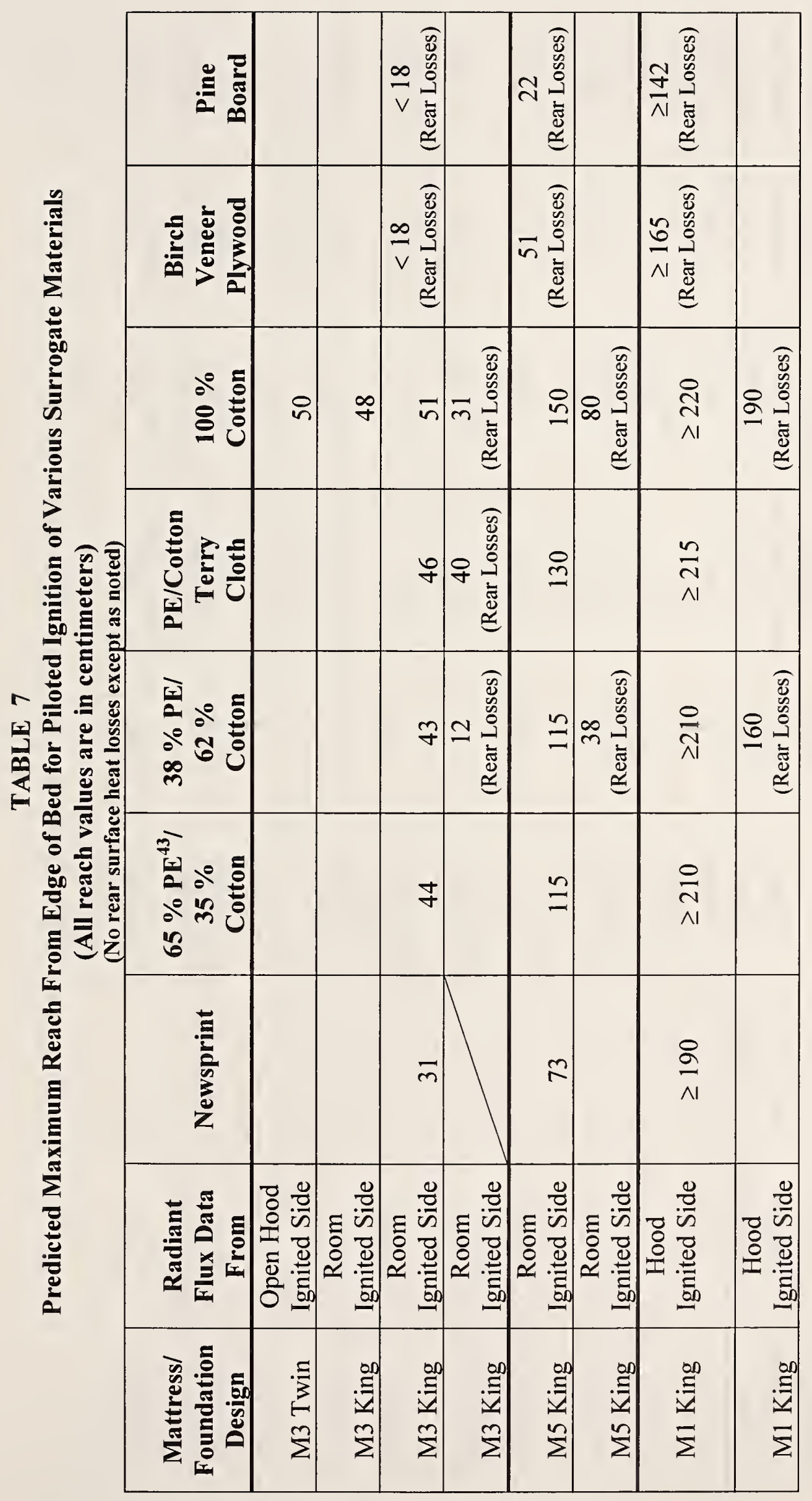




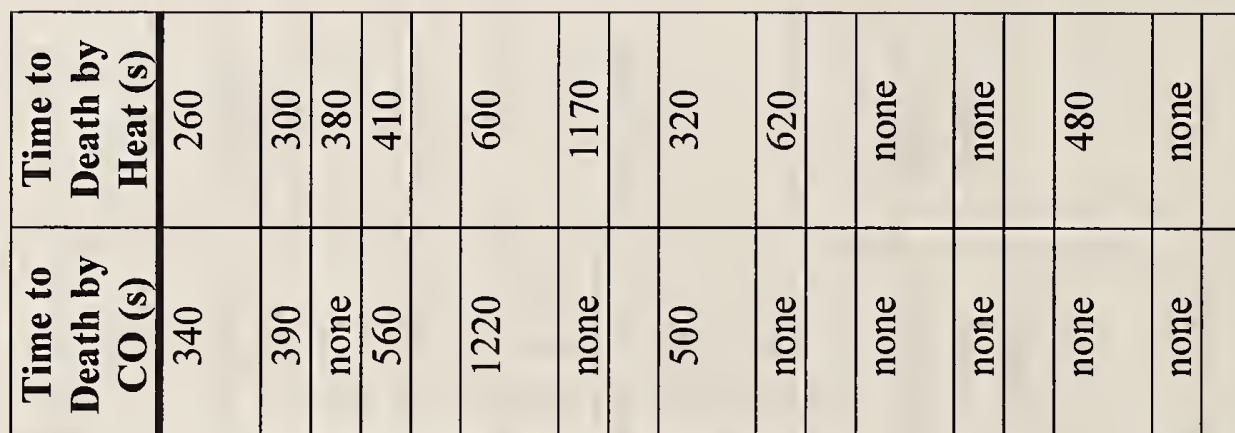

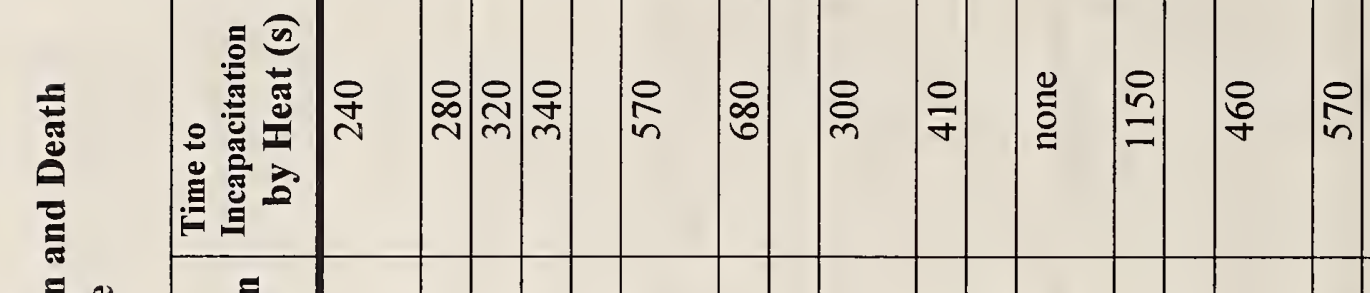
部。

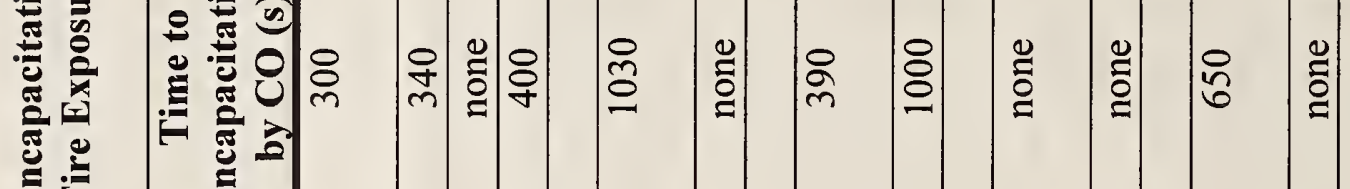
赵党

$-.00$

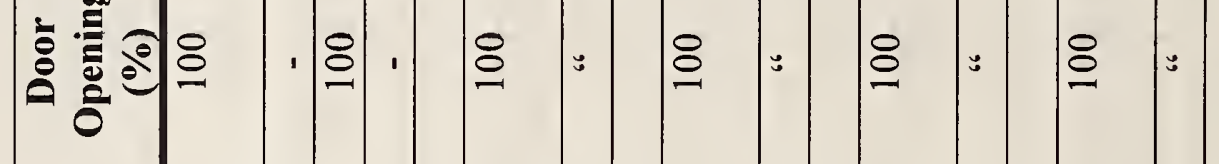

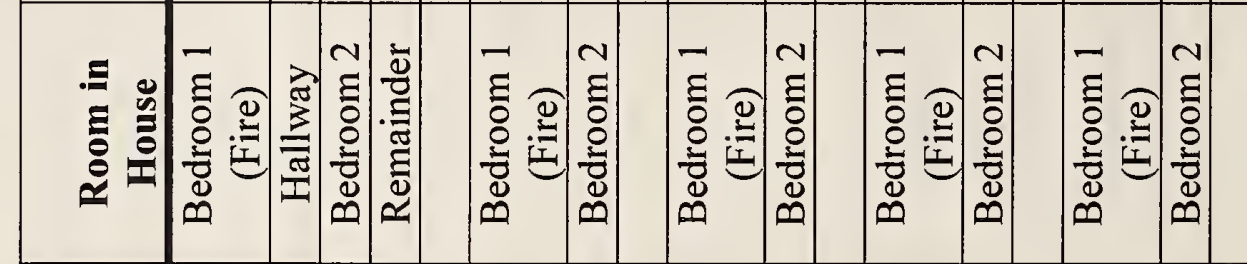

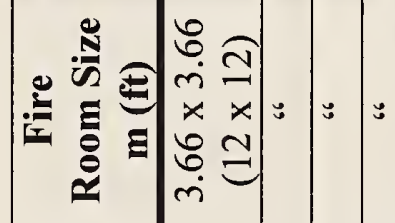

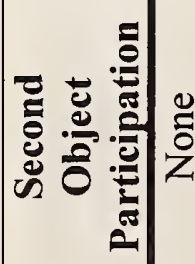

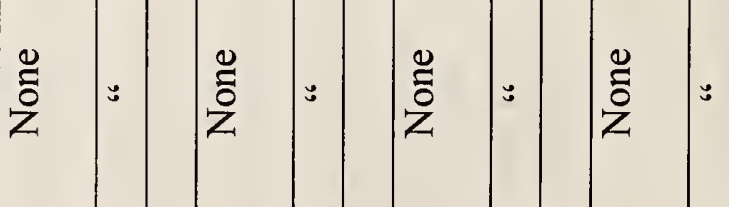

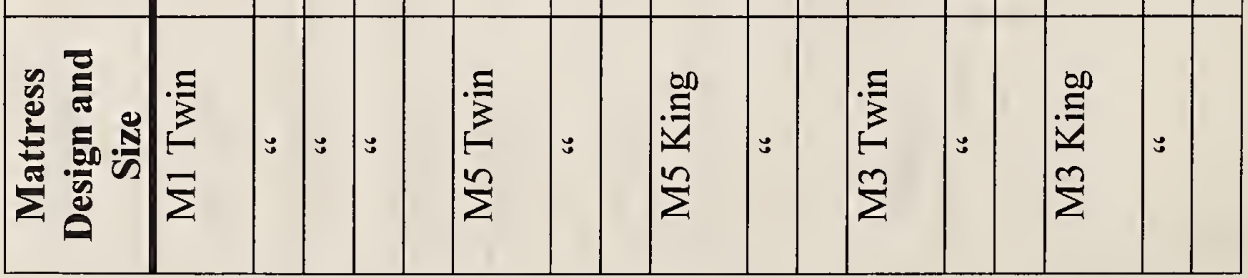




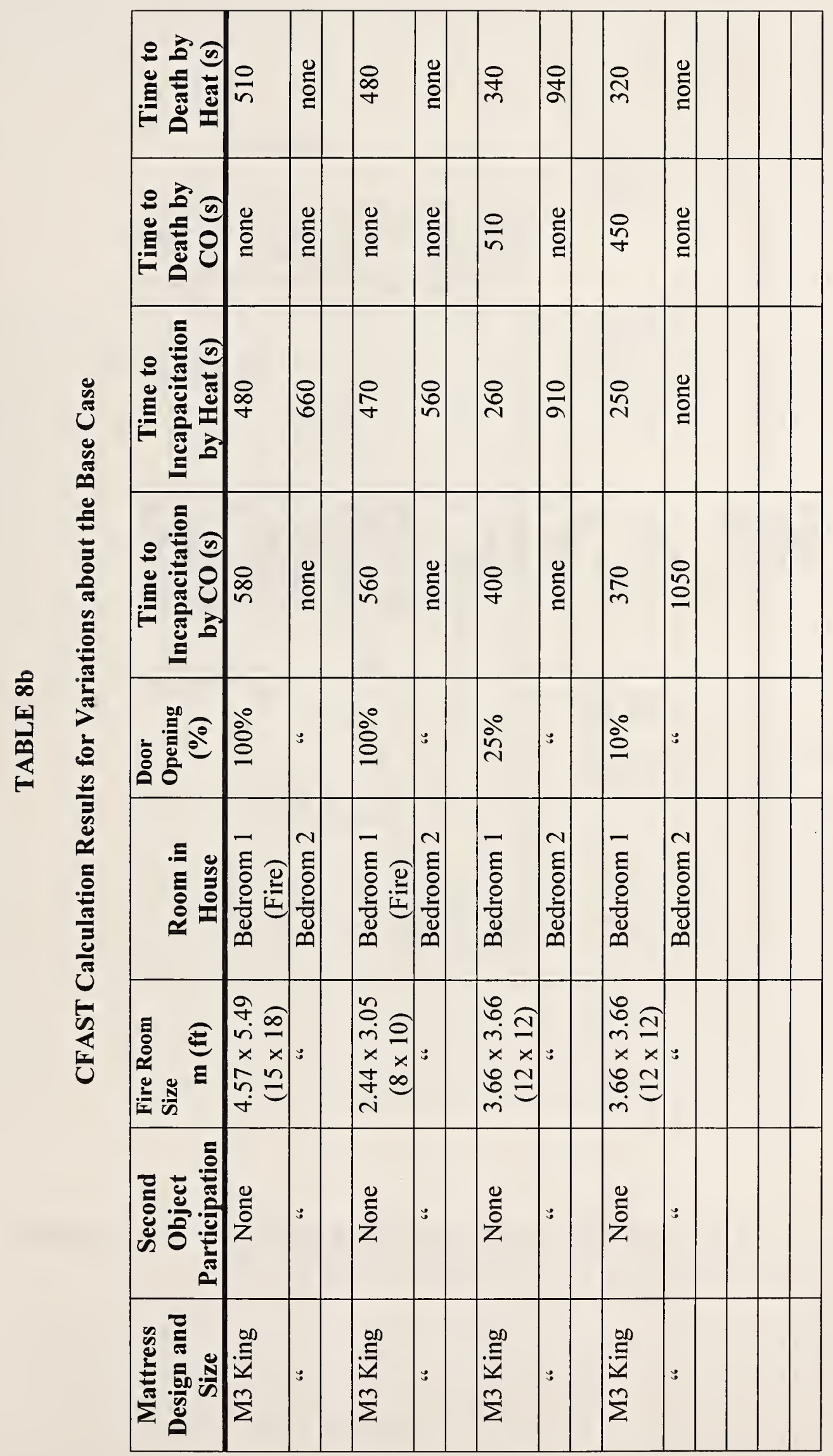




\section{BLANK PAGE}




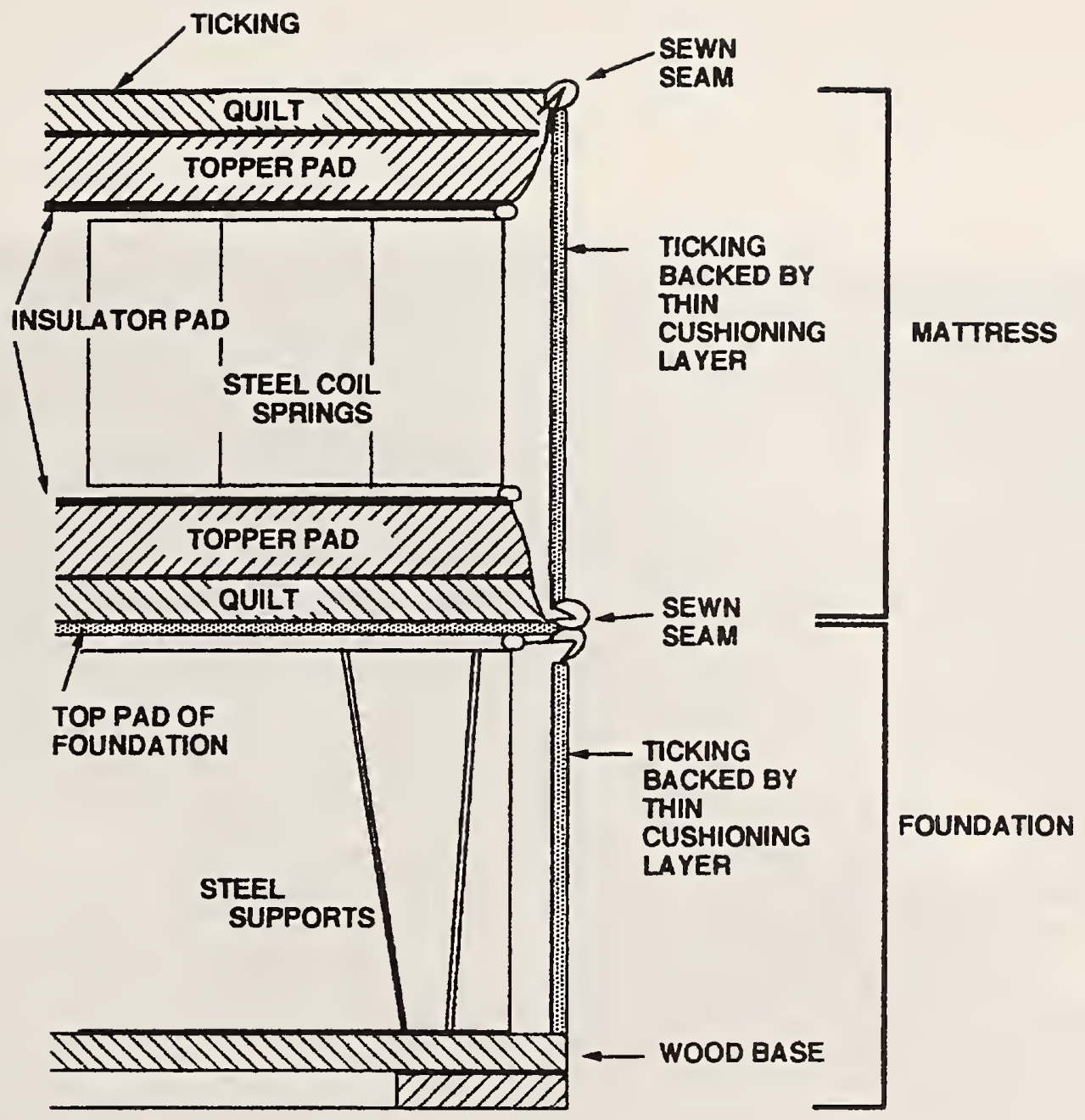

Figure 1. Cross-sectional view of mattress and foundation structure (not to fixed scale). 


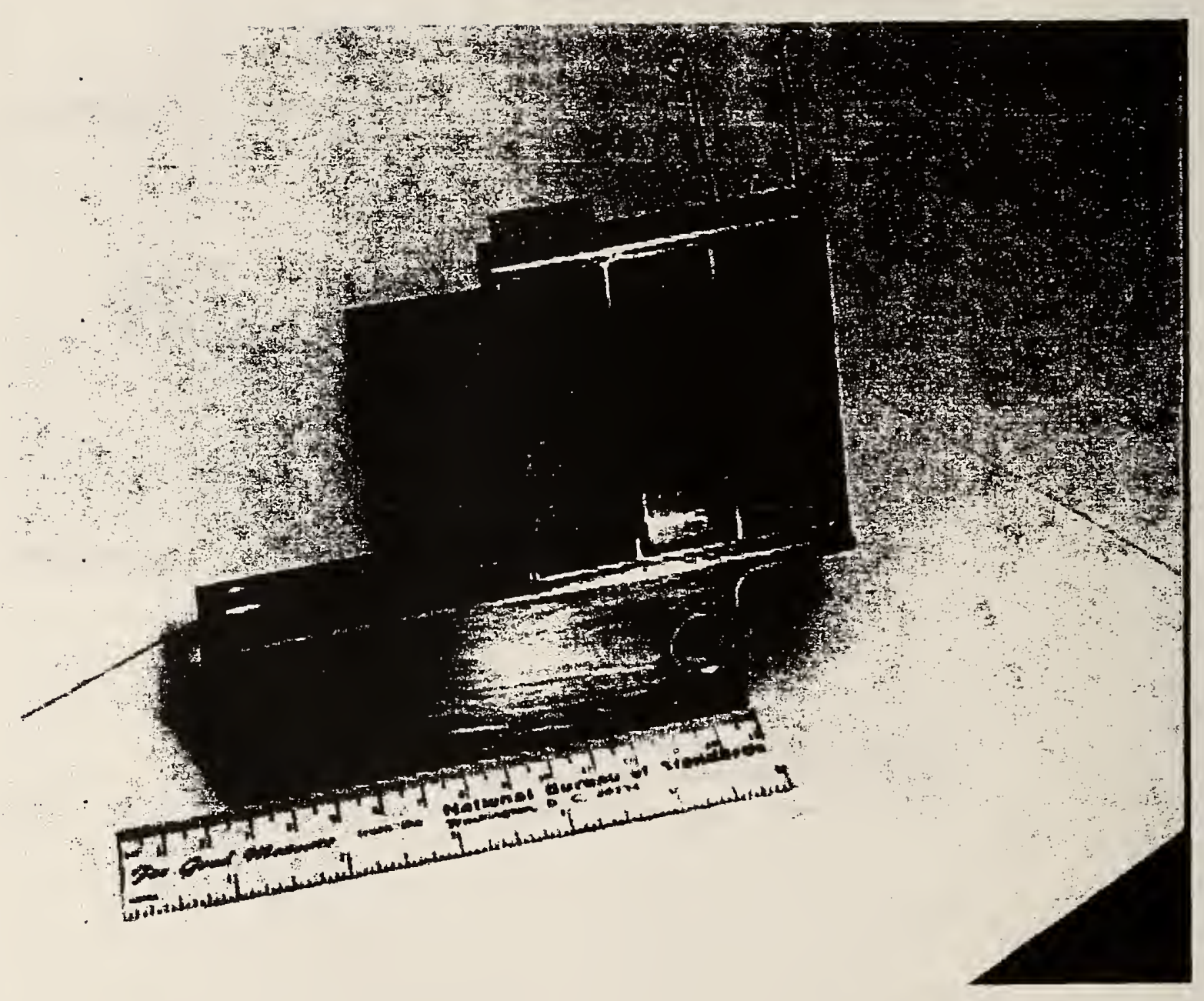

Figure 2a. Surrogate sample holder with newsprint on left and $100 \%$ cotton fabric (actual color dark green) on right. Thermocouple for sample ignition detection just visible above sample on right. Hole beneath central (empty) sample holder slot is for heat flux gage. Assembly is held on a pole at height of top of mattress at selected location relative to edge of bed. 


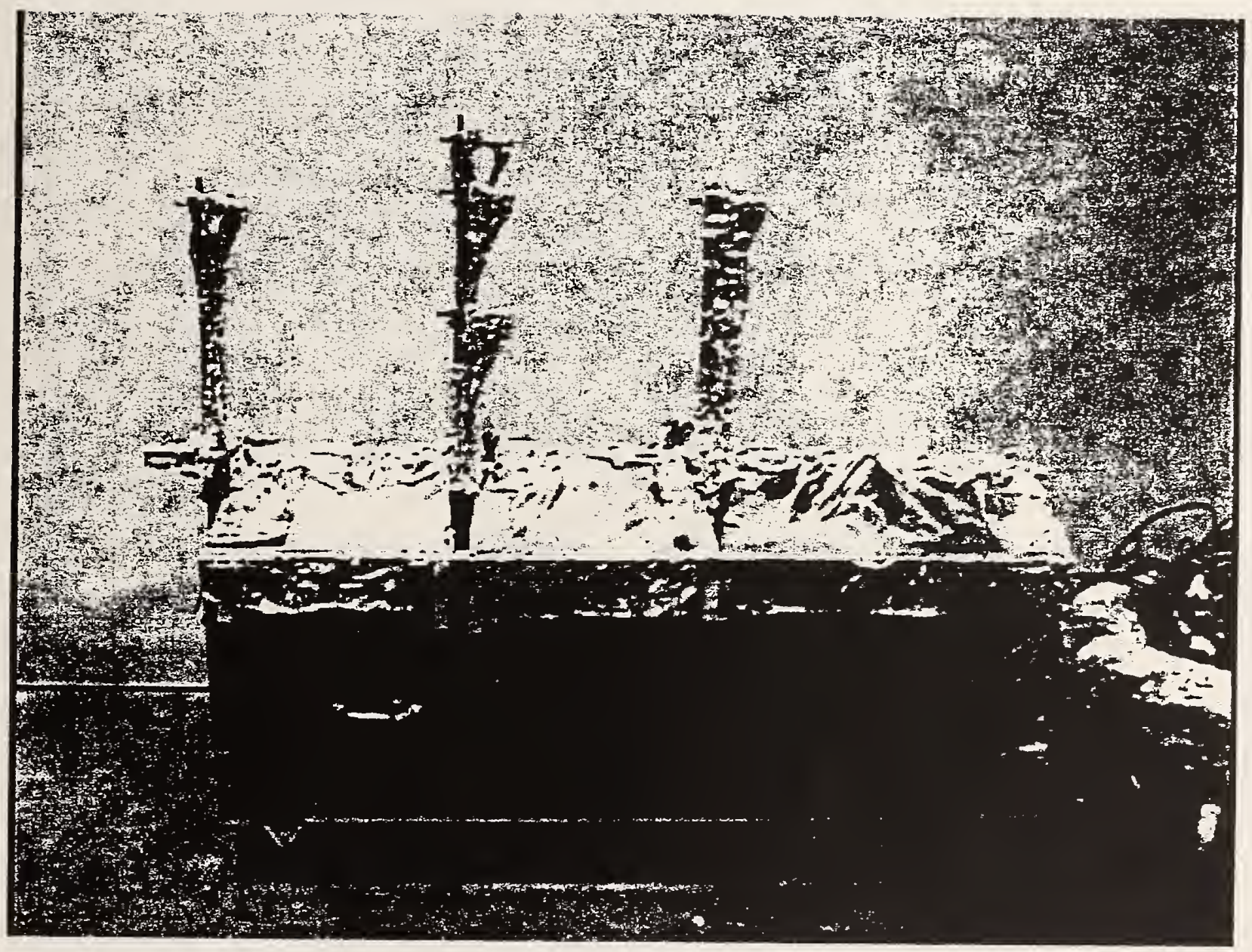

Figure $2 b$. Overall view of flux gage array in the configuration used in the room fire tests. Five horizontal-looking gages and three upward-looking gages are at the tops of the foil-covered support posts. All heat sensitive portions of the array are covered with aluminum foil. As shown here, a fire to be measured would be on the left; the cooling water lines and drains, as well as the signal wires are seen bundled on the right. 


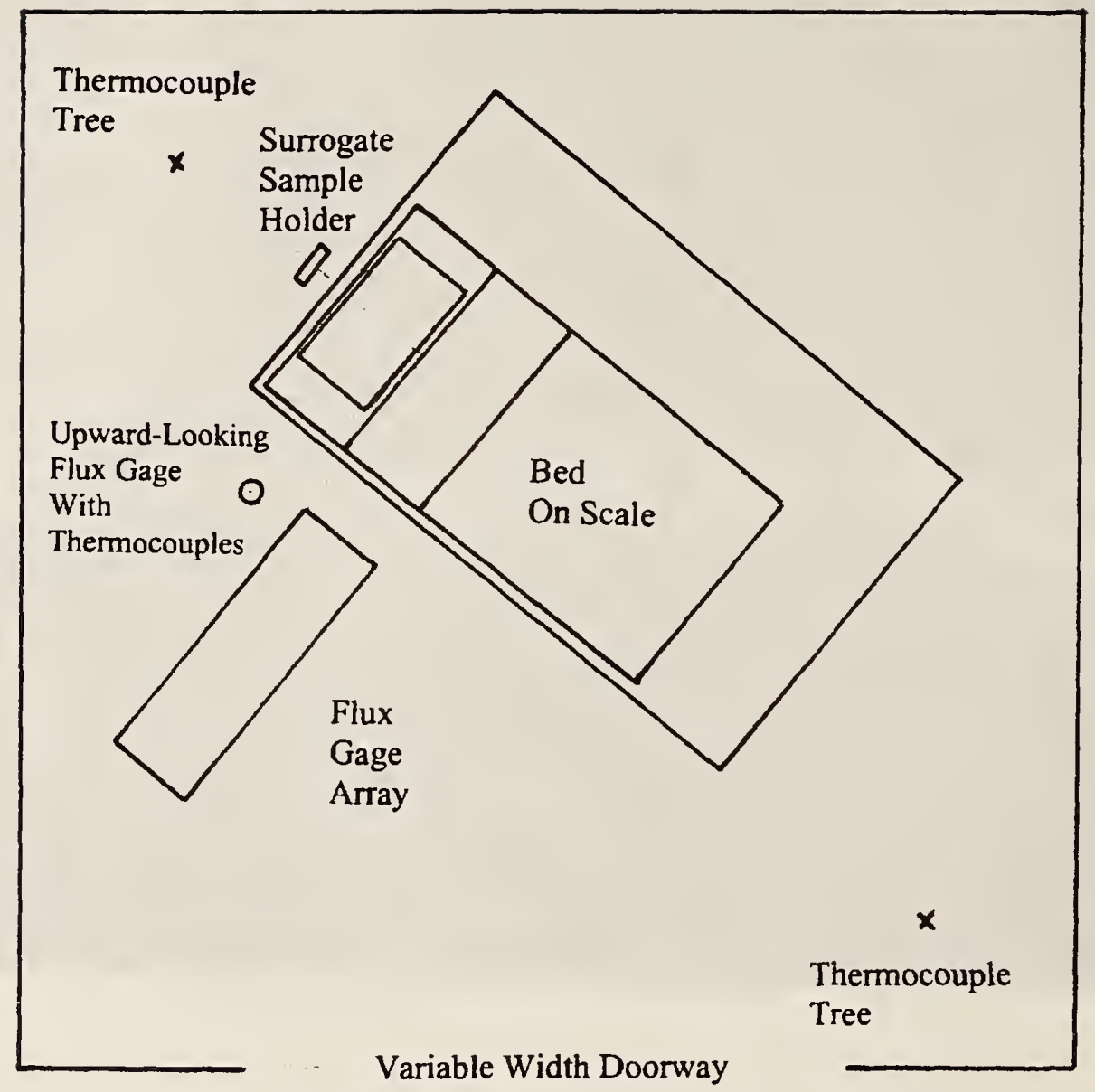

Figure 3. Layout of bed and instrumentation for fire tests in $4.27 \mathrm{~m} \times 4.27 \mathrm{~m}$ ( $14 \mathrm{ft} \times 14 \mathrm{ft}$ ) room. King size arrangement used same scale and similar placement of test items 
Estimates of Flashover Requirements

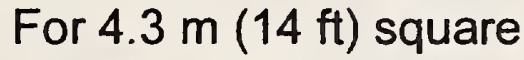

( $2 \mathrm{~m}, 80 \mathrm{in}$, high doorway)

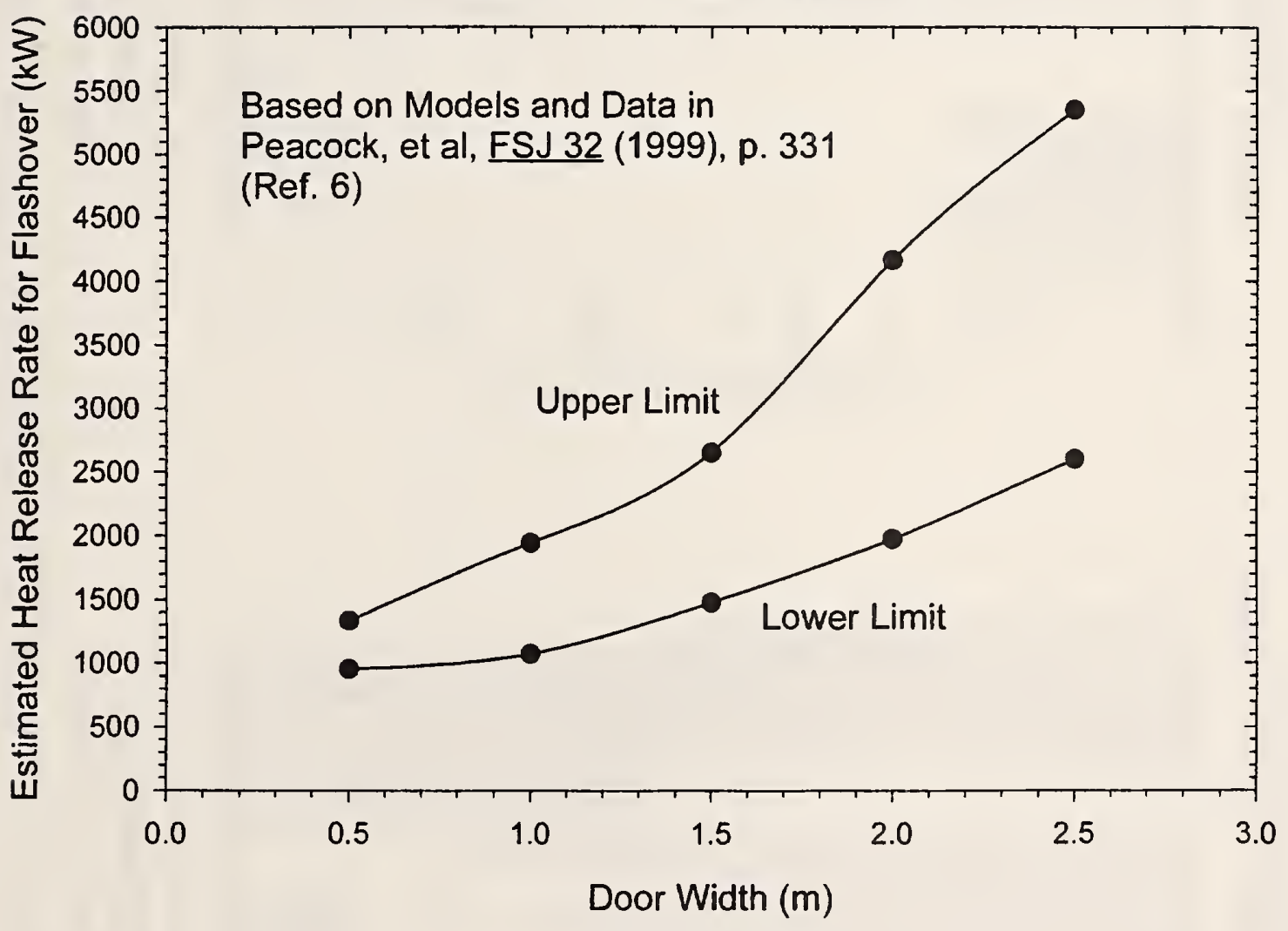

Figure 4. Lower and upper limits of heat release rate needed to cause flashover in a room

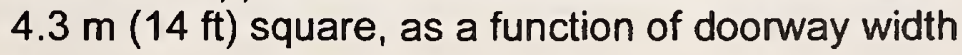




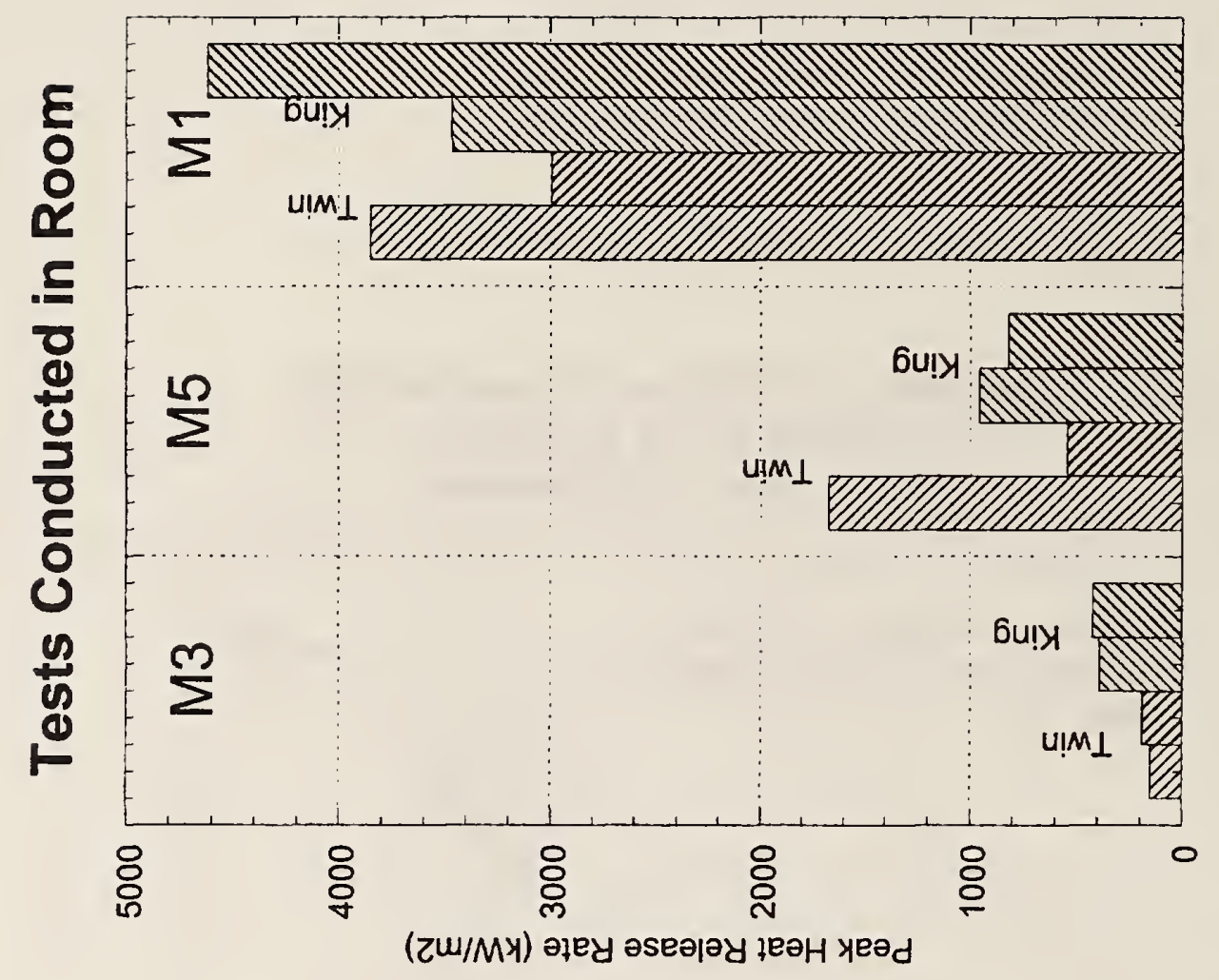

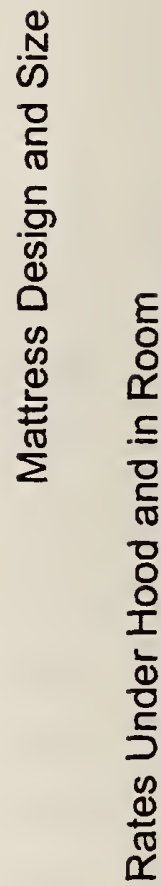

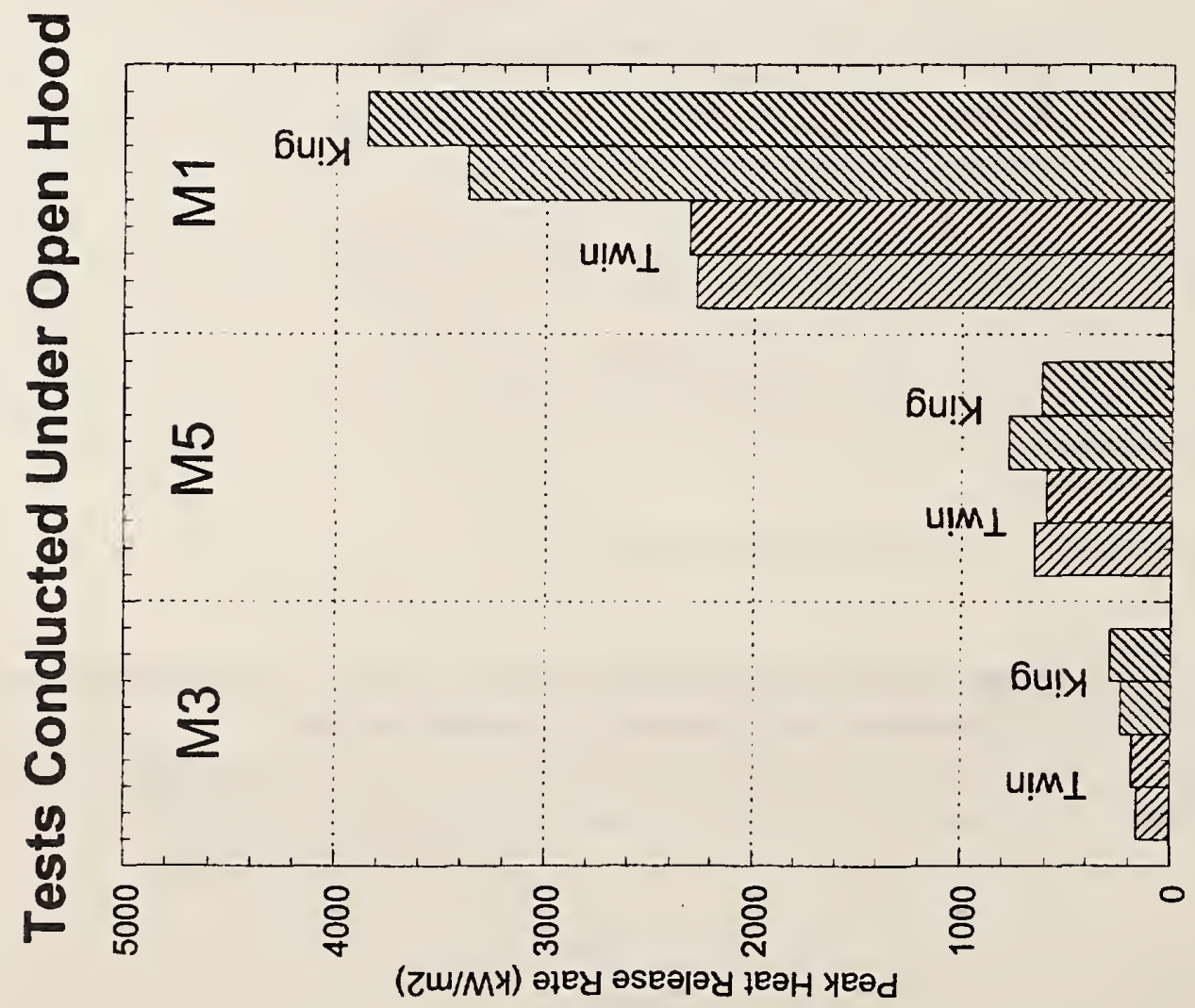

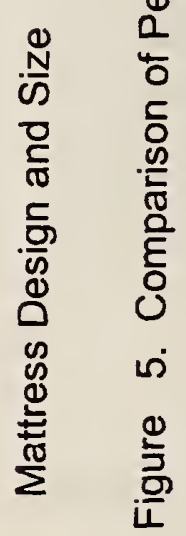



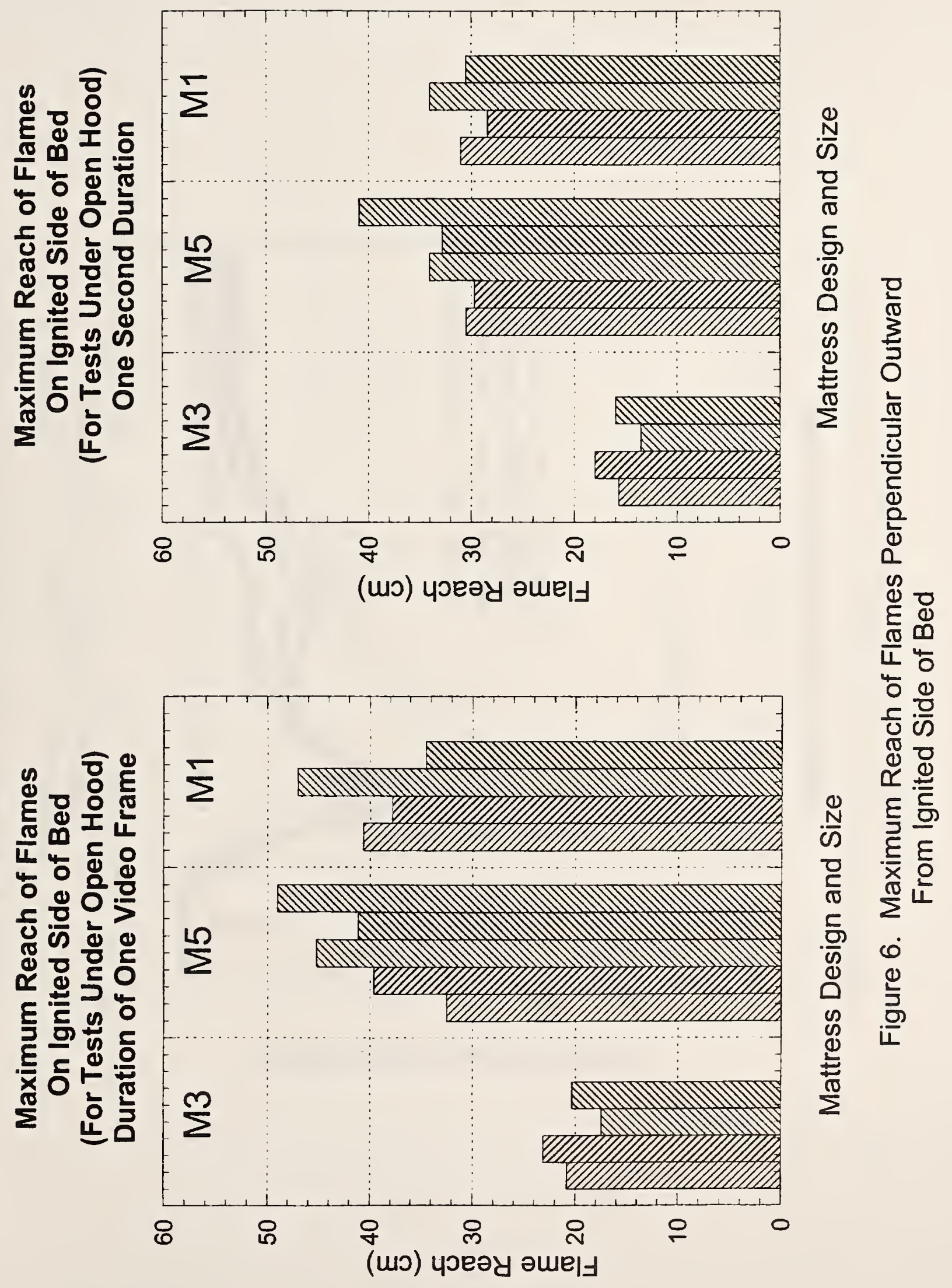


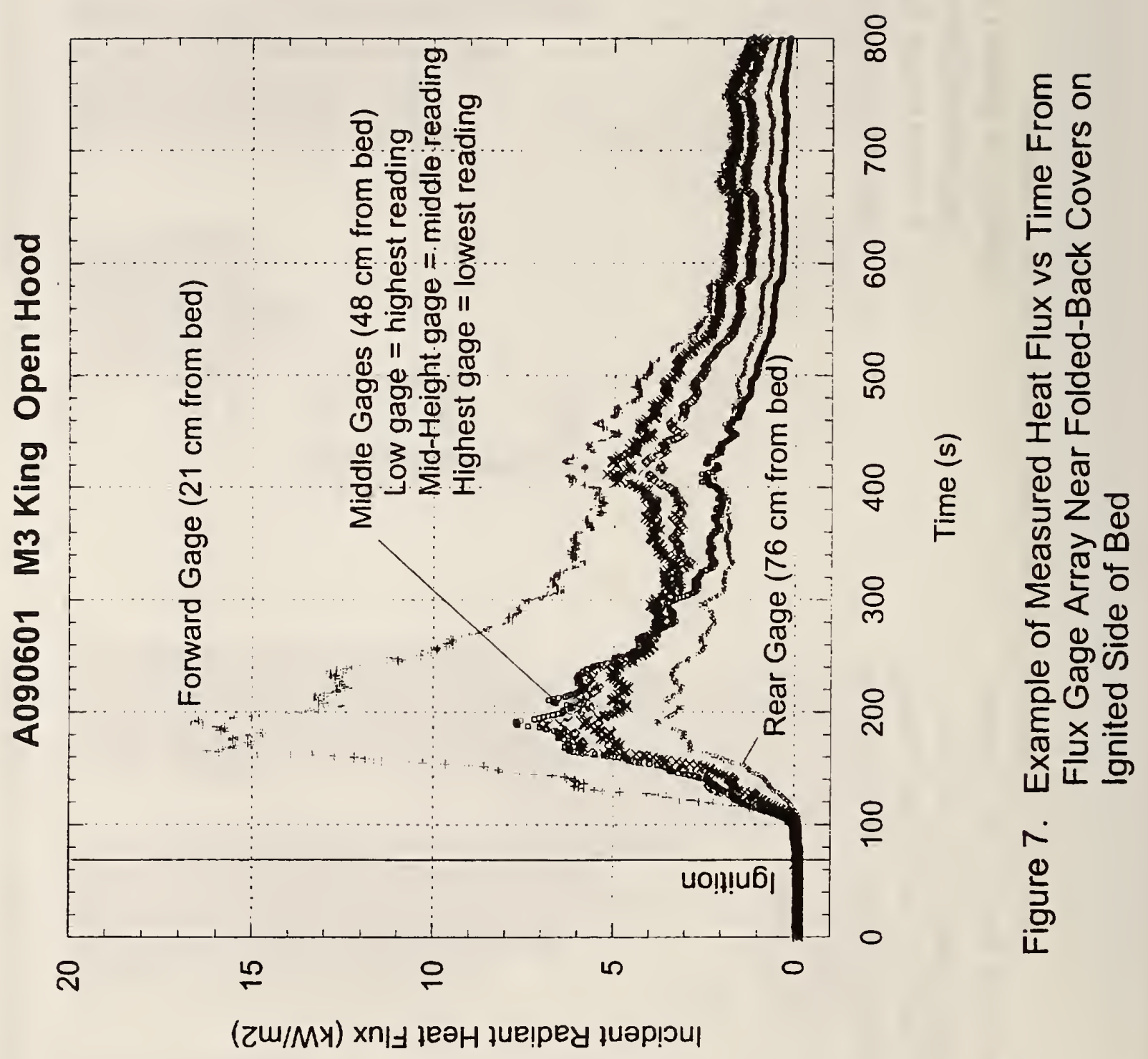




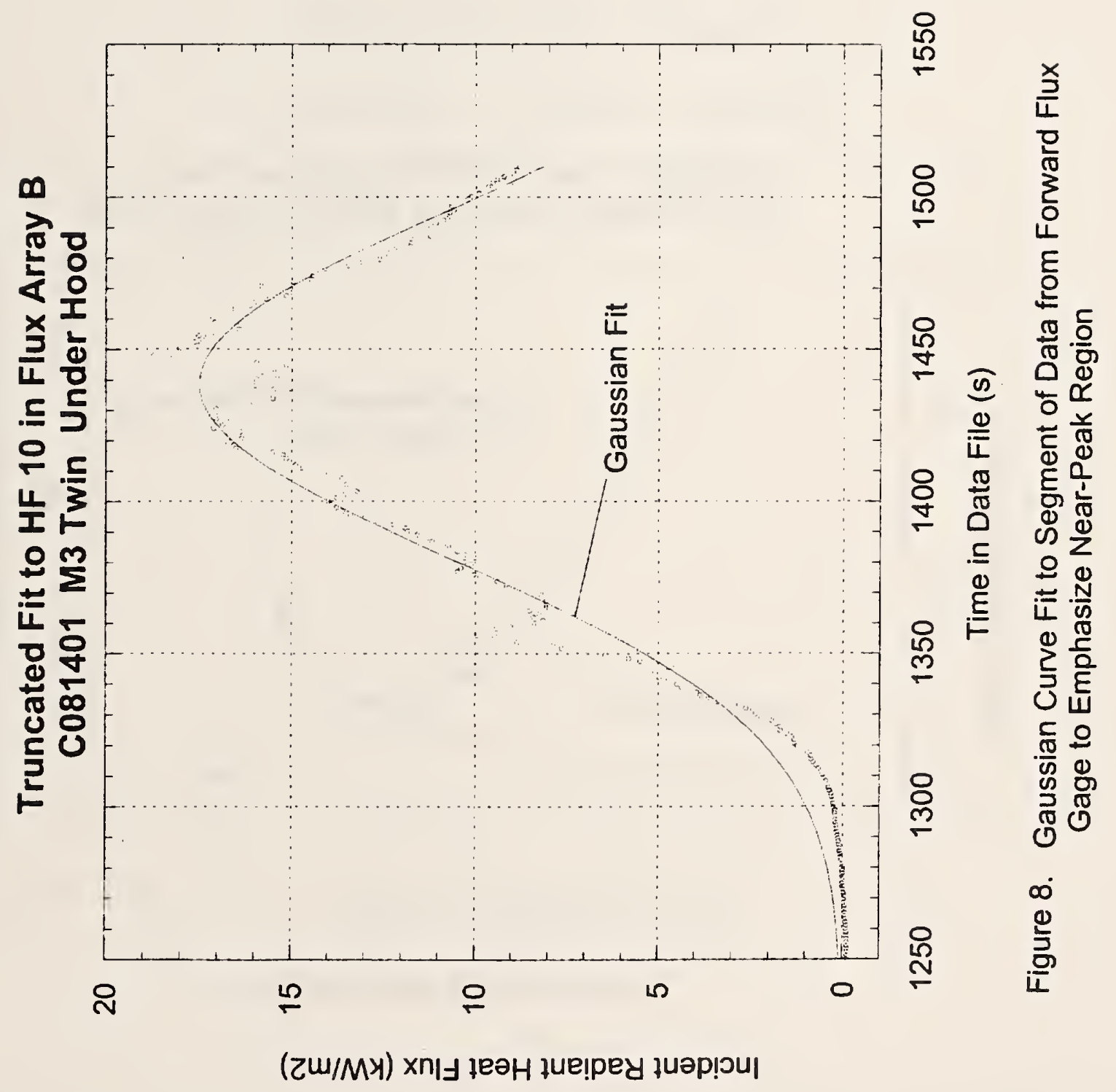




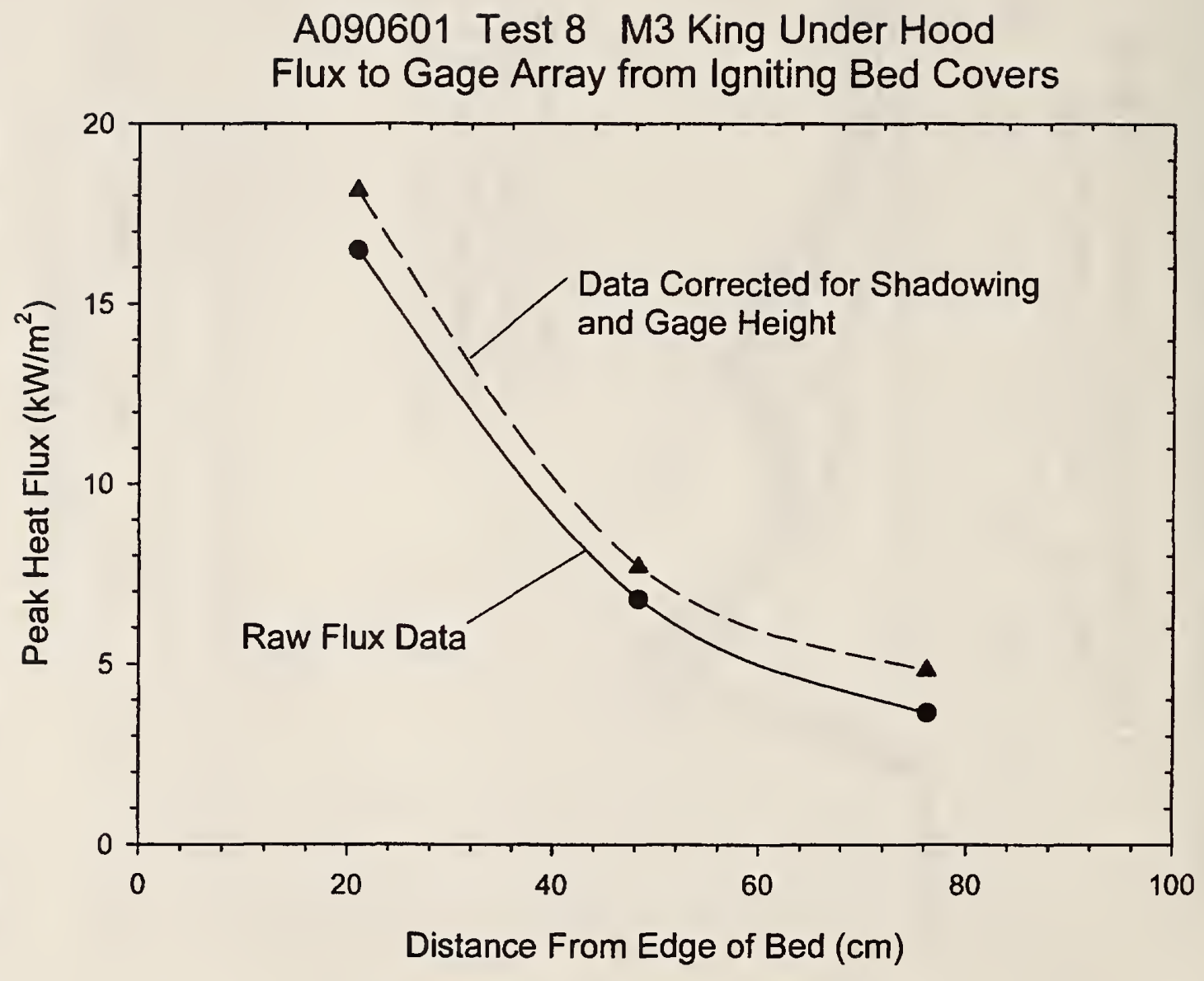

Figure 9. Example of raw and corrected data for peak incident heat flux as a function of distance from the edge of the bed. M3 king. 
$100 \%$ Cotton Fabric, $410 \mathrm{~g} / \mathrm{m}^{2}$

$\mathrm{T}_{\text {ign }}=304 \mathrm{C}, \quad$ Thermin $=1.88 \mathrm{MKS}$

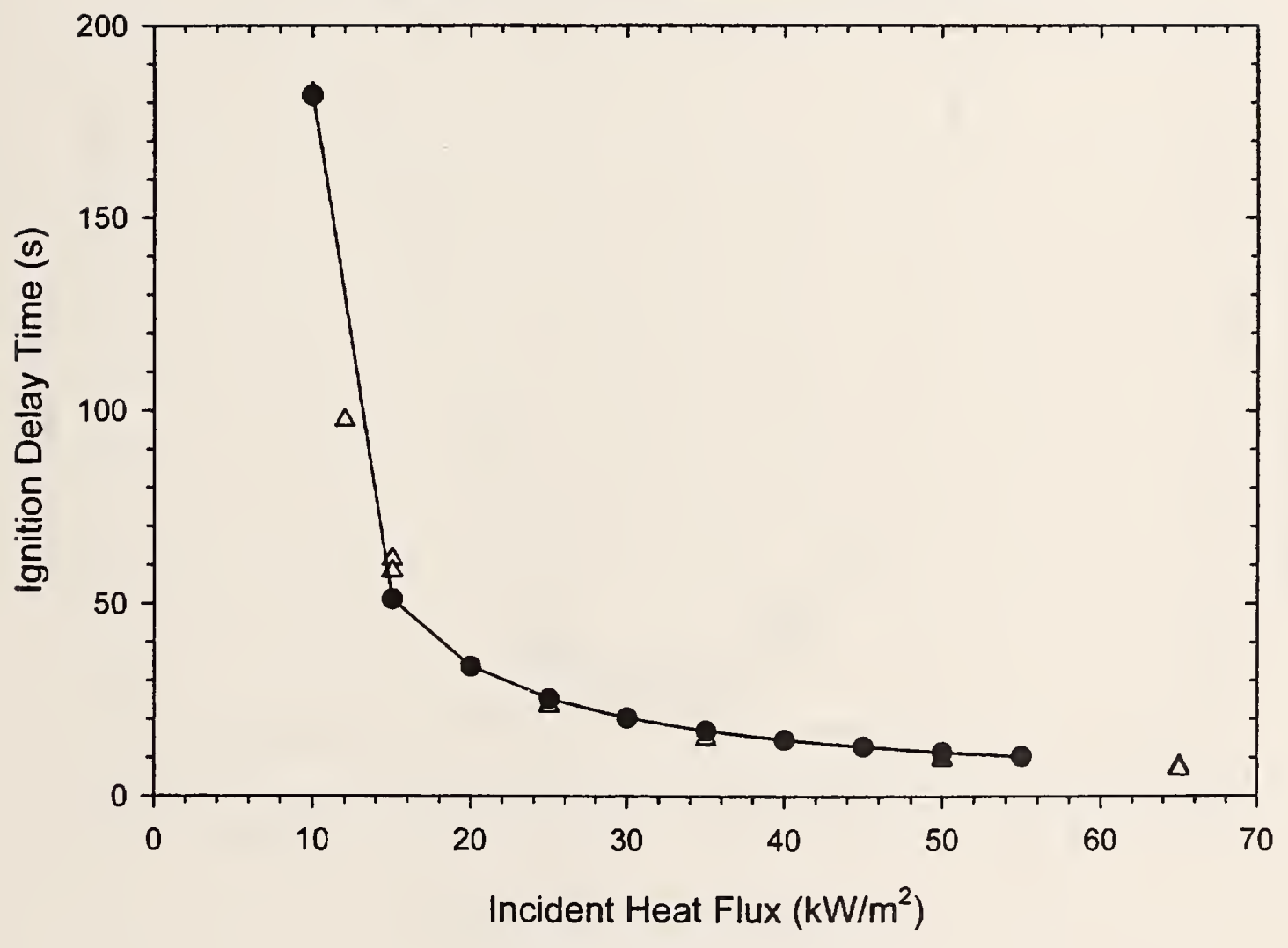

Figure 10a. Comparison of Cone ignition data(triangles) and ignition model (black dots) using indicated values of ignition temperature and thermal inertia; cotton fabric 
$38 \%$ Polyester / $62 \%$ Cotton Upholstery Fabric, $275 \mathrm{~g} / \mathrm{m}^{2}$

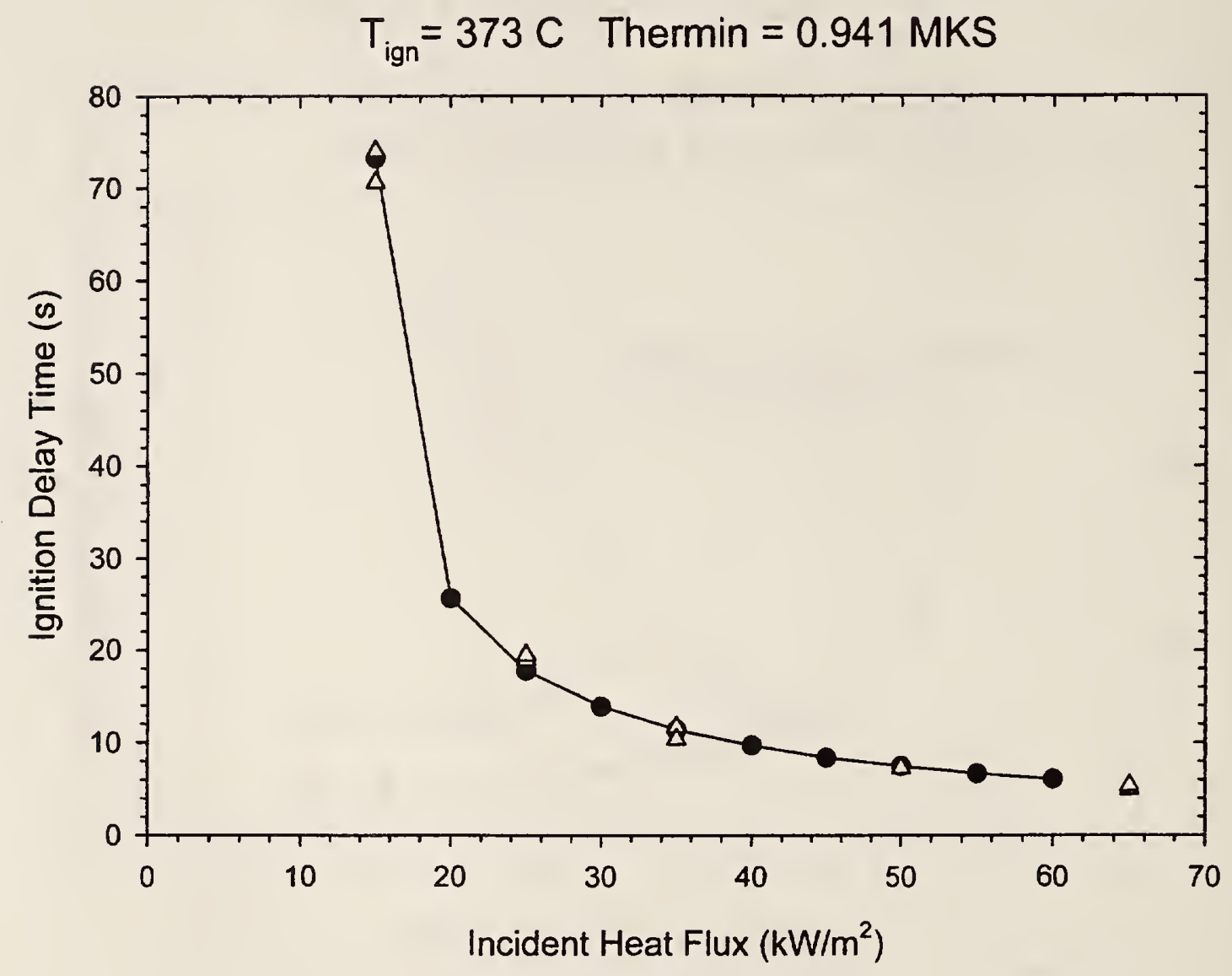

Figure 10b. Comparison of Cone ignition data (triangles) and ignition model (black dots) using indicated values of ignition temperature and thermal inertia; medium weight polyester/cotton blend 


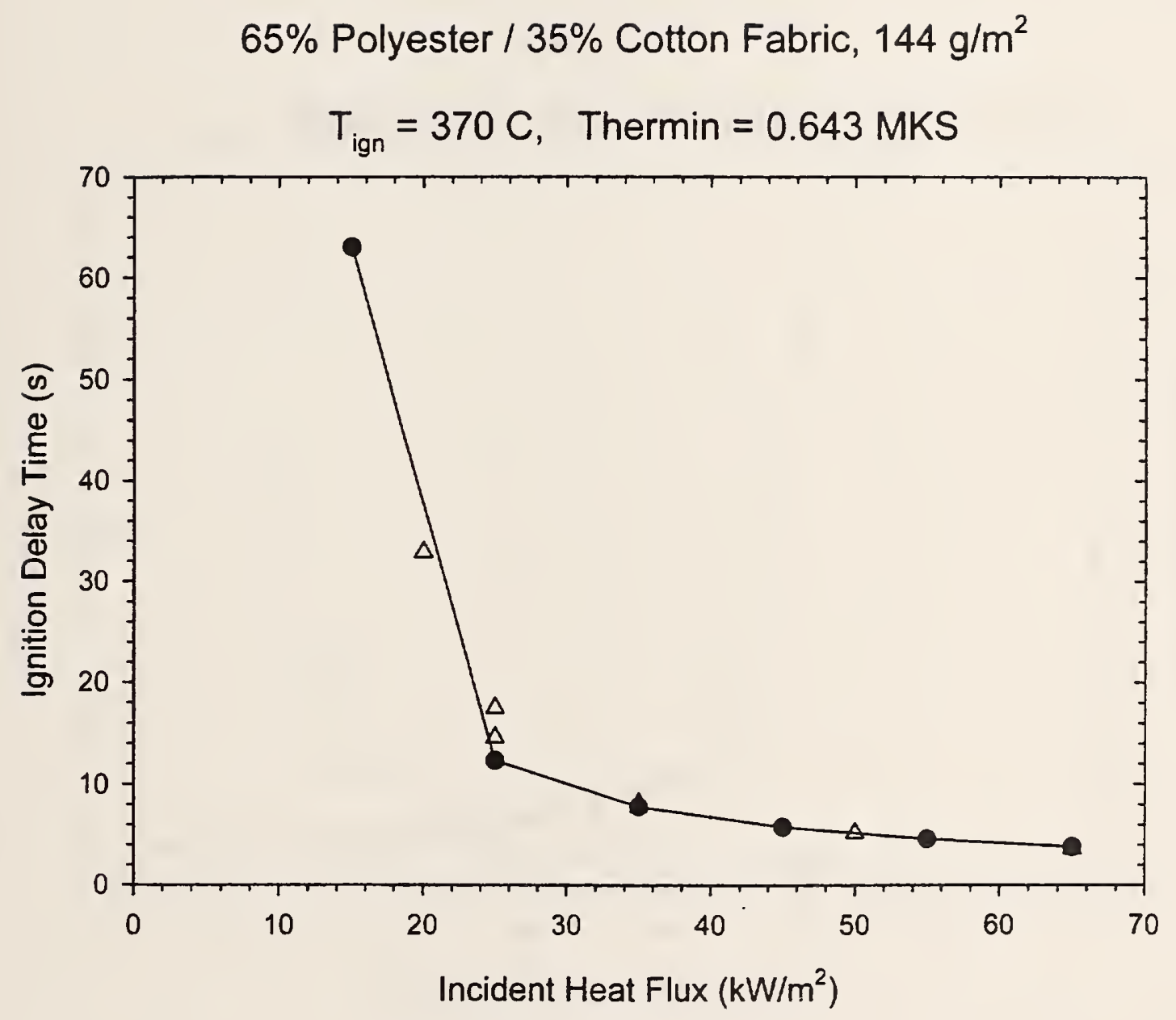

Figure 10c. Comparison of Cone ignition data (triangles) and ignition model (black dots) using indicated values of ignition temperature and thermal inertia; light weight polyester / cotton blend 


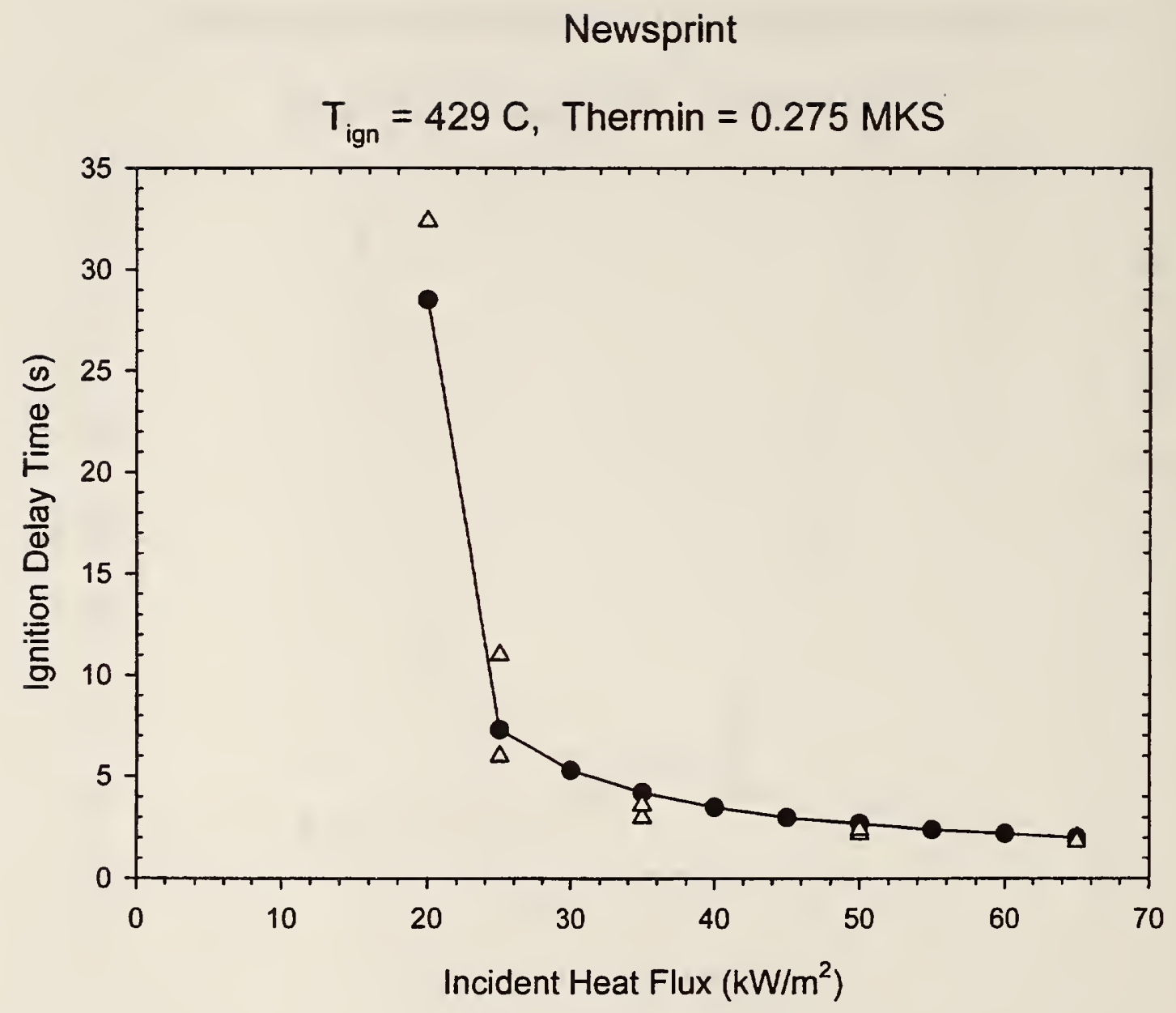

Figure 10d. Comparison of Cone ignition data (triangles) and Ignition model (black dots) using indicated values of ignition temperature and thermal inertia; single sheet of newsprint having uniform fine black printing 


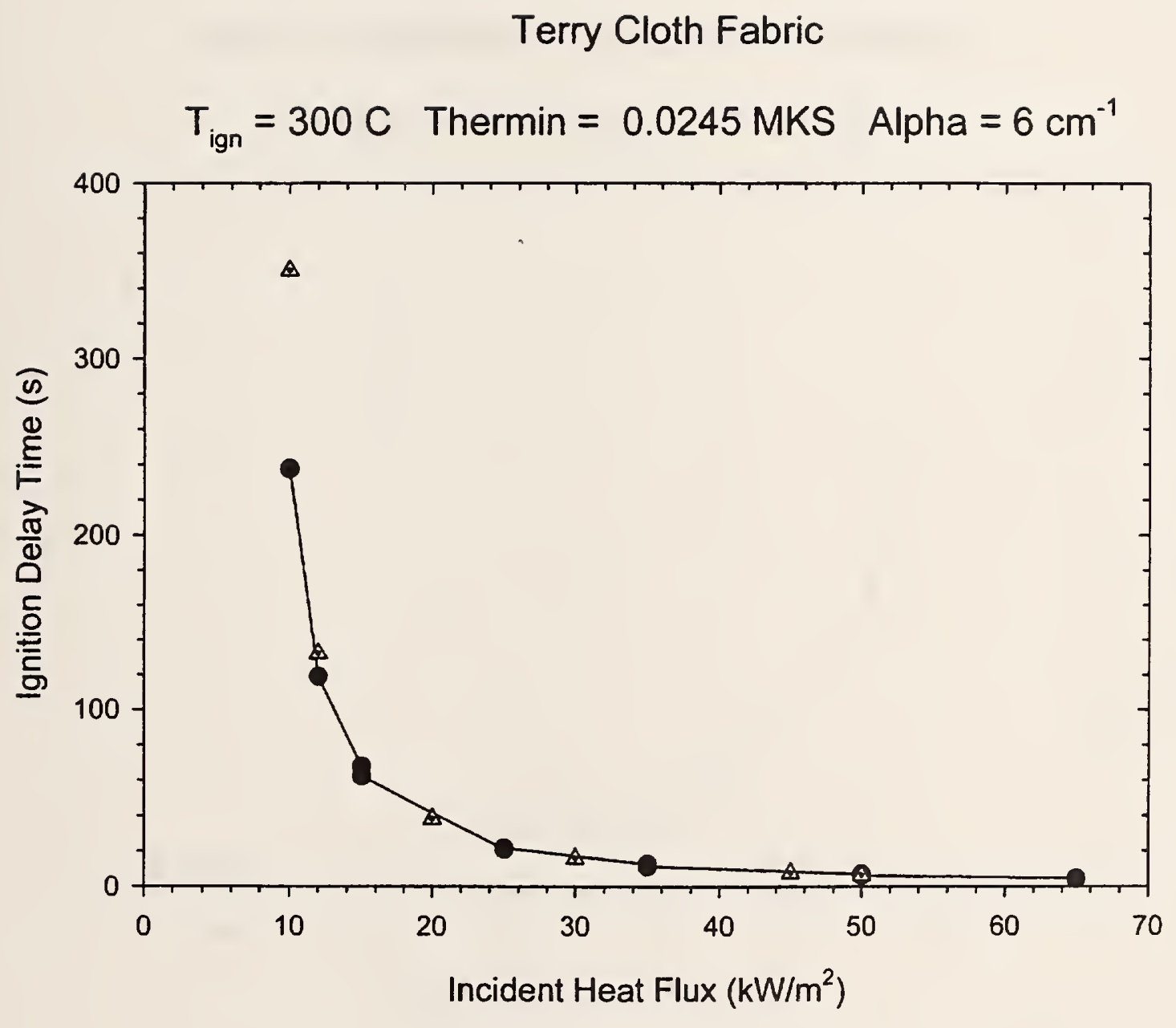

Figure 10e. Comparison of Cone Ignition data (triangles) and ignition model (black dots) using indicated values for ignition temperature, thermal inertia and in-depth absorption coefficient; terry cloth fabric 
$3 \mathrm{~mm}$ Thick Plywood Panel with Birch Veneer

$\mathrm{T}_{\text {ign }}=310 \mathrm{C}$ Thermin $=0.525 \mathrm{MKS}$

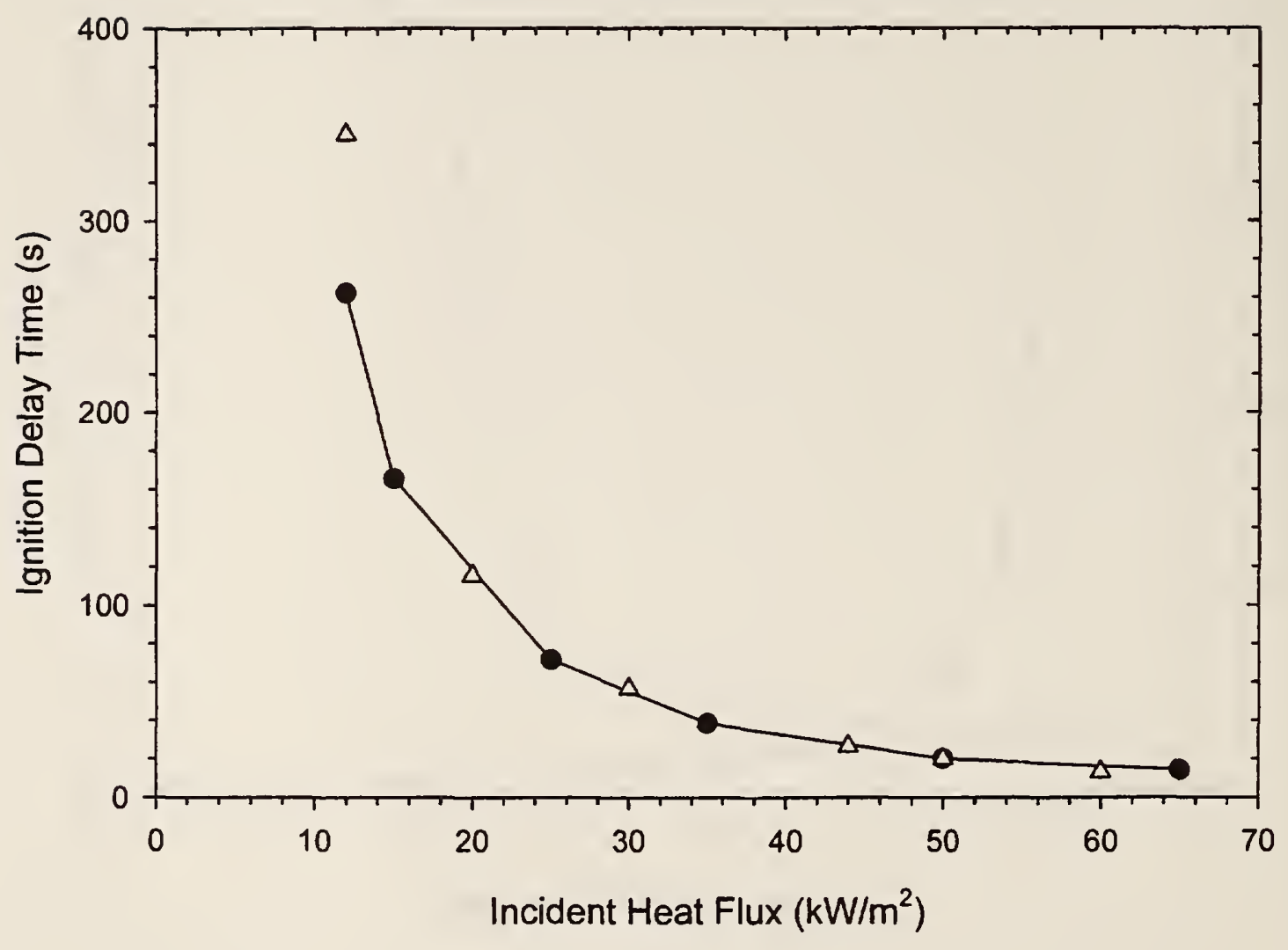

Figure 10f. Comparison of Cone ignition data (triangles) and ignition model (black dots) using indicated values of ignition temperature and thermal inertia; $3 \mathrm{~mm}(1 / 8 \mathrm{in})$ thick plywood with birch veneer 


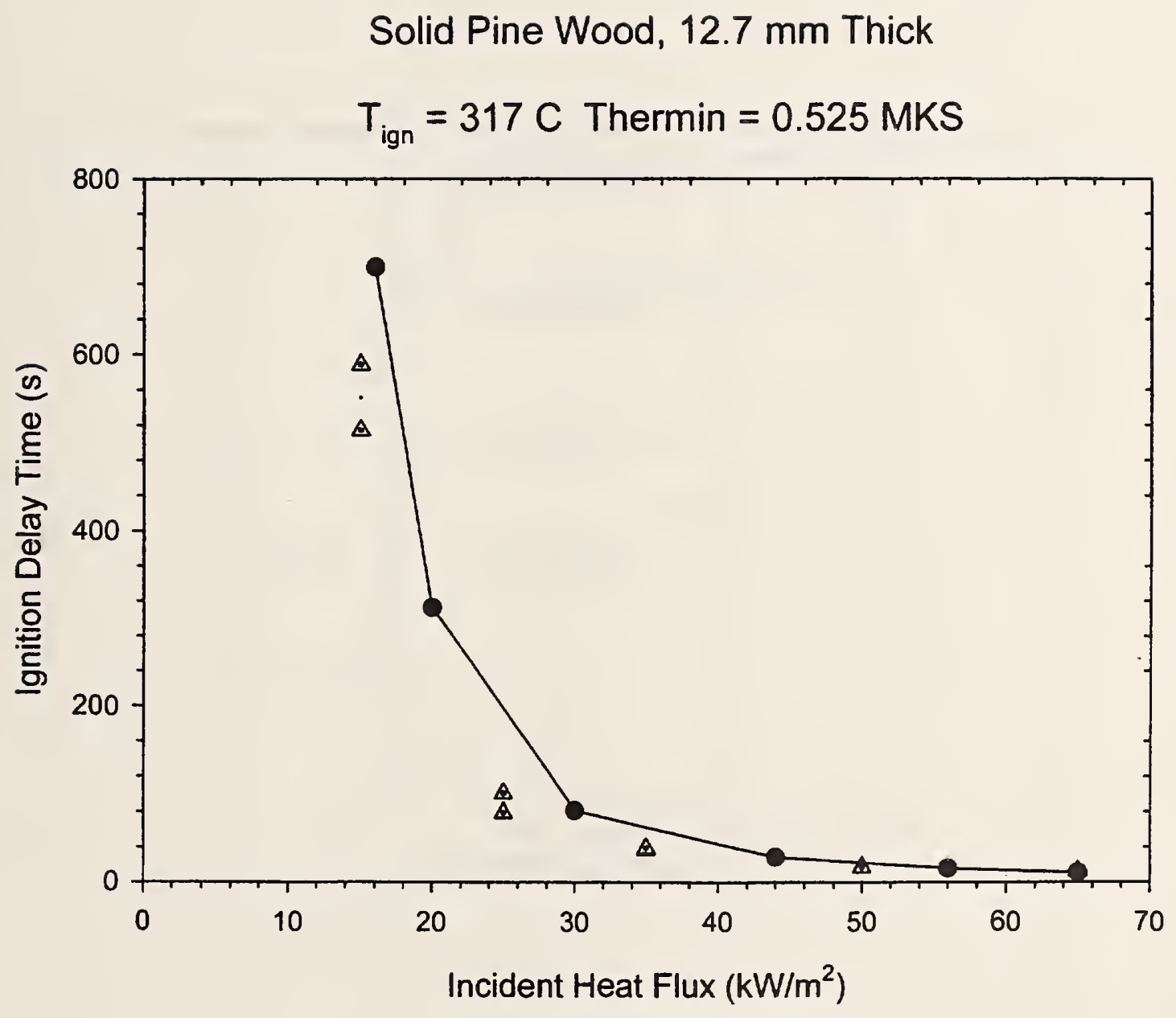

Figure 10g. Comparison of Cone ignition data (triangles) and ignition model (black dots) using indicated values of ignition temperature and thermal inertia; solid pine wood, $12.7 \mathrm{~mm}(1 / 2 \mathrm{in})$ thick 


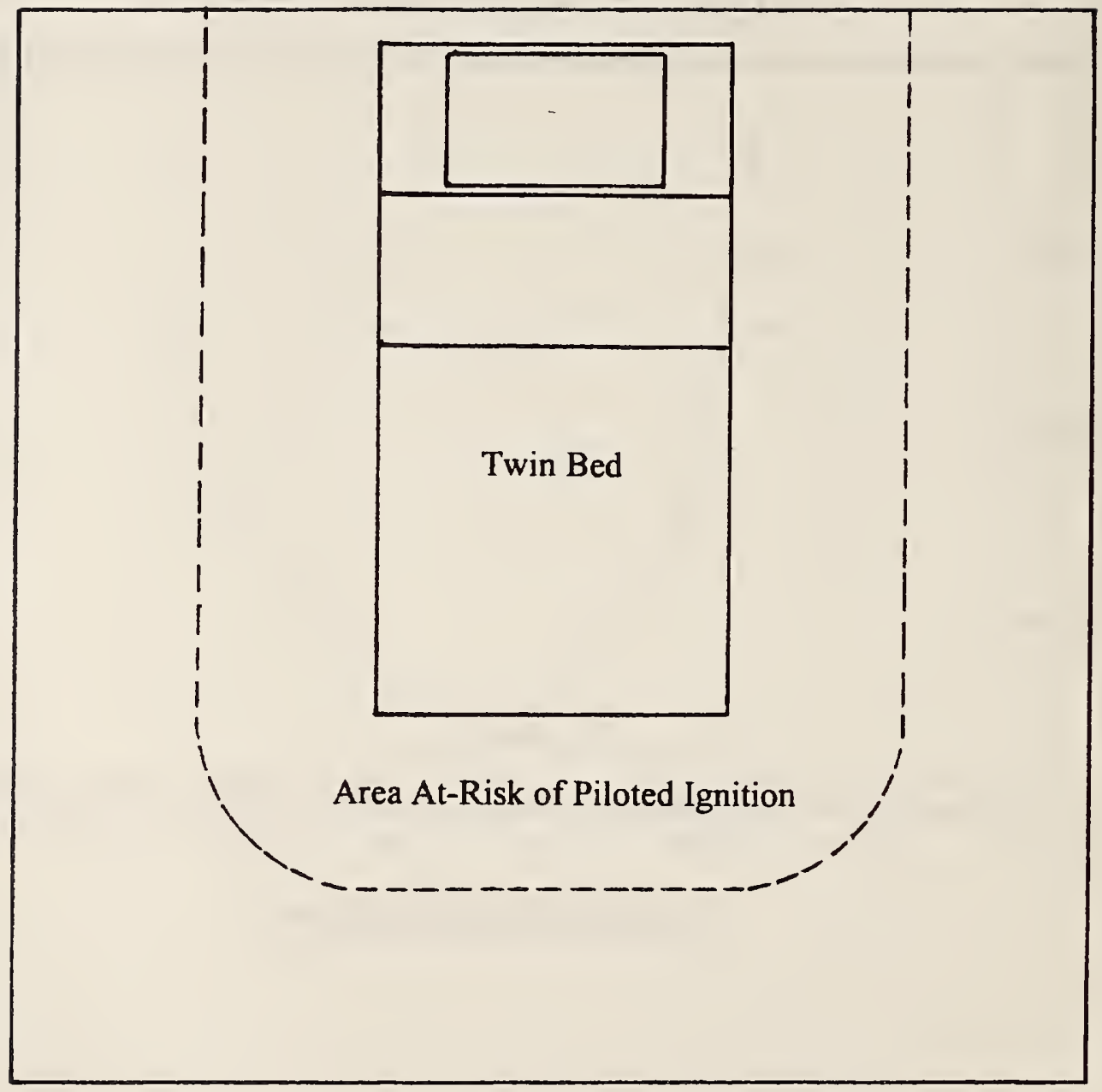

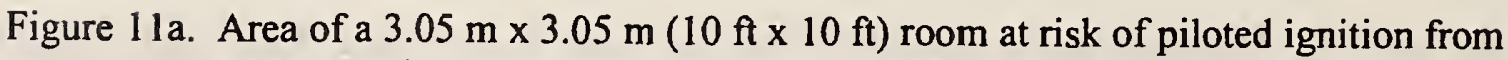
an M3 fire if ignition threat radius (for $100 \%$ cotton fabric) is equal around bed. Area available for second object placement is room area minus bed area. 


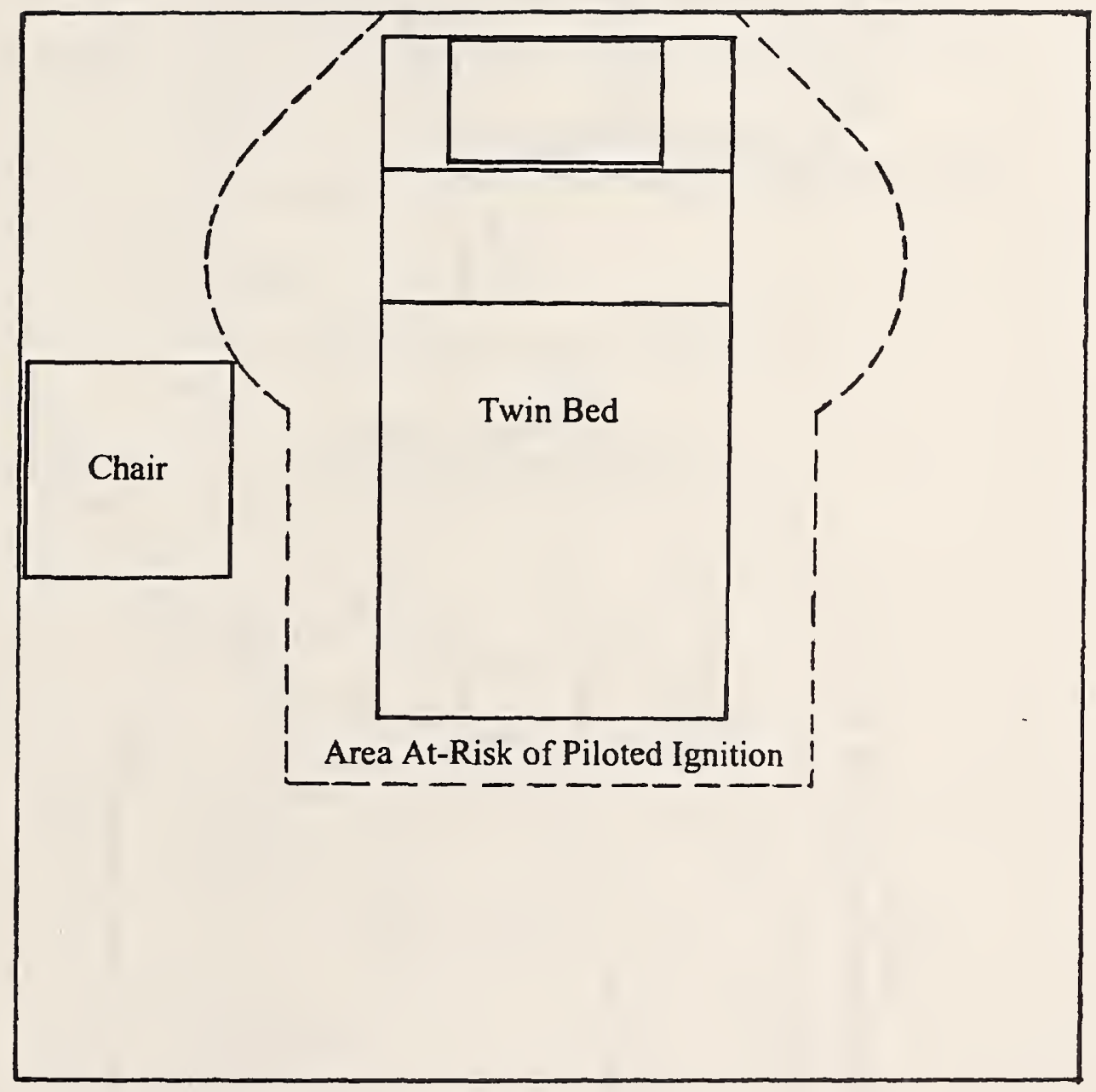

Figure $11 \mathrm{~b}$. Area of a $3.05 \mathrm{~m} \times 3.05 \mathrm{~m}(10 \mathrm{ft} \times 10 \mathrm{ft})$ room at risk of piloted ignition from an M3 fire if ignition threat radius (for $100 \%$ cotton fabric) is varied around bed in accord with area burning on sides. Chair is $0.61 \mathrm{~m} \times 0.61 \mathrm{~m}$ ( $2 \mathrm{ft} \times 2 \mathrm{ft}$ ) and cannot be placed any closer to upper room corner without overlapping area at-risk for piloted ignition. 

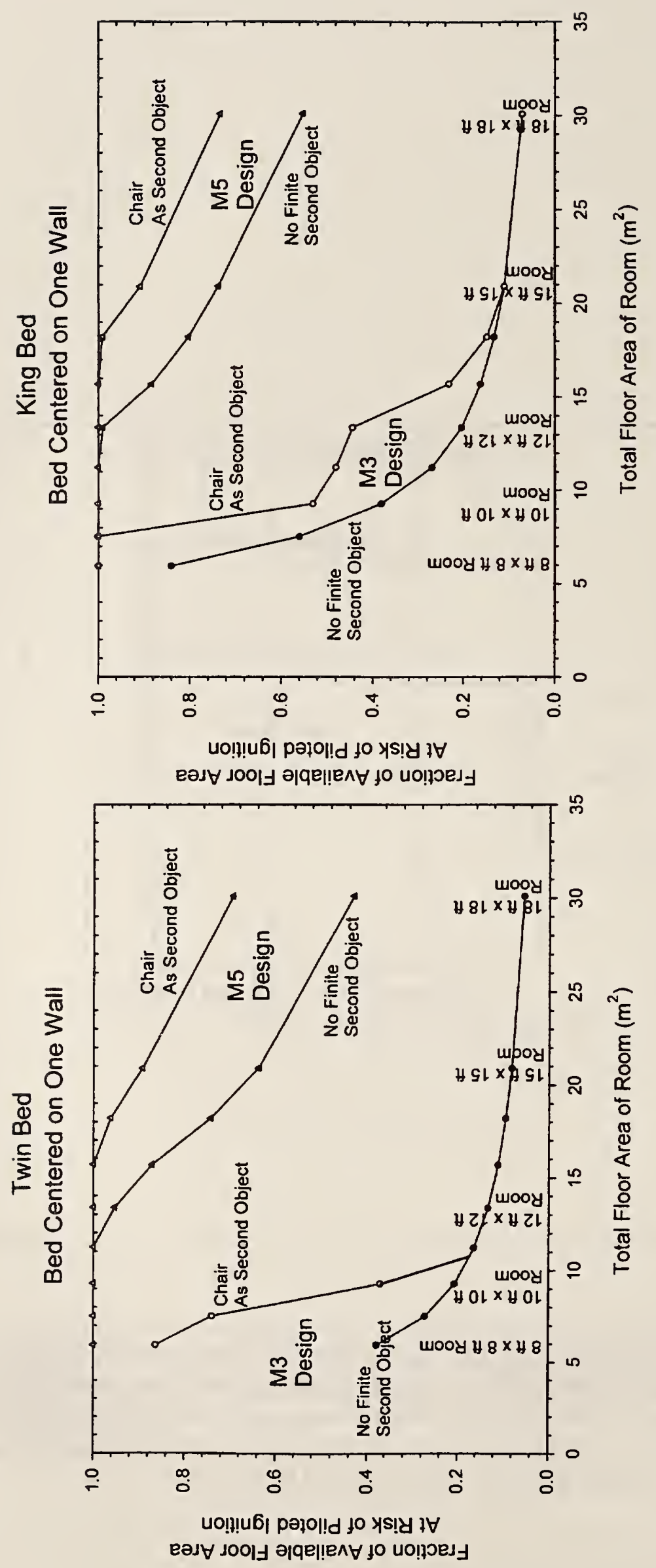

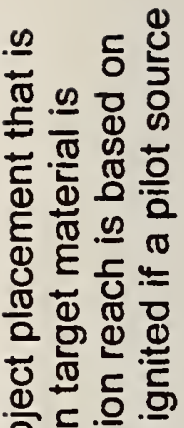

응을

읃흐믄

드음흠

舟

क एक

응 원. 은

ब的帝

응 路文

西

里

$>0$ 응

而造而

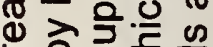

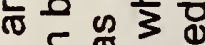

등

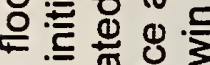

$\varepsilon=$

잉 준

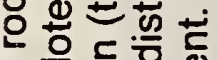

늠 등이

ᄃ

흔

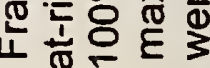

$\frac{\text { ำ }}{\frac{0}{5}}$ 
Twin Bed

Bed Centered on One Wall

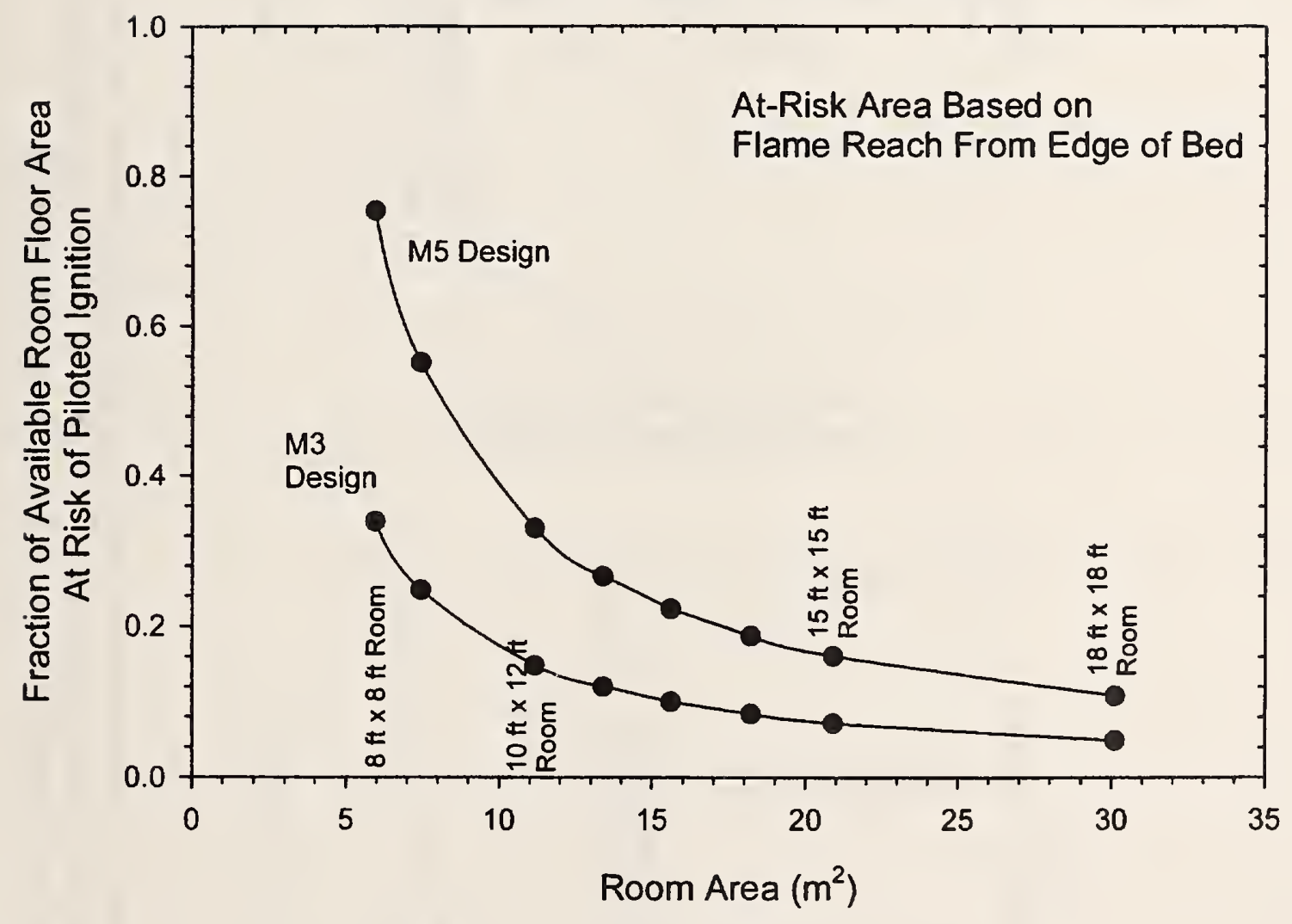

Figure 13. Fraction of available room floor area at risk of piloted ignition when at-risk area is based on flame reach from edge of bed; M3 and M5 fires; reach values assumed are at the $<1 \%$ probability end of the instantaneous flame flicker values; no ignition target properties assumed. 

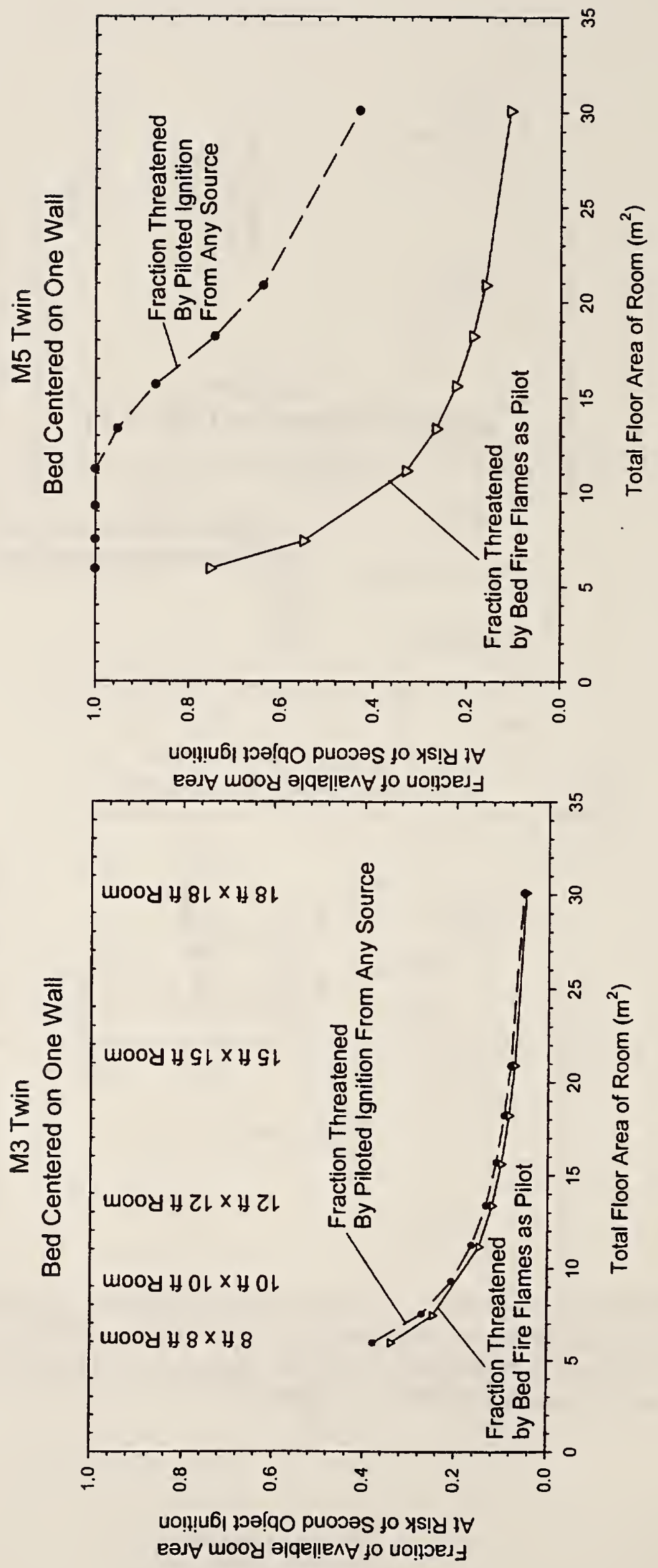

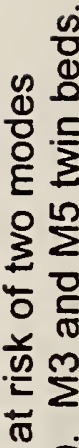

o

స్

Е

동

E

U 어

잉

응 흥

응

듬드.

응항

믕 든

잉

E

西.

응

은 믕

त

స్

उ

흐

¿ 흥

क $\frac{N}{\omega}$

통을 인

은

응

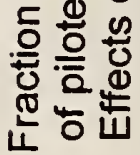



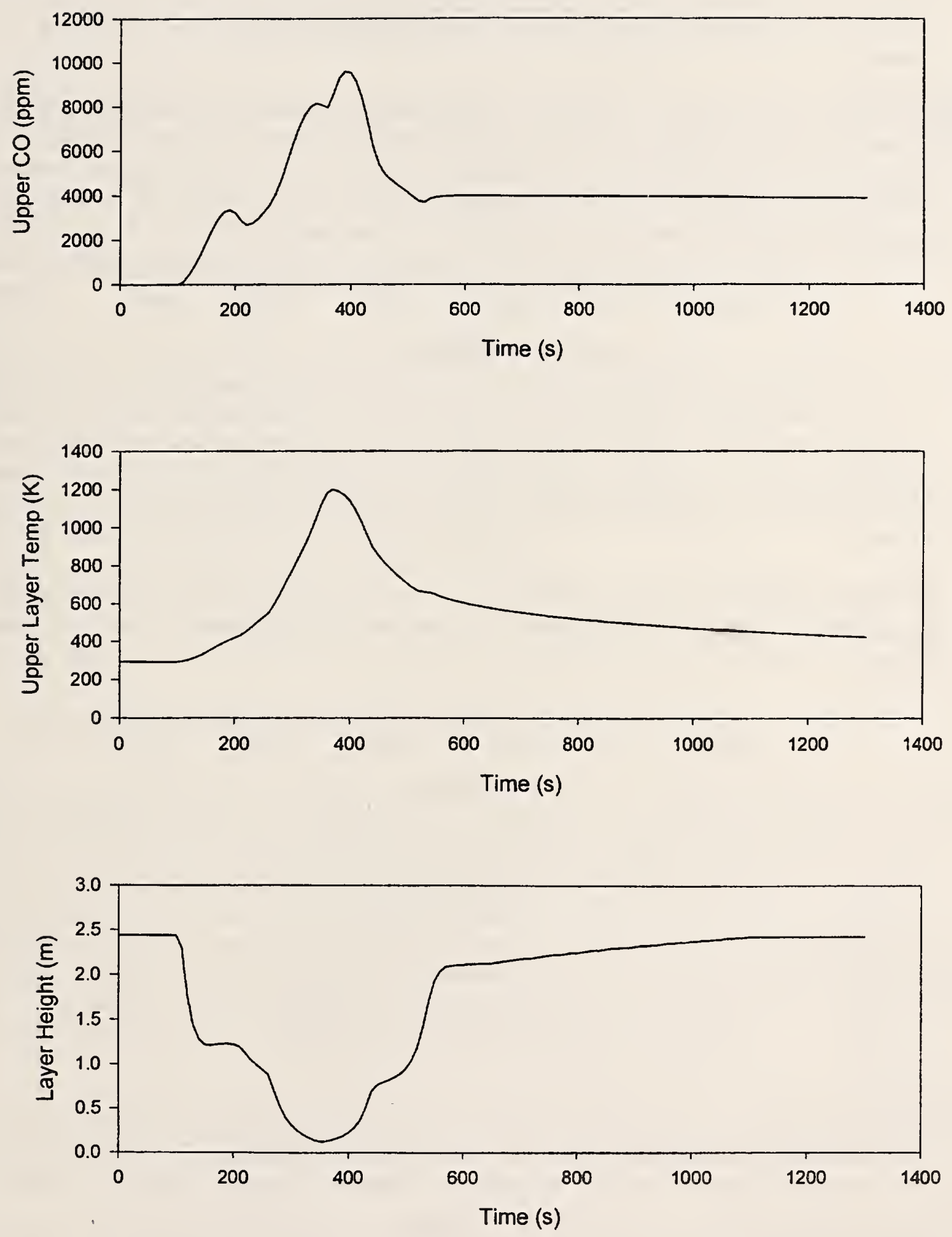

Figure 15a. CFAST calculated results for fire room with an M1 twin bed fire; $3.66 \mathrm{~m}$ by $3.66 \mathrm{~m}$ ( $12 \mathrm{ft}$ by $12 \mathrm{ft}$ ) room with a fully open door. Top graph, ppm of CO in upper layer; middle graph, temperature of upper layer gases; lower graph, height of base of upper layer. 

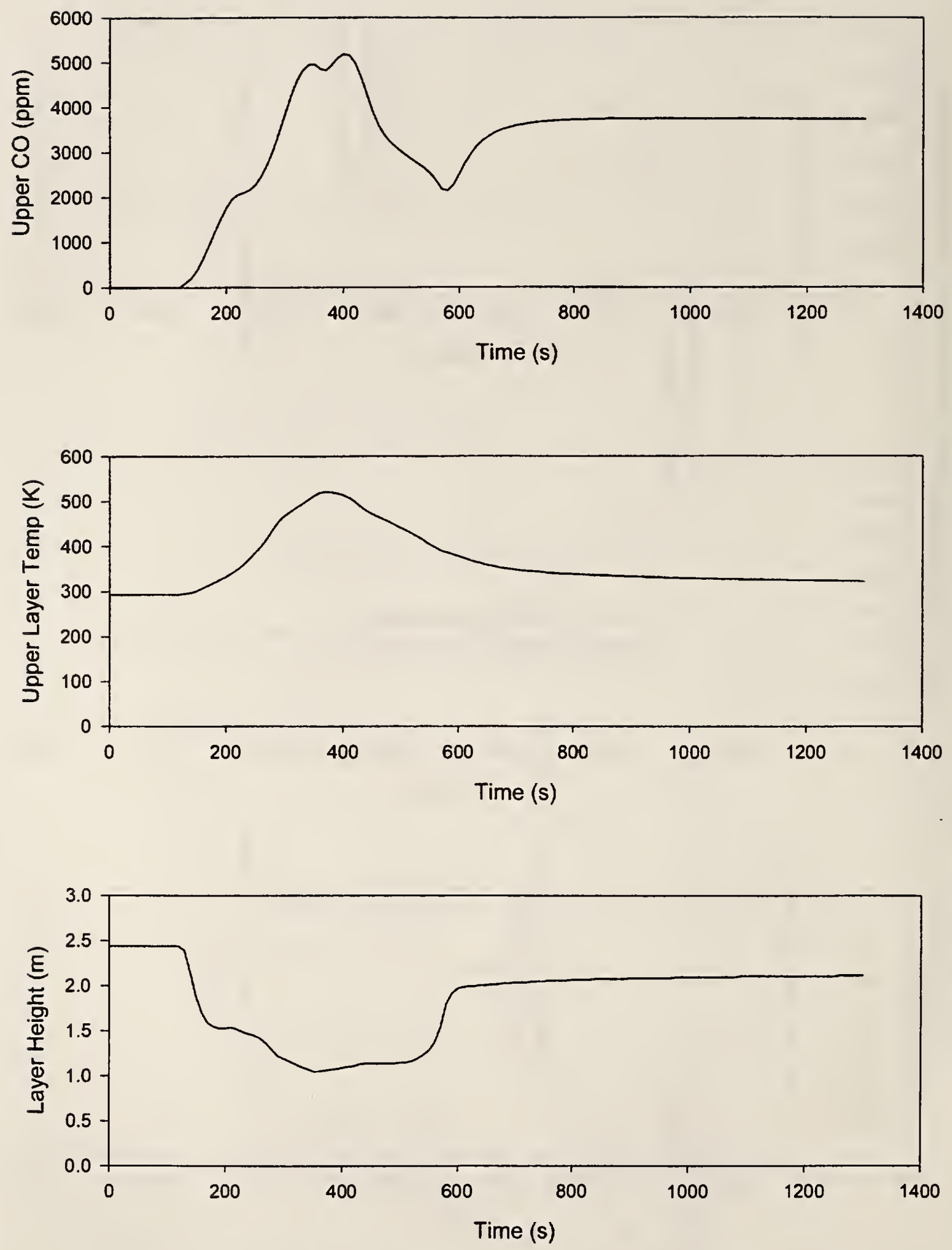

Figure 15b. CFAST results for second, equal-sized bedroom off common hallway with an M1 twin bed fire in first bedroom; $3.66 \mathrm{~m}$ by $3.66 \mathrm{~m}$ ( $12 \mathrm{ft}$ by $12 \mathrm{ft}$ ) room with fully open door. Top graph, ppm of $\mathrm{CO}$ in upper layer; middle graph, temperature of upper layer gases; lower graph, height of base of upper layer. 


\section{APPENDIX 1 \\ Thermal Ignition Models for Surrogate Materials}

The basic assumption of a thermal ignition model is that (piloted) ignition of the heated surface of an object occurs as soon as its surface reaches a critical temperature denoted as $T_{\text {ign }}$. This is, of course, an approximation. It simulates the typically very strong Arrhenius temperature dependence of the surface material degradation/gasification reactions by means of a step function. The real surface temperature at which ignition occurs tends to be a weakly increasing function of incident heat flux; this dependence is ignored to achieve the simplicity of a thermal model.

With material chemistry thus reduced to an effective ignition temperature, it remains only to correctly describe the heat-up of the material surface to this temperature. Real materials are not necessarily simple in their heat up since this can involve temperature-dependent thermal properties and such additional heat sinks as phase changes. In general, the detailed make-up of a material is not known, so one cannot go to a handbook for the properties. Here that issue is bypassed by fitting the model to the piloted ignition data from the Cone Calorimeter, thereby deriving effective values for the model parameters.

A thermally-thin material is one which has no significant temperature gradients through its depth. The rate of heating of such a material, as a consequence of a radiant flux incident on one surface, can be described by the following heat balance equation for unit area of the material.

$$
(\rho C \ell) d T / d t=q_{r a d}-h_{c o n v}\left(T-T_{a m b}\right)-\varepsilon \sigma\left(T^{4}-T_{a m b}^{4}\right)
$$

where $\rho$ is the density of the material, $\mathrm{C}$ is its heat capacity, $\ell$ is the thickness of the material, $\mathrm{T}$ is its temperature, $\mathrm{t}$ is time, $\mathrm{q}_{\mathrm{rad}}$ is the absorbed radiant heat flux (implicit absorptivity is unity), $\mathrm{h}_{\text {conv }}$ is the convective cooling coefficient for the vertically oriented sample face, $\mathrm{T}_{\mathrm{amb}}$ is the temperature of the surroundings (room temperature), $\varepsilon$ is the radiant emissivity of the sample surface (taken as 0.95 ) and $\sigma$ is the Stefan-Boltzmann constant. The convective heat loss coefficient is a linear function of temperature, based on experiments with an inert sample in the Cone Calorimeter. The equation as written describes a material having losses from one surface only. If it has heat losses from both front and back surfaces (by convection and radiation), the last two terms in the above equation get multiplied by a factor of two.

This equation requires numerical solution due to the non-linear radiation loss term. A program was written to solve the equation using a fourth-order Runge-Kutta explicit algorithm, marching forward in time, starting with the sample at room temperature and stopping when $T_{i g n}$ was reached. The program was checked against simple cases for which exact solutions are possible.

To apply the model in predicting ignition reach from a bed fire, one must first determine the effective values of the product $(\rho C \ell)$ and $T_{\text {ign }}$ for a given material. Here these were inferred by matching Cone Calorimeter data for ignition time versus heat flux. This was a trial and error process that started with estimates of $T_{\text {ign }}$ from the minimum flux for ignition of the material in 
the Cone Calorimeter and for $(\rho C \ell)$ from handbook values of similar materials. The high flux solutions were most sensitive to the effective thermal property group and the low flux solutions were most sensitive to the value of $\mathrm{T}_{\text {ign. }}$. It was possible to get reasonably good matches between predicted and experimental Cone Calorimeter (constant incident heat flux) ignition behavior for all of the thin materials by this procedure. Using these values in the model, the ignition behavior for that material in a room fire was predicted by replacing the constant flux with the Gaussianapproximated, time-dependent incident radiant flux coming from a bed fire. Again, trial and error was necessary to find the minimum incident peak flux which could just cause ignition of a given material. The measured flux vs. distance data for a given bed fire then allowed this to be turned into a maximum value for piloted ignition reach for that material from the specific burning bed. The characteristic times of the material heating and of the Gaussian flux variation were such that the sample surface temperature was tightly coupled to the time-dependent incident flux and ignition tended to occur at or just after the flux reached its peak in time.

Three of the ignition surrogate materials could not be described as thermally-thin (two wood samples and the terry cloth toweling). These required a more general model of the heat-up process that accounted for energy penetration in depth. This model is as follows.

$$
(\rho C) \partial T / \partial t=k \partial^{2} T / \partial t^{2}+\alpha q_{0} \exp (-\alpha x)
$$

At the front surface of the sample, a heat balance gives

$$
\left(q_{0}\right)=\varepsilon \sigma\left(T_{s}^{4}-T_{a m b}^{4}\right)+h_{c o n v}\left(T_{s}-T_{a m b}\right)-k(\partial T / \partial x)_{s}
$$

and a similar condition can be applied to the back or it can be assumed to be adiabatic. Here $\alpha$ is the in-depth absorption coefficient of the incident radiation, $\mathrm{x}$ is the distance into the material depth from its heated surface, $k$ is the thermal conductivity of the material and $T_{s}$ is the temperature of the surface of the material. In Eq (3) the incident flux $\mathrm{q}_{0}$ is in parentheses because it does not appear in this surface boundary condition if the radiation is absorbed in-depth according to the last term in Eq. (2). Only the toweling requires some description of in-depth absorption since it has a very open structure. For the two wooden materials. the incident radiation is assumed to be absorbed at the sample surface.

This partial differential equation was solved using a Fortran program provided by $\mathrm{K}$. McGrattan of NIST/BFRL. The program has been used by the author for several years and is extensively validated. Effective thermal properties were obtained in essentially the same way as for the thermally thin model. Usage to predict maximum ignition reach from a bed fire is also the same as above. 


\section{APPENDIX 2}

\section{Estimates of Fuel Package Contributions in M3 and M5 Bed Fires}

NFPA 555 defines a "fuel package" as a group of items so close together as to act as one (via continuous flame spread) if one item in the package is ignited [5]. Here an estimate is made of the implications of this idea for the two bed fires of primary interest, M3 and M5.

The first point to recognize is that identical physical set-ups will not lead to identical contributions to the bed fire from adjacent objects. Involvement of even immediately adjacent objects is a function of the intensity and behavior of the bed fire itself.

Three adjacent objects are expected to be present in a substantial fraction of bed fires: (1) painted gypsum board on the wall, at least at the head end of the bed, (2) carpeting below the bed and (3) a bed stand on one side of the head end of the bed.

Wall Board. Painted gypsum board would be exposed to the pillow fire at the head of the bed. Mowrer [23] showed that wall board with two coats of paint will ignite in $60-80 \mathrm{~s}$ at $35 \mathrm{~kW} / \mathrm{m}^{2}$. In the tests here, the heat flux to a gage $13 \mathrm{~cm}$ from the head end edge of the bed reached 20 $\mathrm{kW} / \mathrm{m}^{2}$ but the peak was very brief, staying above $10 \mathrm{~kW} / \mathrm{m}^{2}$ for about $100 \mathrm{~s}$. Thus it appears that it would not ignite the wall board unless the flames laid directly on it (which is possible). Inspection of the fire plume on the pillow suggests that even if extended by wall contact, flame contact would ignite only 0.1 to $0.2 \mathrm{~m}^{2}\left(1\right.$ to $\left.2 \mathrm{ft}^{2}\right)$. Mowrer reports heat release rate curves that lasted about $20 \mathrm{~s}$ and peaked at about $100 \mathrm{~kW} / \mathrm{m}^{2}$ (at an incident flux of $35 \mathrm{~kW} / \mathrm{m}^{2}$ ). Given an average flux of $50 \mathrm{~kW} / \mathrm{m}^{2}$, the wall board would add 5 to $10 \mathrm{~kW} / \mathrm{m}^{2}$ for $20 \mathrm{~s}$. On a king-size bed the two pillows would give two such peaks well-separated in time. This is a brief perturbation to an M3 fire. An M5 fire might, at its much larger peak, ignite some further area around that ignited earlier by the pillow but that would again be a minor perturbation to the bed fire heat release rate ${ }^{44}$. If, instead of wallboard, there was thin wooden paneling on the wall (or a comparable headboard on the bed) the result could be larger but the frequency of such occurrences is probably less since such paneling is less frequently used.

Carpet. Carpeting is a potentially much larger contributor ${ }^{45}$. For an M3 fire, however, there is little radiation reaching out and down to force this potential heat release into reality. Using data on carpet flame spread as a function of incident heat flux and pre-heat time in Ref. 25, one can, with some difficulty, infer that a carpet strip on the order of $15 \mathrm{~cm}$ in width will burn around the periphery of an M3 fire. This is a consequence of ignition by flaming melt drip material from the bedclothes followed by 100-200 s of irradiation from the burning bedclothes on the side of the bed. Hirschler [26] reports heat release rate data for nylon carpet tiles at radiant fluxes higher

\footnotetext{
${ }^{44}$ Recall, however, one room test here gave ignition of much of the ceiling gypsum board and caused a very large, though brief, heat release rate excursion. Presumably this threat exists with any M5 fire in the real world. The brevity of the peak should preclude its leading to flashover in most cases, unless there was some very readily ignited material laying horizontally in the room.

${ }^{45}$ Ref. 24 reports room fire tests with gas burners in a ISO 9705 type of stepped burner heat release rate that caused polypropylene carpets to burn very rapidly, yielding hundreds of $\mathrm{kW}$ in heat release rate.
} 
than are likely to be seen on a carpet in an M3 fire. Extrapolating his time-averaged heat release rate to a lower average flux of ca. $15 \mathrm{~kW} / \mathrm{m}^{2}$ and assuming about $10 \%$ of the peripheral strip is burning at any given time yields an estimated heat release rate contribution from carpeting of 5$10 \mathrm{~kW} / \mathrm{m}^{2}$. This could easily be off by a factor of two but even if the actual heat release rate is two times larger it is still only $10 \%$ of that due to the bed fire.

The interaction between an M5 fire and carpeting is significantly different. It will begin like that in the M3 fire, yielding a somewhat wider peripheral strip of burning carpeting because the burning area on the side of the bed is somewhat wider and thus radiated farther. This is still a minimal supplement to the larger early heat release rate of an M5 fire. However, as the foundation of this design begins to burn, it becomes a strong radiator to the space below the bed. (In the tests here it always ignited the paper on the gypsum board beneath the bed.) This fire in the foundation tends to propagate longitudinally along the bed over a period of $4 \mathrm{~min}$ to $5 \mathrm{~min}$, involving roughly $1 / 4$ to $1 / 3$ of the area at any given time. Here the radiant flux incident on the carpet would be substantially higher due to a large radiating area with a relatively large view factor. There are indications in these tests that the flux can spontaneously ignite the wood at the base of the foundation, implying a flux there greater than $40 \mathrm{~kW} / \mathrm{m}^{2}$. The flux to the floor would be somewhat lower so Hirschler's data at $30 \mathrm{~kW} / \mathrm{m}^{2}$ is extrapolated roughly to $35 \mathrm{~kW} / \mathrm{m}^{2}$. If one third of the carpet beneath a twin bed is burning at one time the heat release rate contribution becomes greater than $200 \mathrm{~kW}$. This is an appreciable boost to the second peak values shown in Table 4 for M5 fires. There would also be some further (though lesser) possible contribution during the bed's second heat release rate peak due to the increased radiative reach of the fire pushing the peripheral carpet fire further outward from the bed.

Bed Stand. A bed stand is an ill-defined piece of furniture, being, probably, quite variable in the real world. A search of the literature on the heat release rate of real objects has turned up no data in which such an object was burned in isolation. Ref. 27 gives empirical formulas for calculating the peak heat release rates from wood cribs and from stacks of wood pallets. Both give improbably large numbers for a wooden object the size of a bed stand, probably because a bed stand will not have the internal radiative transfer that boosts the burning rate of those objects. Ref. 28 reports data for a large bookcase $(30 \mathrm{~kg})$ constructed from $1.3 \mathrm{~cm}(0.5 \mathrm{in})$ thick plywood exposed to a $50 \mathrm{~kW}$ gas flame for $200 \mathrm{~s}$. This object burned only during the flame exposure, probably because of the thickness of the wood and the relatively short time of exposure. The exposure time of a bed stand to a bed fire would be longer than this for an M5 fire and comparable for an M3 fire. The net result would depend on the thickness of the wood and the possible presence of other objects (e.g., a clock radio with a thermoplastic case) placed on top of the bed stand. Intuition suggests a plausible number to be of the order of $50 \mathrm{~kW}$ during the peak burning of the bed fire. That would be an insignificant supplement to an M5 fire but a marginally significant boost to an $\mathrm{M} 3$ fire. 

